\title{
دور التوازن الديناهيكي في الأداء التسويقي دراسة استطلاعية على عدد من المارف العراقية الخاصة
}

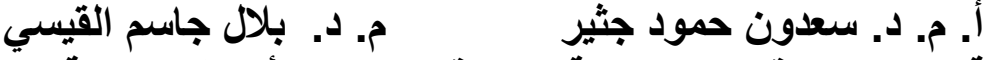 \\ كلية الإدارة والاقتصاد- جامعة بذداد قسم إدارة الأعمال- جامعة بغداد
}

|الستسفامن

الغرض Purpose- تسـعى هذه الدراسـة إلى تقديم وجهة النظر القائمسة على الاداء التسـويقي

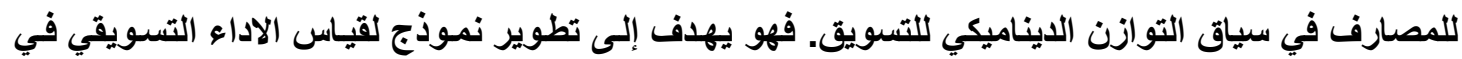

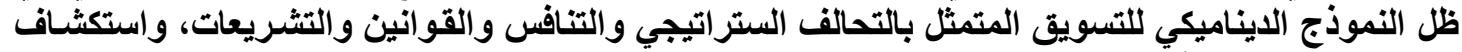
اي من الابعاد اكثر تأثيرا في تحقيق الاداداء.

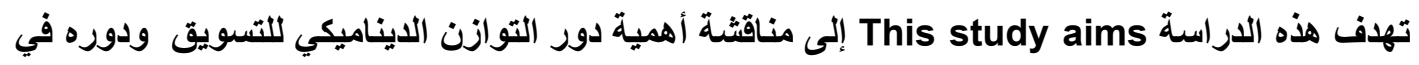
تحقيق الأداء التسويقي في ظل التوازن الديناميكي للتسويق وأثره في القطاع المصرفي العراقي.

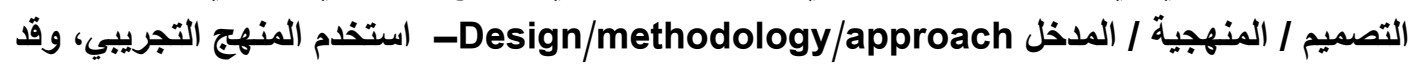

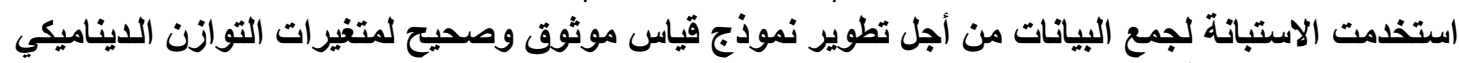

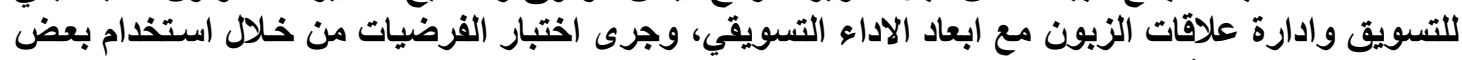
المعالجات الاحصائية.

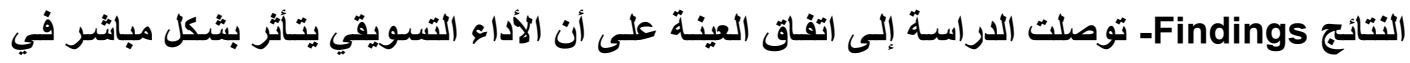

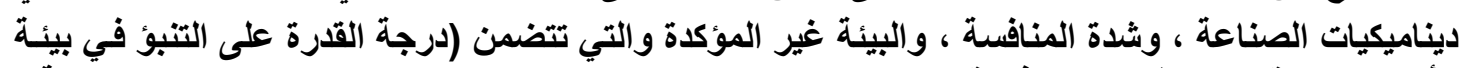

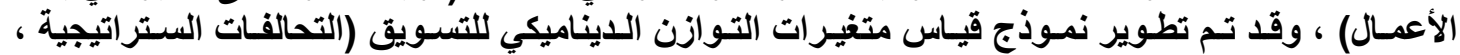

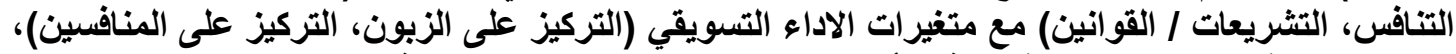

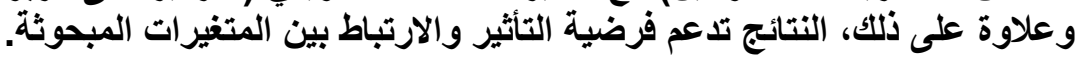

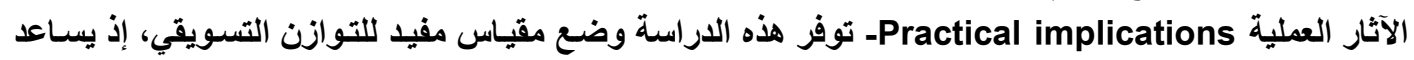

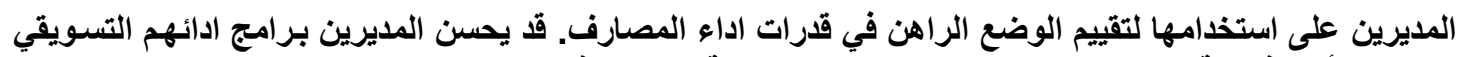

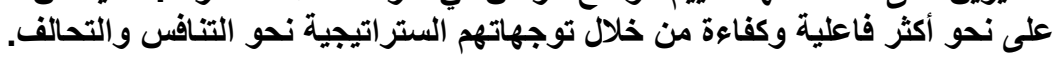

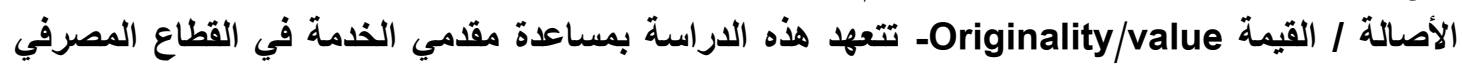

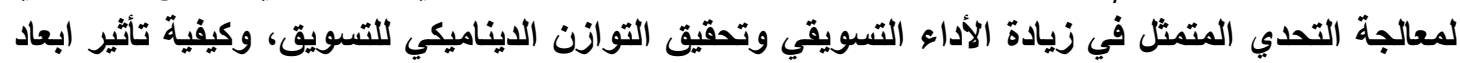
التوازن التسويقي في تحقيق الاداء التسويقي.

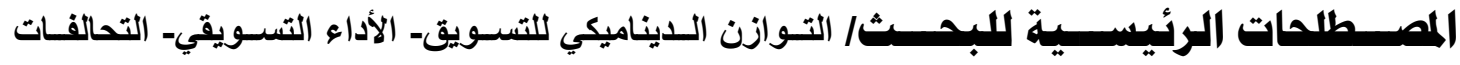
الإستراتيجيةـ المنافسة. التشريعات والقوانين- التركيز على الزبون.

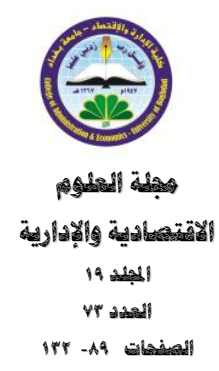

البحث مستل من اطروحة دكتوراه 


\section{دور التوازن الديناميكي في الأداء التسويقي دراسة استطلا عية} على عدد من المصارف العراقية الفاصة

القدهمة Introduction

على الرغم من الاسهامات النظرية لكثير من العلماء في التركيز على الزبون والتركيز على المنافسـة، إلا أن هناك اهتماما قليلا حول تأثيرها على الأداء التسويقي في المنظمات المصني التصرفية (Nwokah,2009:25).

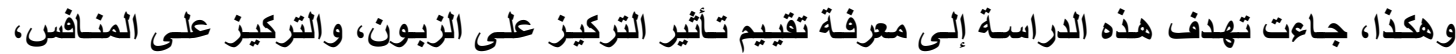

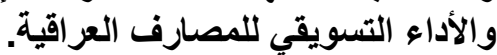

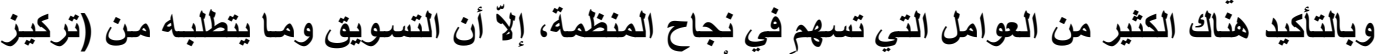

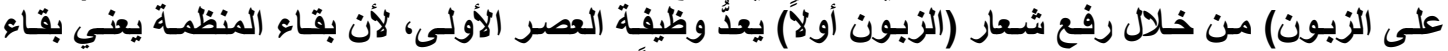

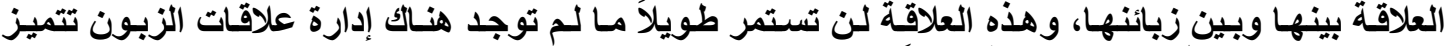

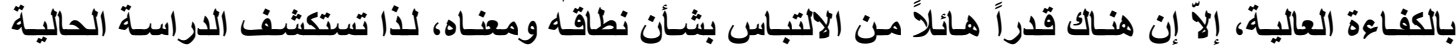

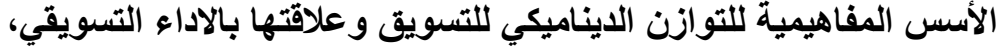

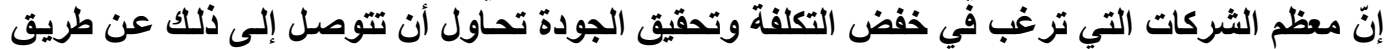

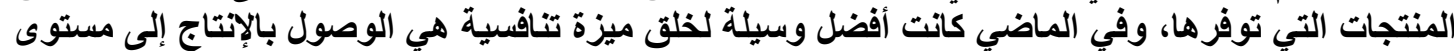

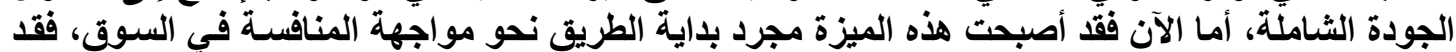

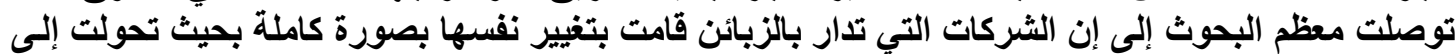

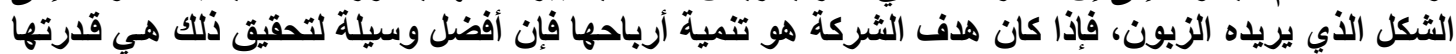

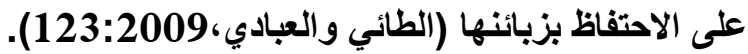

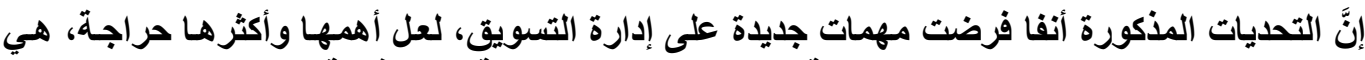

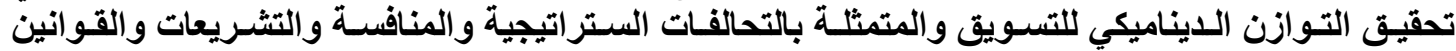

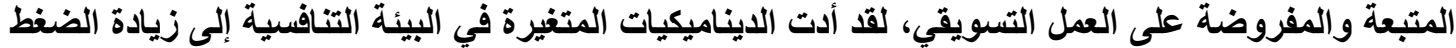

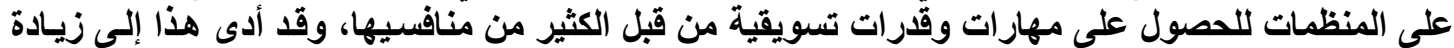

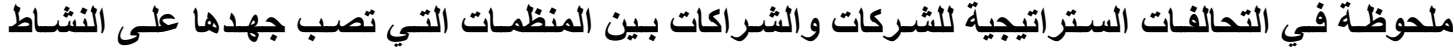

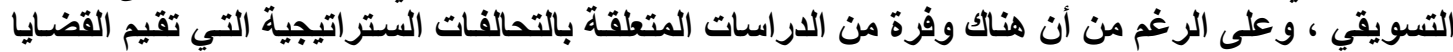

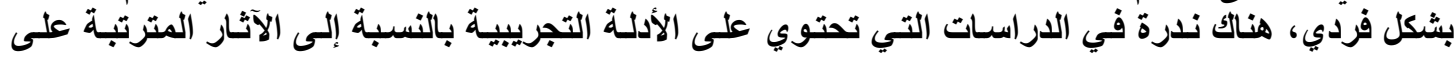

التحالفات الستراتيجية على تكوين التوازن الايناميكي للتسويق (Ranganathan,2002:1).

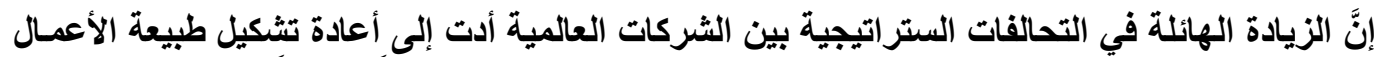

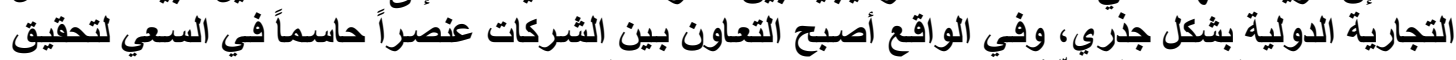

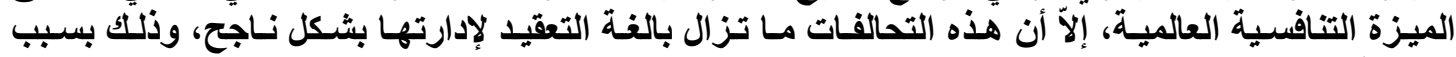

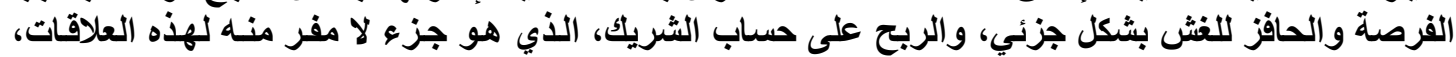

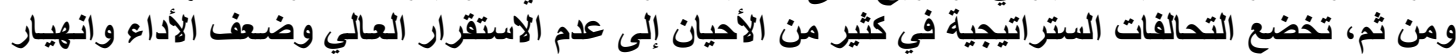

سابق لأو انه (Parkhe, 1993:301).

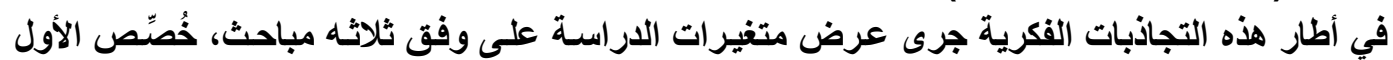

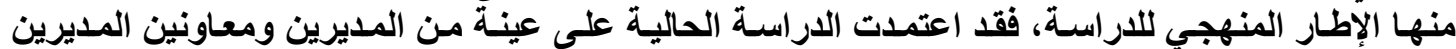

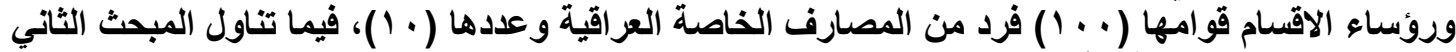

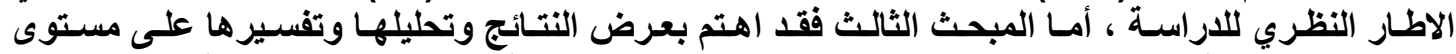

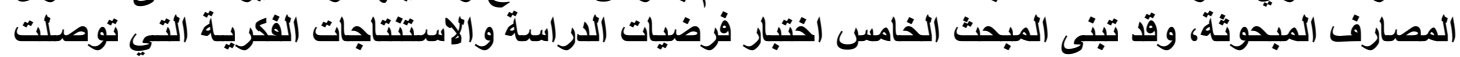
إليها الاراسة، كما تبعتها بعض تبن التوصيات المستوحاة من هذه الاستنتاجات . 
دور التوازن الديناميكي في الأداء التسويقيي دراسة استطلا عية

على عدد من المصارف العراقية الفاصة

\section{المبحث الاول/ هنهبية الدراسة}

يقدم هذا المبحث عرضاً لمنهجية الداسة التي تتضمن مشكلة الدراسة والمنهج الذي التئه اعتمدته وأهدافها

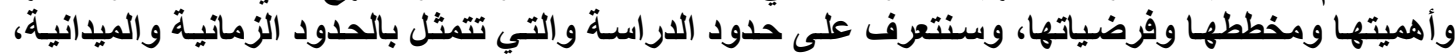

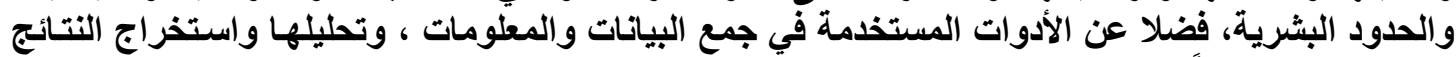
ـ وفيما يأتي تفصيلاً لما جرى ذكره.

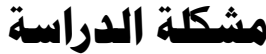

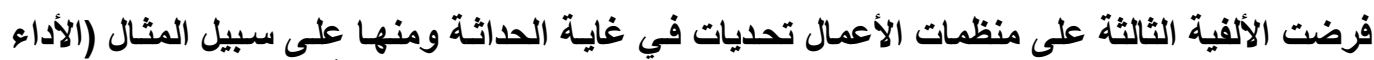

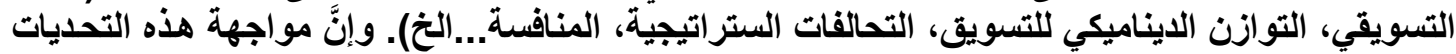

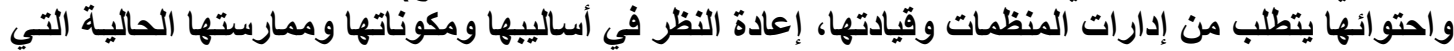

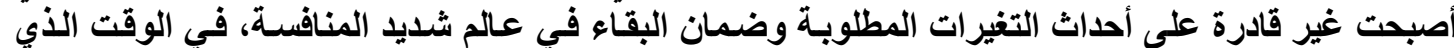

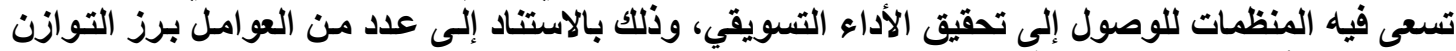

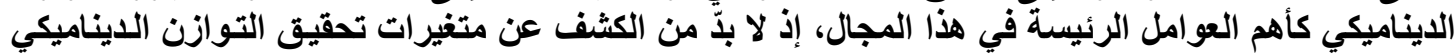

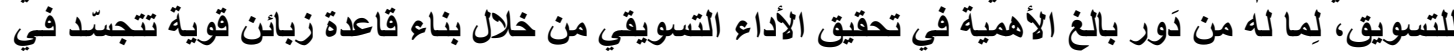

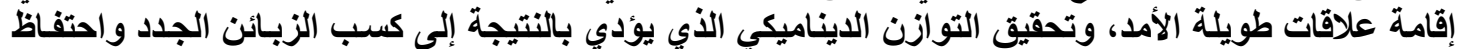

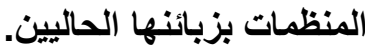

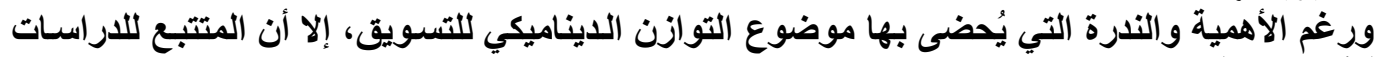

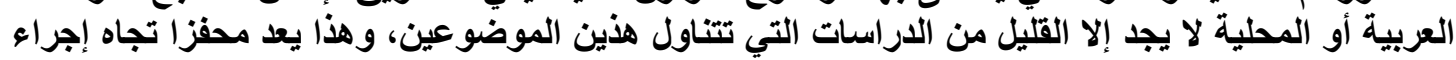

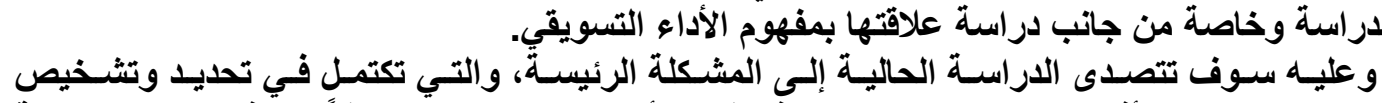
المقاييس والإجراءات الأفضل التي يمكن اعتمادها في قياس أداء المنظمـات، وانطلاقاً من ذلتك يمكن صياغة المشكلة بمجموعة من التساؤلات الآتية:

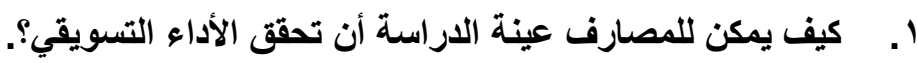

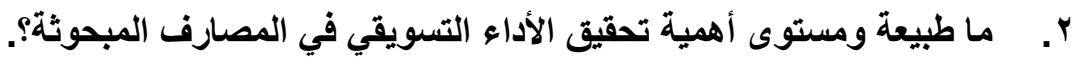

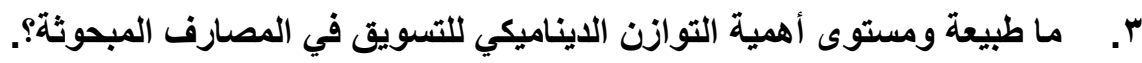

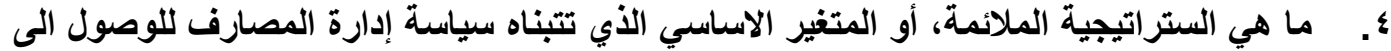

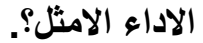

•. هل هناك دَور للعلاقة بين التوازن الديناميكي للتسويق في تحقيق الأداء التسويقي؟. I. ما هو شكل وطبيعة اتجاهات التأثير للتوازن الديناميكي للتسويق في الأداء التسويقي؟

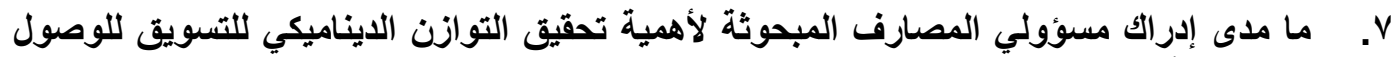
إلى زيادة الأداء التسويقي لإدارة المصارفي المارفي

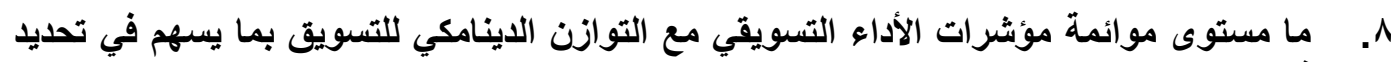

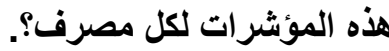
9. هل توجد محاولات في المصارف المبحوثة في تبني التحالفات الستراتيجية؟ 
 \\ دور التوازن الديناميكي في الأداء التسويقي دراسة استطلا عية}

على عدد من المصارف العراقية الفاصة

\section{أهمية الدراسة:}

تثتثل أهمية الاراسة من خلال النقاط الآتية:

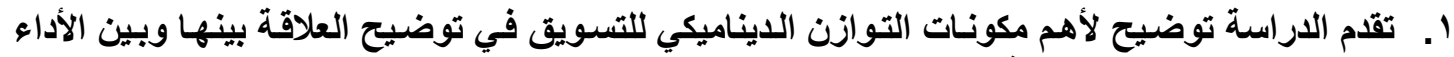

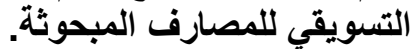

r. من خلال المراجعة المتواضعة للأدبيات الإدارية السابقة لم يجد الباحث دراسة تختبر العلاقة بين التوازن الايناميكي والاداء التسويقي.

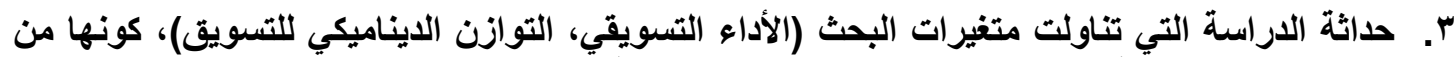

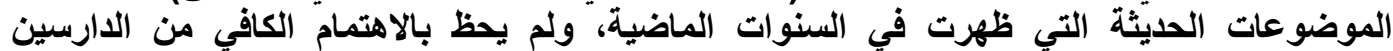

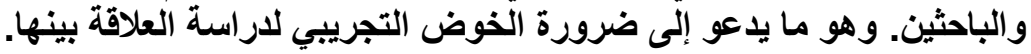

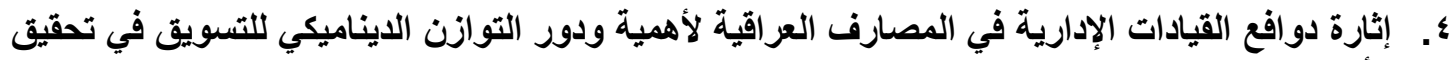
الأداء التسويقي.

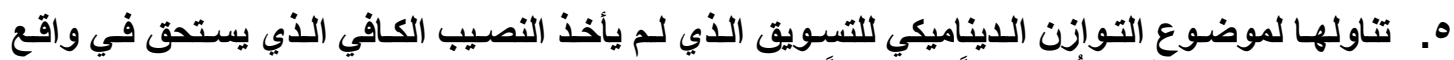

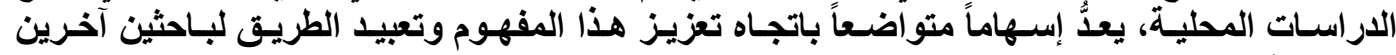
ل ل الخوض في مضماره.

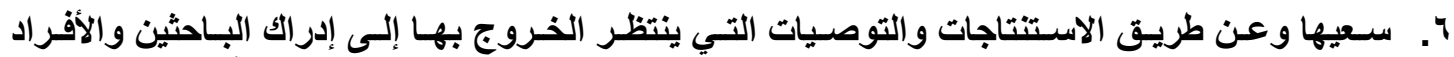

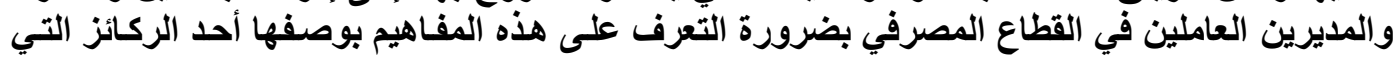
تحقق أهداف المنظمة وغين فيتها.

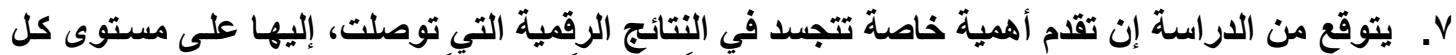

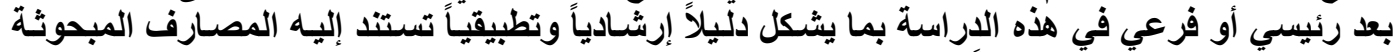
بهنف التحسين المستمر وصو لأل إلى تحقيق الأداء التسويقي.

\section{أهداف الدراسة}

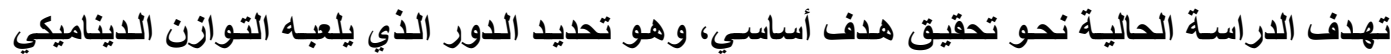

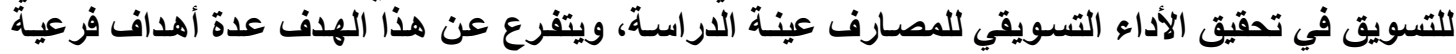

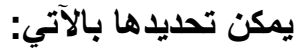

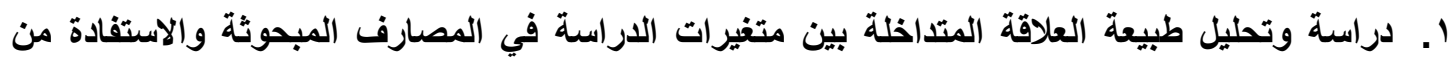

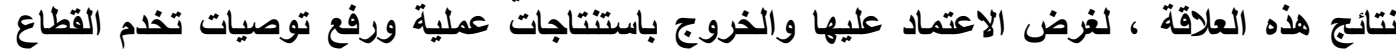
المصرفي العراقي. r. تسعى الاراسة إلى توضيح المفاهيم والمضامين المتعلقة بقيام التحالفات الستراتيجية في زيادة الأداء

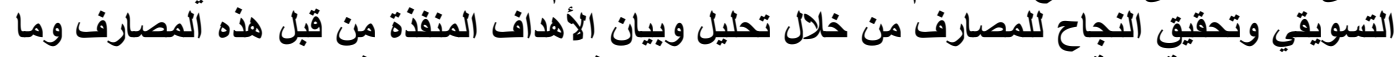

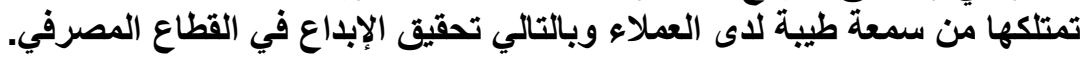

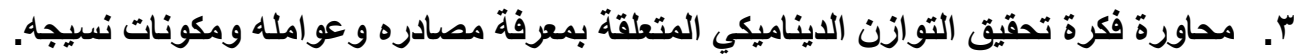

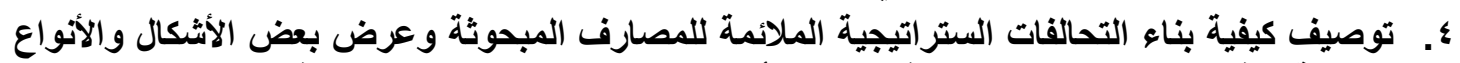

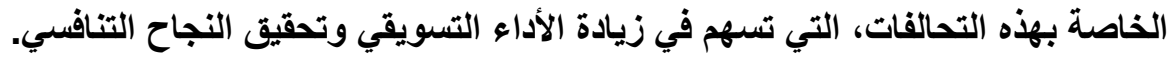

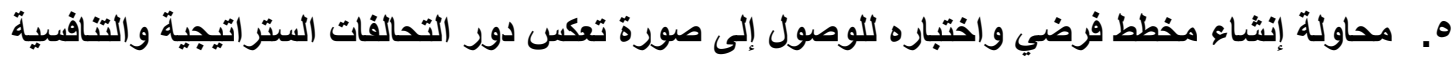

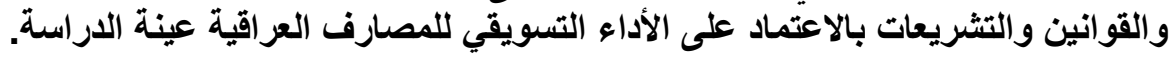




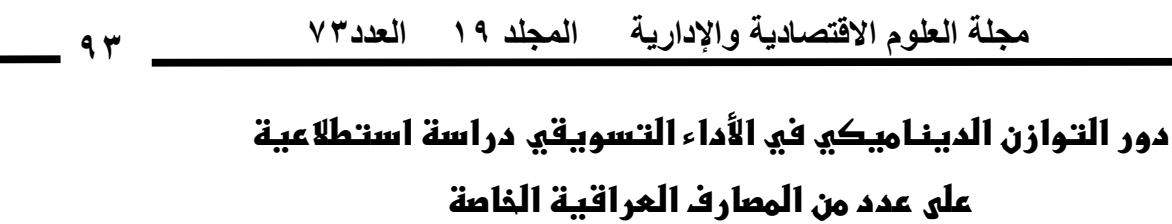

هنطط الدراسة الفرضي

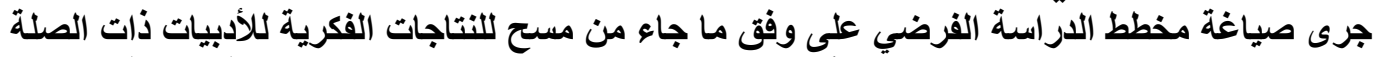

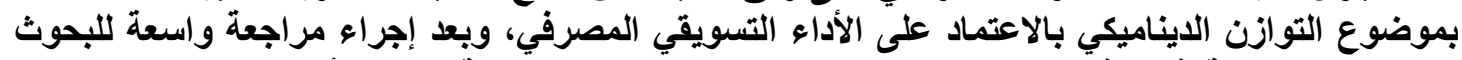

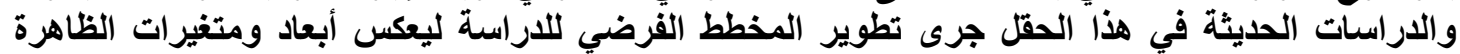

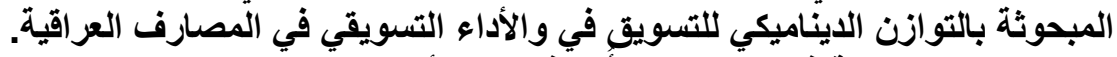

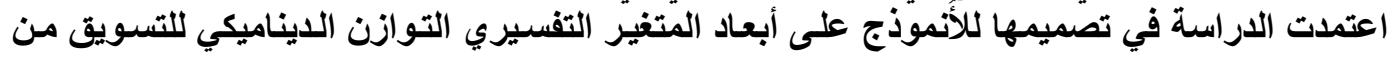

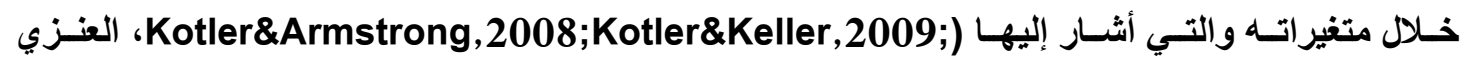

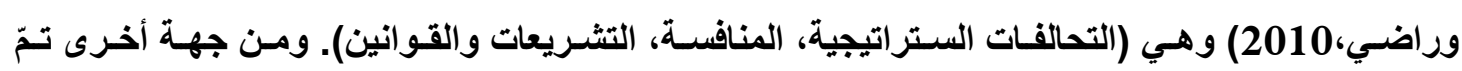

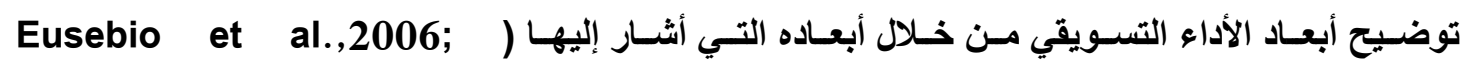
(Nwokah,2009; da Gama (A),2011; da Gama (B),2011; Sweeney et al.,2011 وهي (التركيز على الزبون والتركيز على المنافس)، والتي مثّلت المتغير الإستجابي، ويصور الثكل (1) (1)

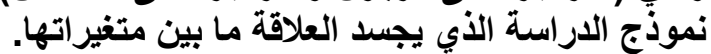

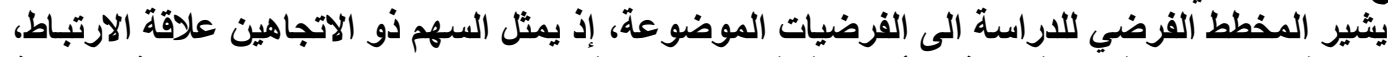

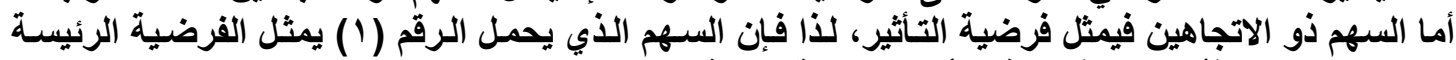

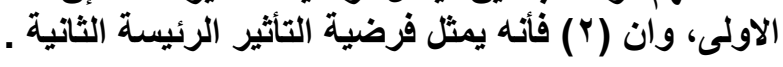

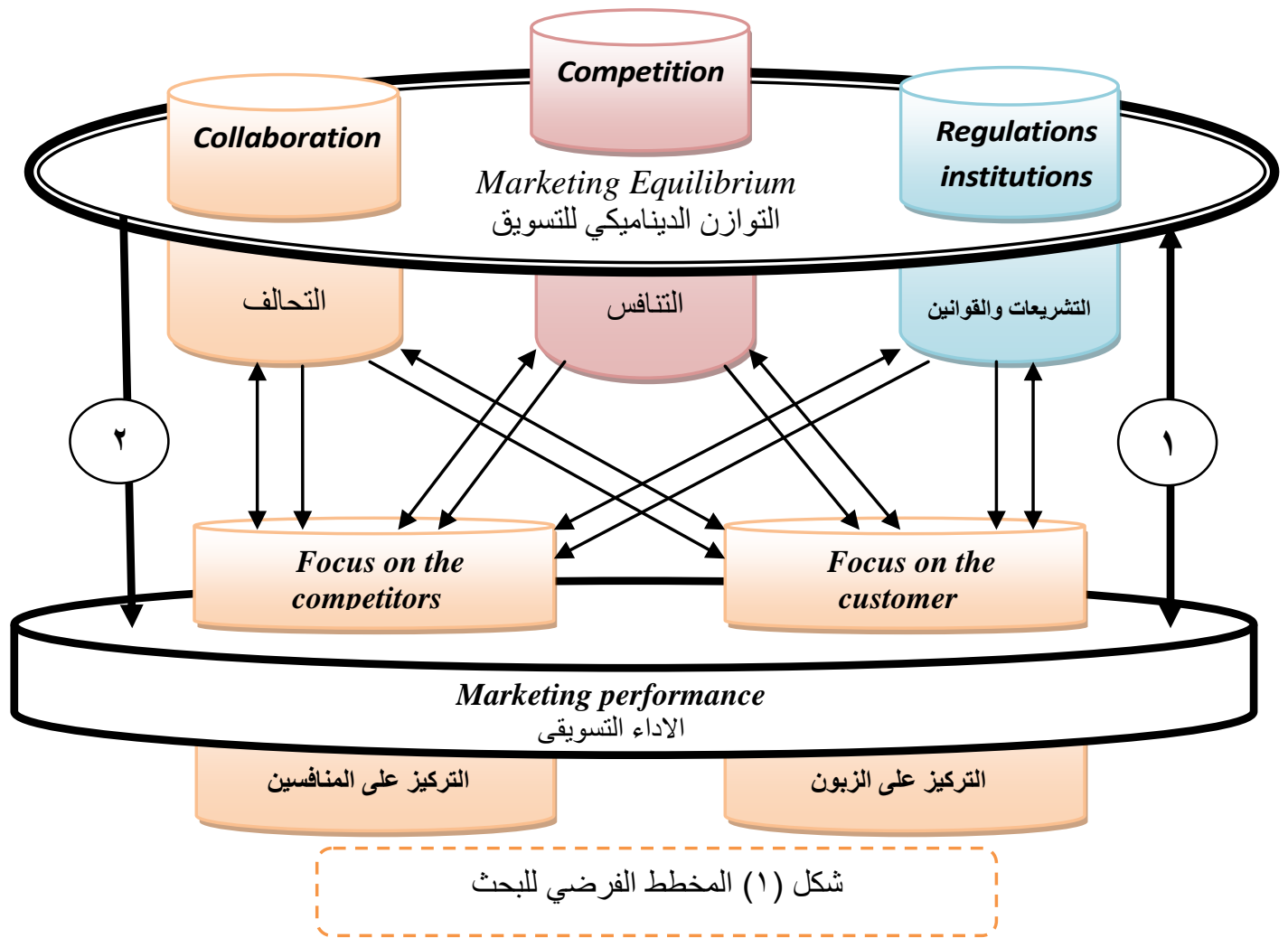




\section{دور التوازن الديناميكي في الأداء التسويقي دراسة استطلا عية}

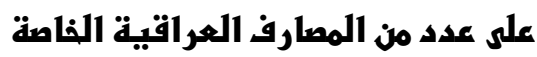

الفرضية الرئيسة الاولى : تزداد مساهمة التوازن الديناميكي للتسويق في الأداء التسويقي، وقد تفرعت عنها

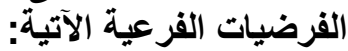

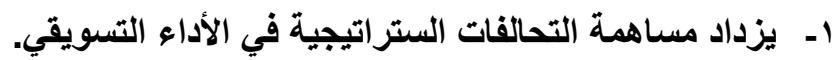
r r يزداد مساهمة التنافس في الأداء التسويقي.

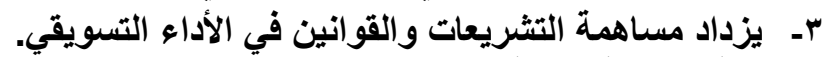

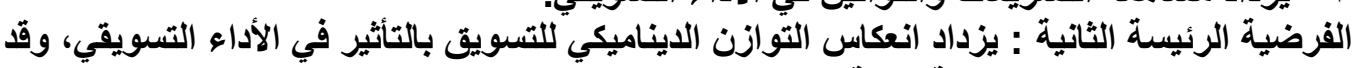
تفرعت عنها الفرضيات الفرعية الاتية : 1- بزداد انعكاس التحالفات الستراتيجية بالتأثير في الأداء التهاء التسويقي

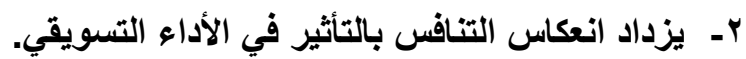
r- ب يزداد انعكاس التثريعات والقوانين في الأداء التسويقي.

\section{هجتهع الدراسة وعينتها:}

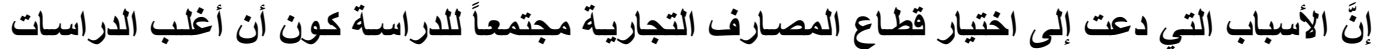

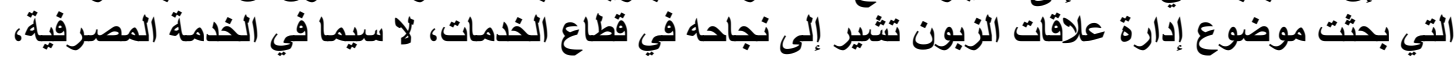

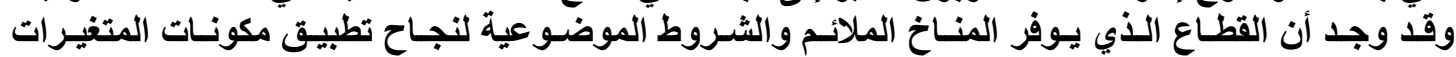

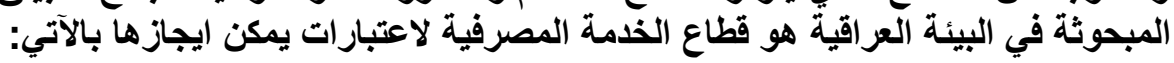
ا- - أهمية ونضج قطاع الخدمة المصرفية قياساً بالقطاعات الخدمية الأخرى.

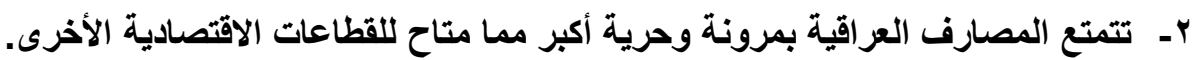

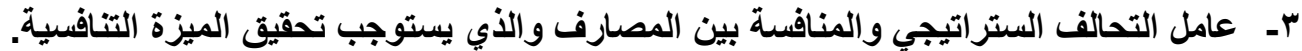

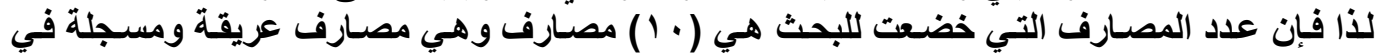

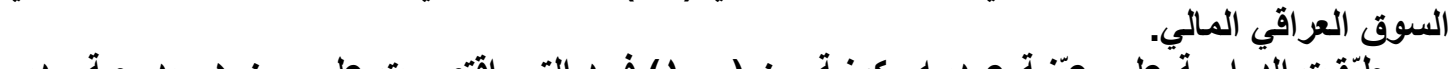

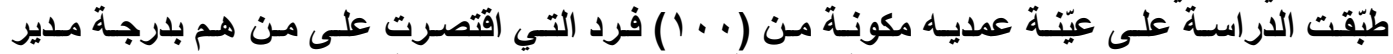

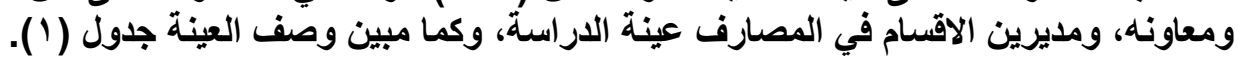

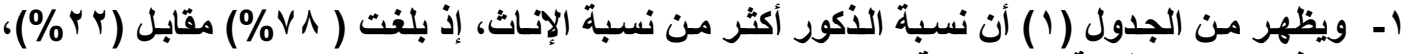
وهذا يعود إلى طبيعة عمل العينة.

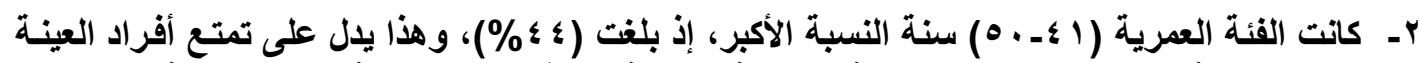

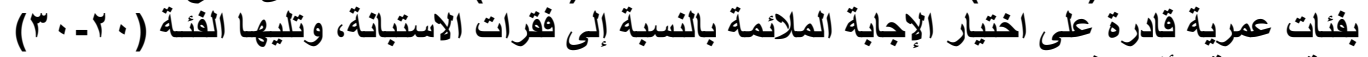

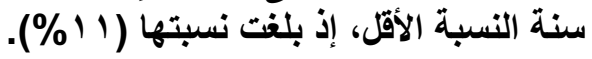

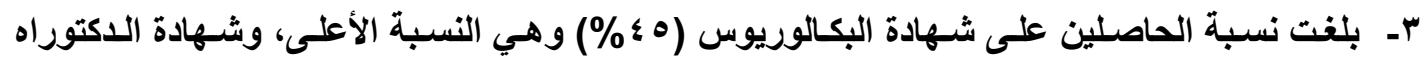

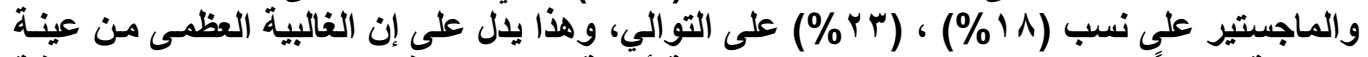

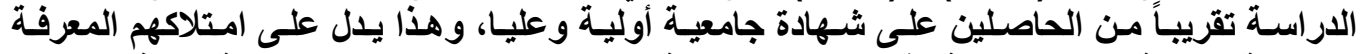

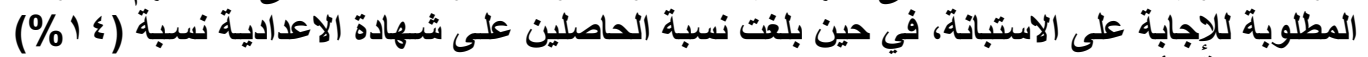

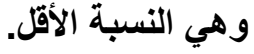

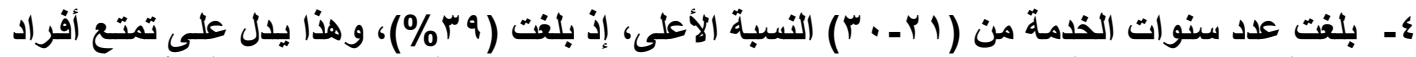

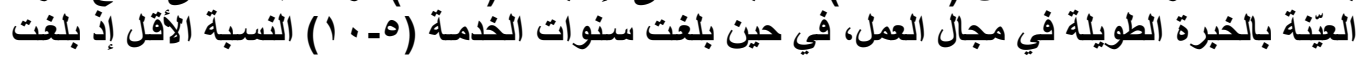




\section{دور التوازن الديناميكي في الأداء التسويقيي دراسة استطلا عية}

\section{على عدد من المصارف العراقية الفاصة}

ه- بلغت نسبة من هو بعنوان رئيس قسم (1\%VI) و هي النسبة الأعلى بالنسبة لعينة الدراسـة لتمتعهم بالخبرة والإشر اف المباشر على العاملين، في حين بلغت نسبة من هم بعنوان مستثار النسبة الأقل إذ بلغت ( • (\%).

\begin{tabular}{|c|c|c|c|c|}
\hline \multicolumn{5}{|c|}{ جلول ( ) خصائص عينة البحث } \\
\hline النسبة \% & 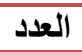 & ت توزيع الخاصية & المتغيرات & ت \\
\hline$\% \vee \wedge$ & $V \wedge$ & ذكر & \multirow{2}{*}{ الجنس } & \multirow[t]{2}{*}{1} \\
\hline$\%$ \%r & rr & أنثى & & \\
\hline$\% 1 \ldots$ & $1 \ldots$ & \multicolumn{3}{|c|}{ المجموع } \\
\hline$\% \backslash 1$ & 11 & $r \cdot-r \cdot$ & \multirow{4}{*}{ الفئة العمرية (سنة) } & \multirow{4}{*}{ r } \\
\hline$\% r^{q}$ & rq & $\varepsilon \cdot-r \mid$ & & \\
\hline$\% \leqslant \varepsilon$ & « & $0 \cdot-\leqslant 1$ & & \\
\hline$\% 17$ & 17 & إهـ فما فوق & & \\
\hline$\% 1 \ldots$ & $1 \cdots$ & \multicolumn{3}{|c|}{ المجموع } \\
\hline$\% \backslash \wedge$ & 11 & دكتوراه & \multirow{4}{*}{ المؤهل العلمي } & \multirow{4}{*}{$r$} \\
\hline$\%$ rr & $r r$ & ماجستير & & \\
\hline$\% \leqslant 0$ & $\leqslant 0$ & بكالوريوس & & \\
\hline$\% 1 \leq$ & $1 \varepsilon$ & اعدادية & & \\
\hline$\% 1 \ldots$ & $1 \ldots$ & \multicolumn{3}{|c|}{ المجموع } \\
\hline$\% 9$ & 9 & مدير تنفيذي & \multirow{4}{*}{ العنوان الوظيفي } & \multirow[t]{4}{*}{$\varepsilon$} \\
\hline$\% 1$. & $1 \cdot$ & مدير مفوض & & \\
\hline$\% \vee 1$ & vi & رئيس قسم & & \\
\hline$\% 1$. & $1 \cdot$ & مستثار & & \\
\hline$\% 1 \ldots$ & $1 \ldots$ & \multicolumn{3}{|c|}{ المجموع } \\
\hline$\% \wedge$ & $\Lambda$ & $1 \cdot .0$ & \multirow{4}{*}{ سنوات الخدمة } & \multirow[t]{4}{*}{0} \\
\hline$\%$ \%r & rr & $r \cdot-11$ & & \\
\hline$\%$ rq & $r q$ & $r \cdot-r \mid$ & & \\
\hline$\%^{r}$. & $r \cdot$ & اسـ- فما فوق & & \\
\hline$\% 1 \ldots$ & $1 \ldots$ & & & \\
\hline
\end{tabular}

\section{أدوات جمع البيانات}

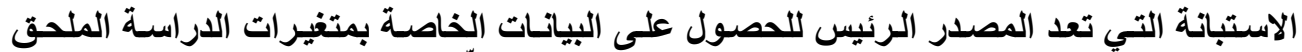

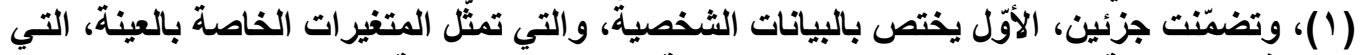

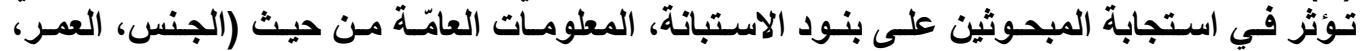
التحصيل العلمي، عدد سنوات الخدمة، الموقع الوظيفي الحالي). 
دور التوازز الديناميكي في الأداء التسويقيي دراسة استطلا عية على عدد من المصارف العراقية الفاصة

\begin{tabular}{|c|c|c|c|}
\hline \multicolumn{4}{|c|}{ جدول (Y) المصادر المعتمدة عند تصميم الاستبانة } \\
\hline 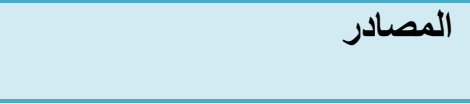 & المتغيرات الفرعية & الرئيسة المتغيرات & 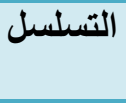 \\
\hline $\begin{array}{l}\text { (Eusebio et al.,2006) } \\
\text { (Nwokah,2009) } \\
(\text { da Gama (A),2011) } \\
\text { (da Gama (B), 2011) } \\
\text { (Sweeney et al.,2011) }\end{array}$ & التركيز على المنافسئ. & الأداء التسويقي & أولاً \\
\hline 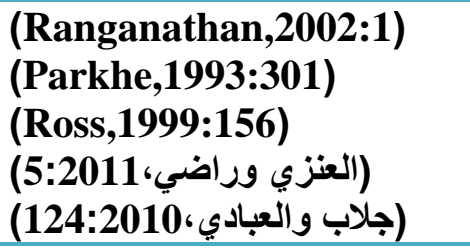 & التشافساتةات الستراتيجية، & للتسويق التوازن الديناميكي & ثانياً \\
\hline
\end{tabular}

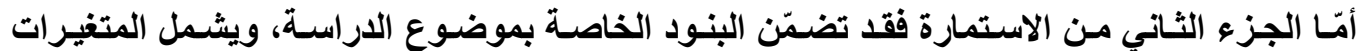

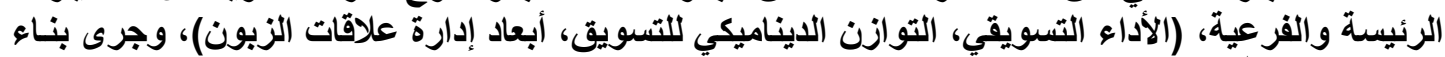

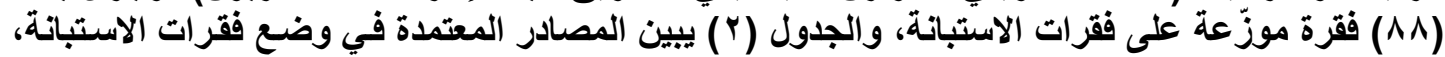

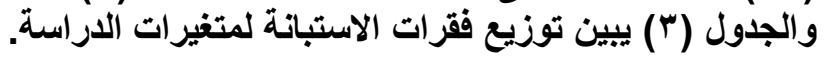

\begin{tabular}{|c|c|c|}
\hline \multicolumn{3}{|c|}{ جدول (r) توزيع فقرات الاستبانة على وفق متغيرات الدراسة الرئيسة والفرعية } \\
\hline عدد الفقرات & المتغيرات الفرعية & المتفير الرئيس \\
\hline 1. & التركيز على الزبون & \multirow{3}{*}{ 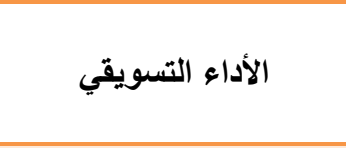 } \\
\hline 1. & التركيز على المنافس & \\
\hline$r \cdot$ & 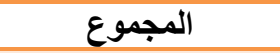 & \\
\hline 1. & الاحتفاظ بالزبون & \multirow{5}{*}{ 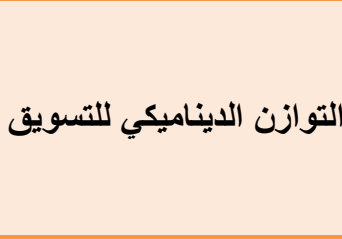 } \\
\hline 1. & رضا الزبون & \\
\hline 1. & ولاء الزيون & \\
\hline 1. & قيمة الزبون & \\
\hline$\varepsilon$. & المجموع & \\
\hline 9 & التحالفات الستراتيجية & \multirow{4}{*}{ 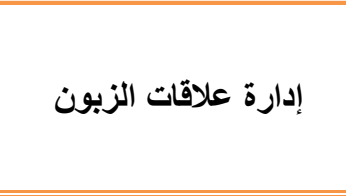 } \\
\hline $1 \cdot$ & 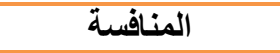 & \\
\hline 9 & التشريعات و القوانين & \\
\hline rA & 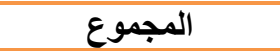 & \\
\hline$\Lambda \wedge$ & \multicolumn{2}{|c|}{ 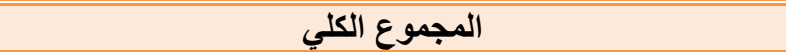 } \\
\hline
\end{tabular}

حدود الدراسة

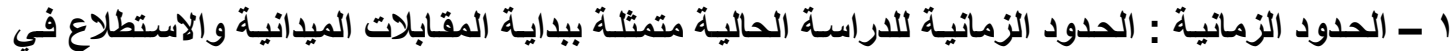

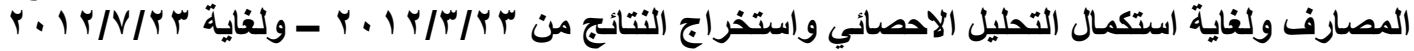

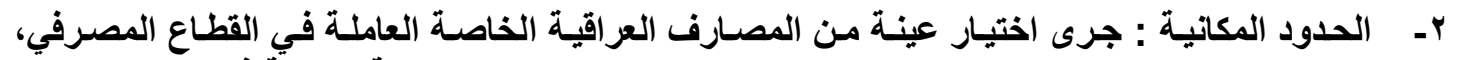

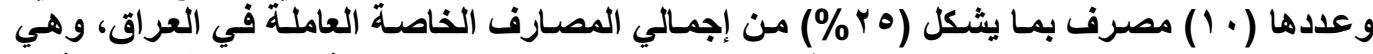

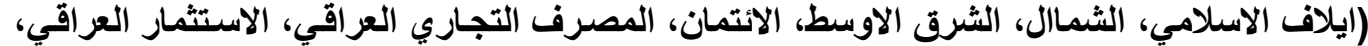

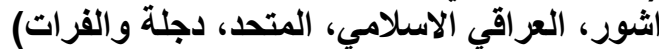

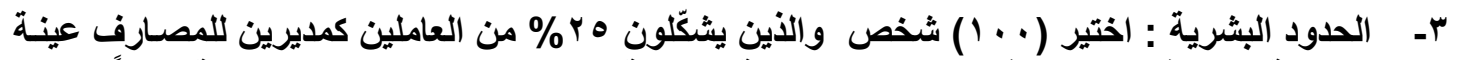

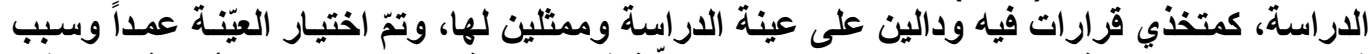

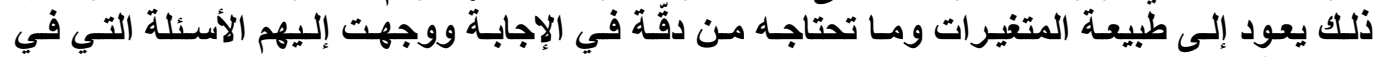




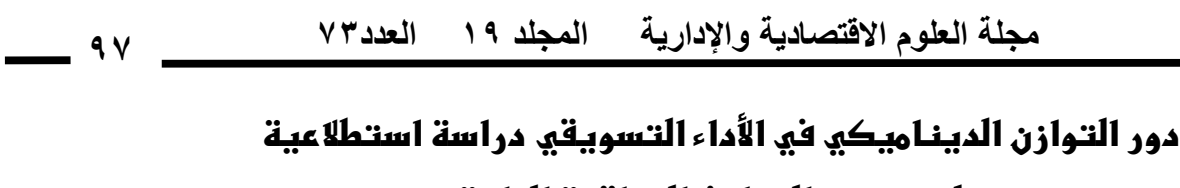 \\ على عدد من المصارف العراقية الفاصة}

صدق وثبات المقياس لغرض أن تستُوفي الاستبانة الدراسـة للثشروط العلميـة المعتمدة فلابد من إخضـاعها لثـروط البحث العمي، وعليه فق روعيت هذه الثروط على وفق الفقرات الآتية:

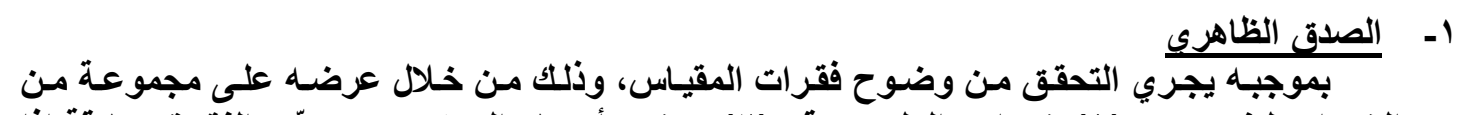

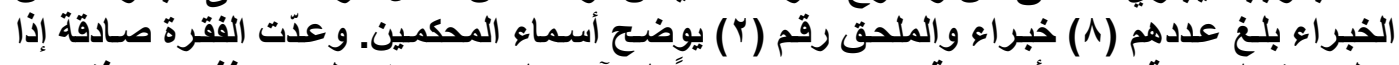

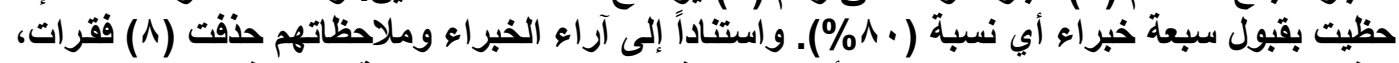

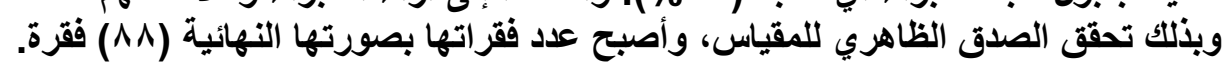

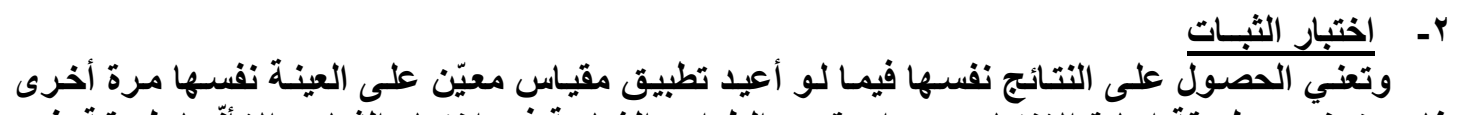

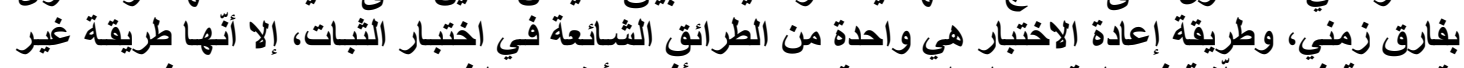

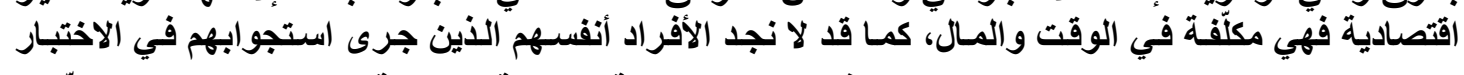

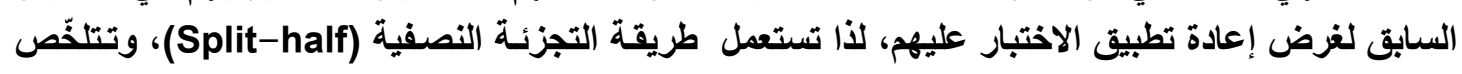

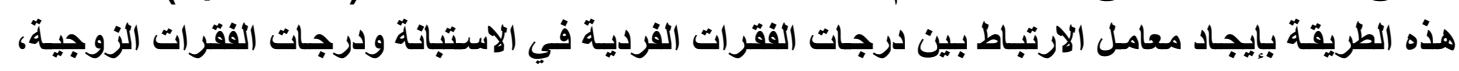

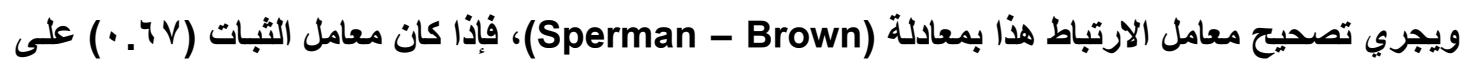

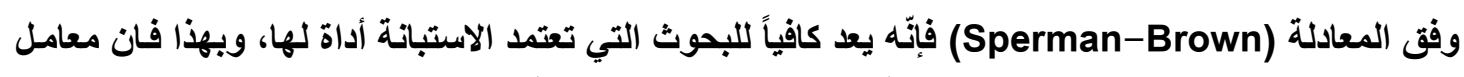

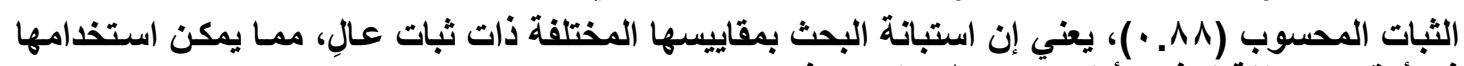

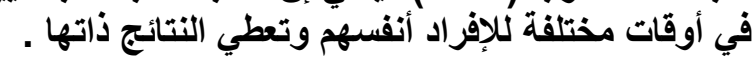




\section{$-91$ \\ دور التوازن الديناميكي في الأداء التسويقيي دراسة استطلا عية \\ على عدد من المصارف العراقية الخاصة}

\section{المبحث الثاني / الاطار الفكري للبحث}

Dynamic equilibrium of marketing اولا : التوازن الديناميكي للتسويق

أقترح (Gummesson,2008:160) نموذج لتوازن السوق من وجهة نظر الاقتصاد ويسمى التوازن

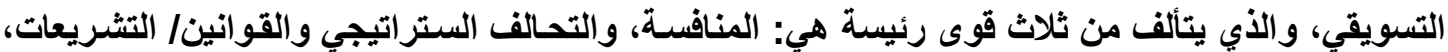

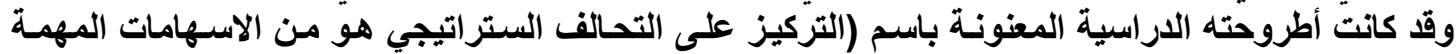

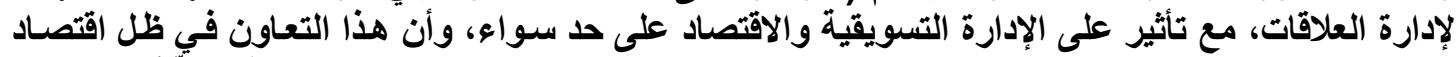

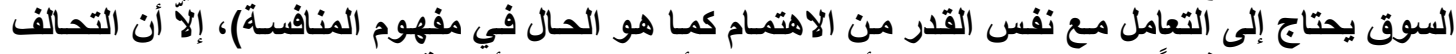

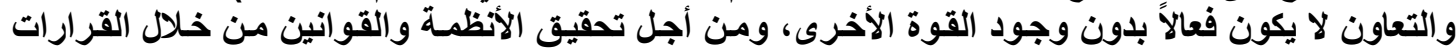

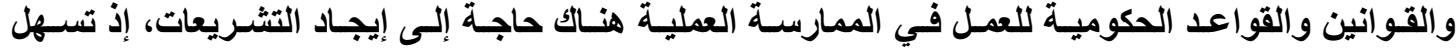

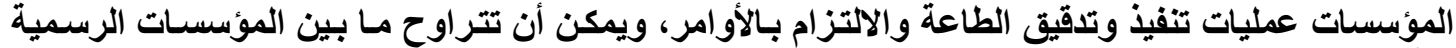

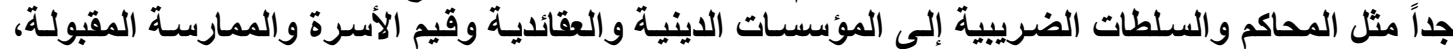

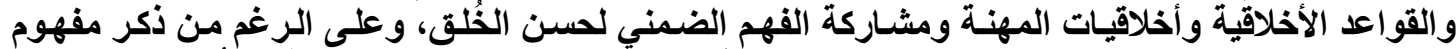

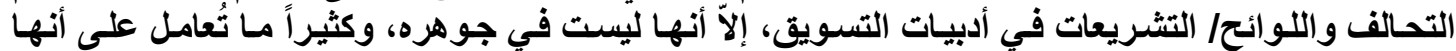
عوائق تقف أمام المنافسة.

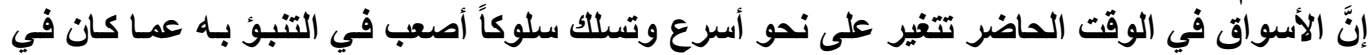

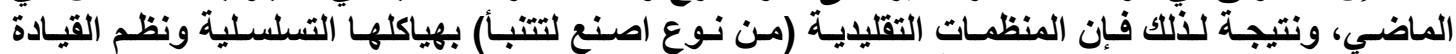

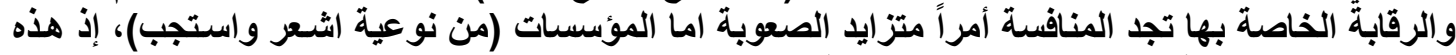

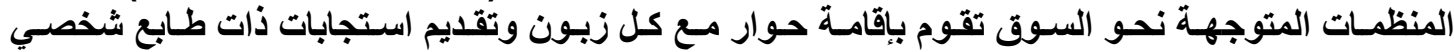

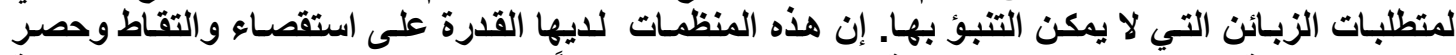

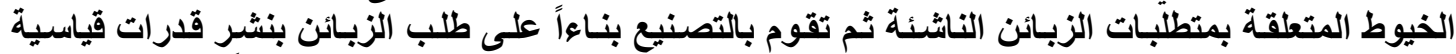

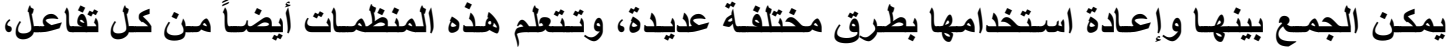

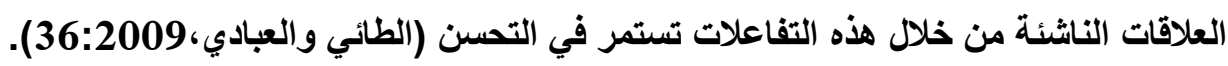

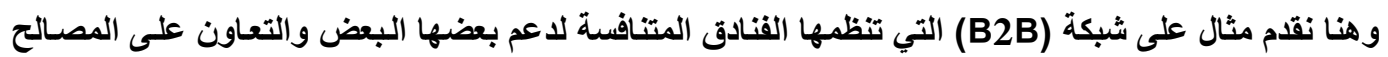

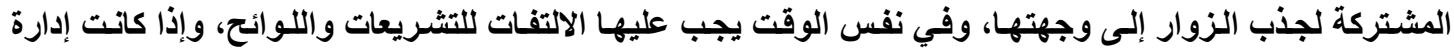
العلاقات تثلدد على مبدأ التنافس، فإن (Gummesson,2008:62) يرى أن إدارة العلاقات هي توليف بين المنافسة والتحالف واللوائح/ التشريعات كما هو مبين في الثكل (r) (r). 
دور التوازز الديناميكي في الأداء التسويقي دراسة استطلا عية

على عدد من المصارف العراقية الفاصة

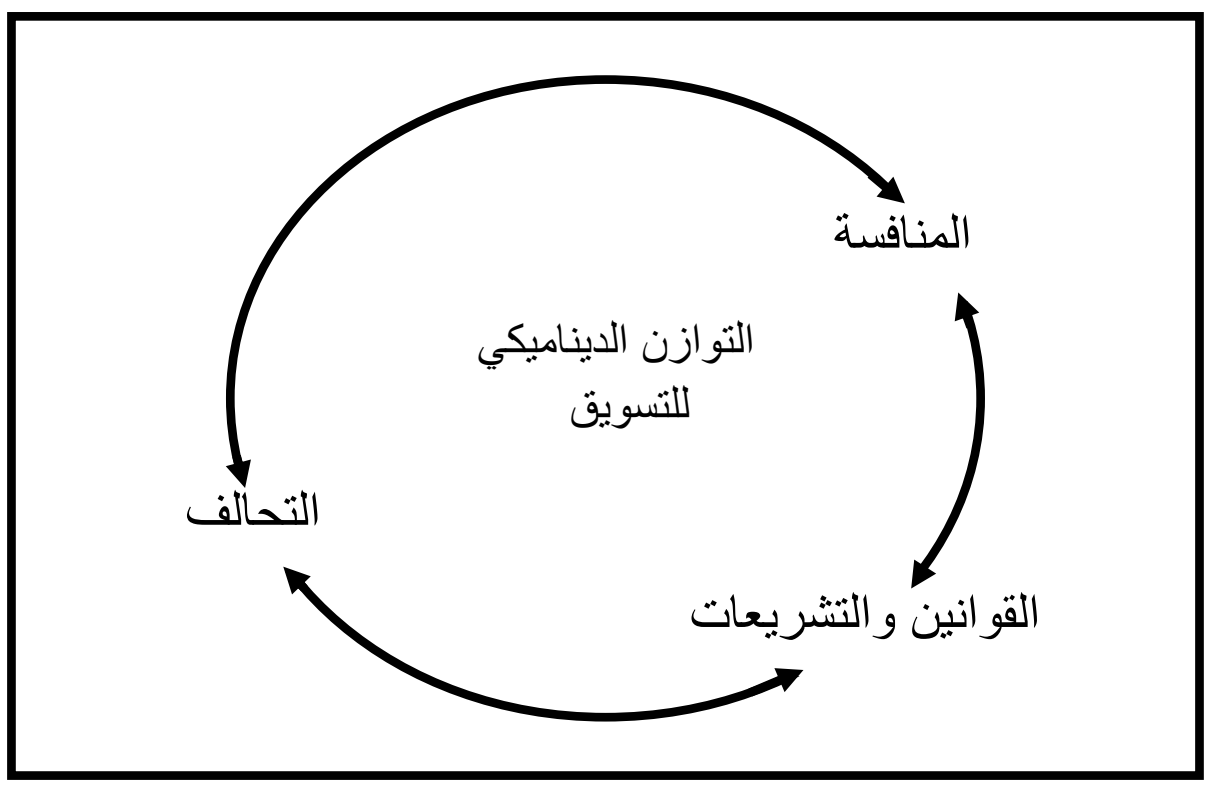

شكل (r) نموذج القوى الثناث لاقتصاد السوق و التي يمكن أن تخلق معاً التوازن التسويقي

Source: Gummesson, Evert, (2008), "Total Relationship Marketing", $3^{\text {rd }}$ ed., Elsevier Ltd. USA, P:61.

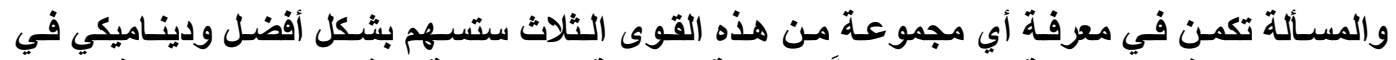

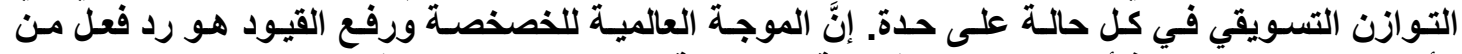

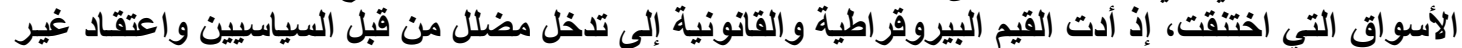

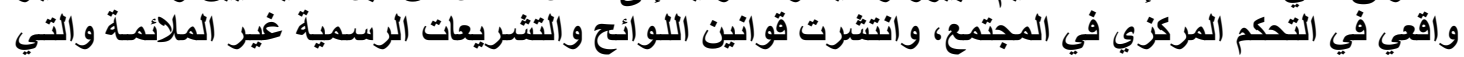

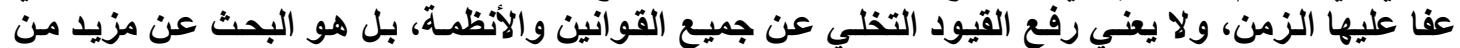

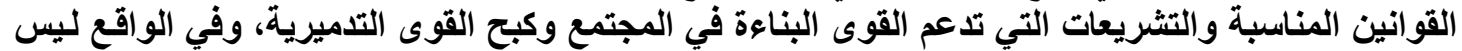

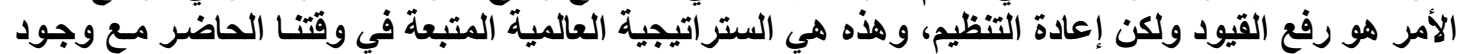

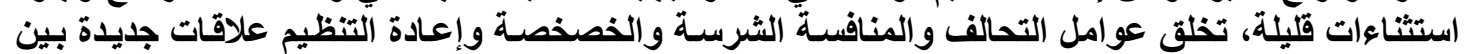

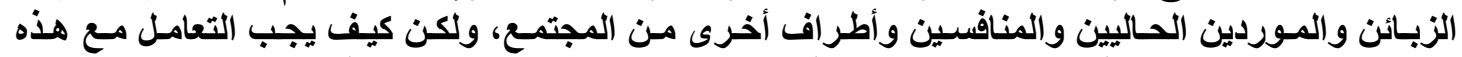

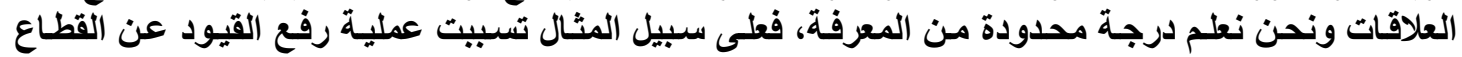

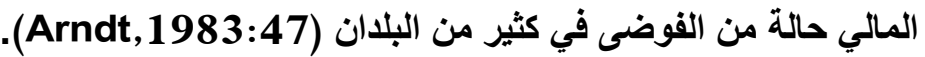

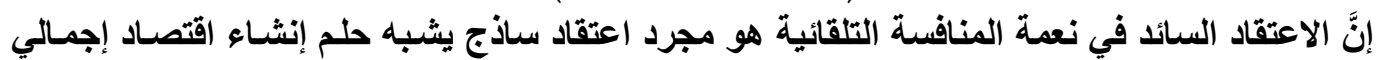

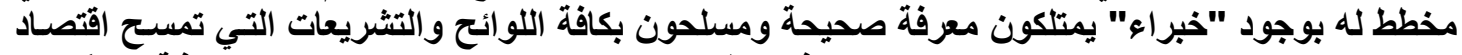

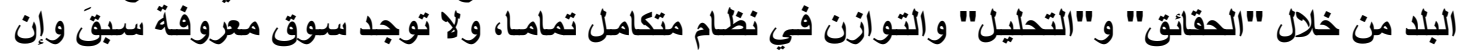

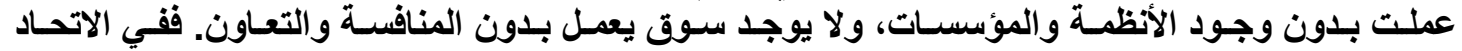

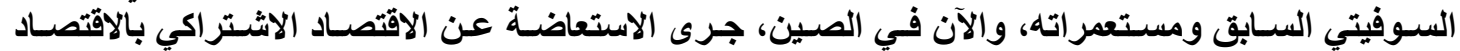

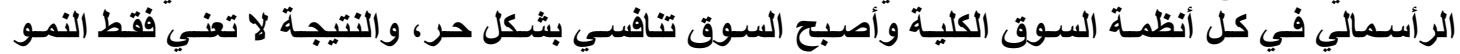

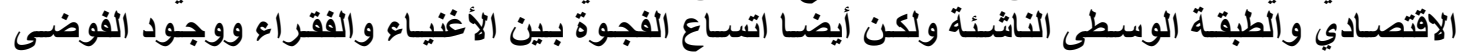

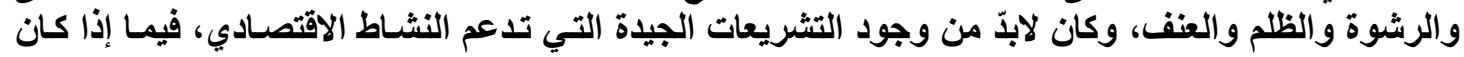

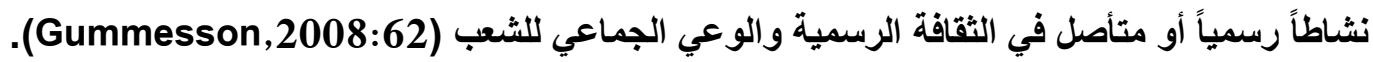

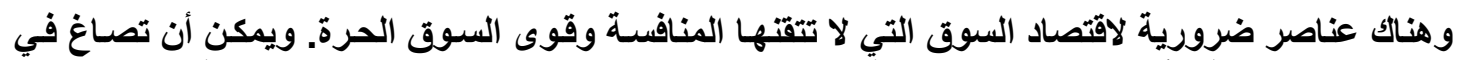

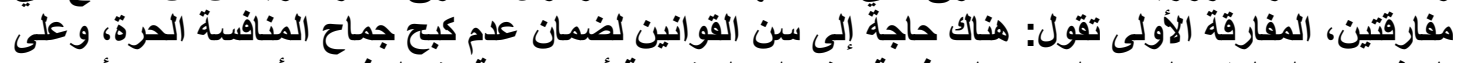

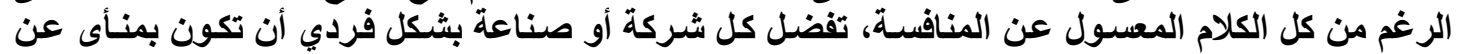

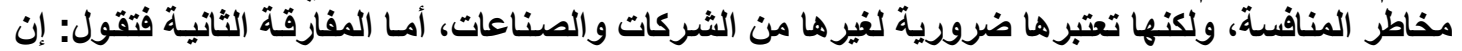

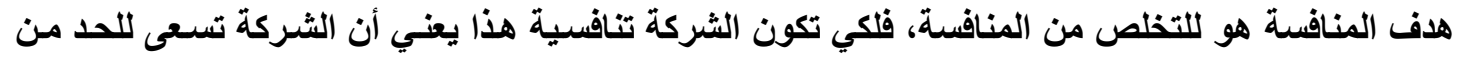




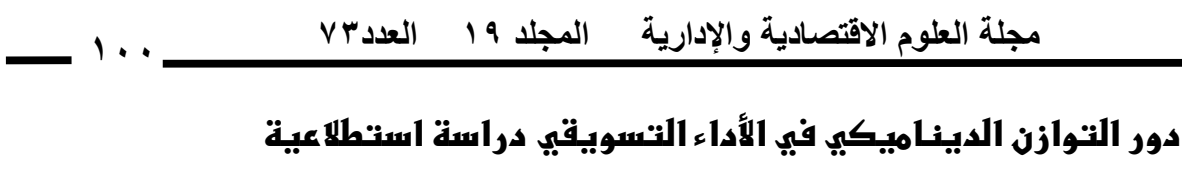 على عدد من المصارف العراقية الفاصة}

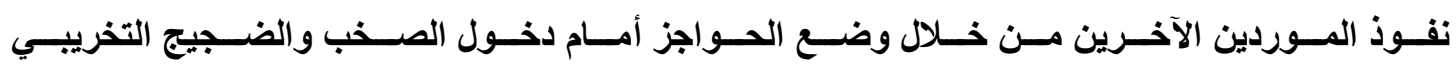

(Thorelli, 1986:41)

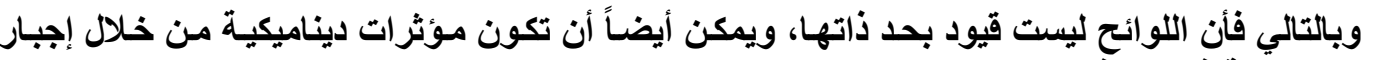

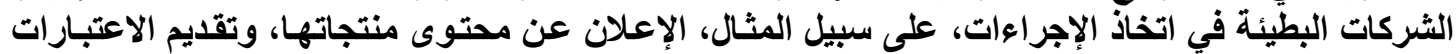

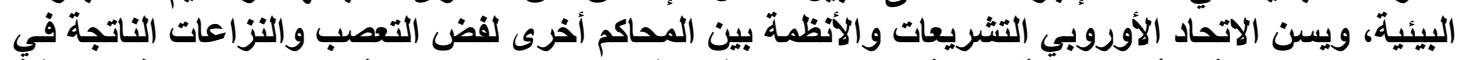

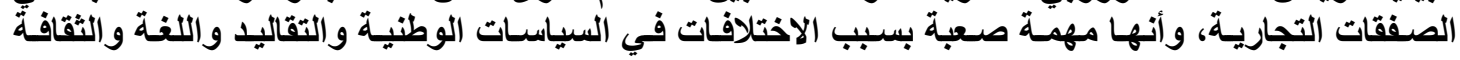

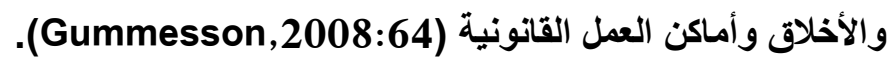

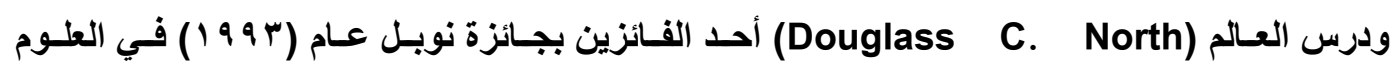

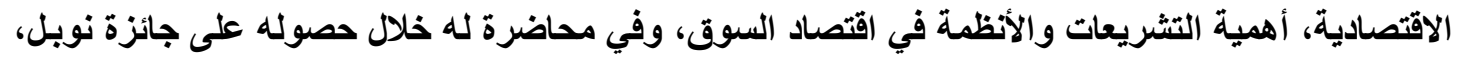

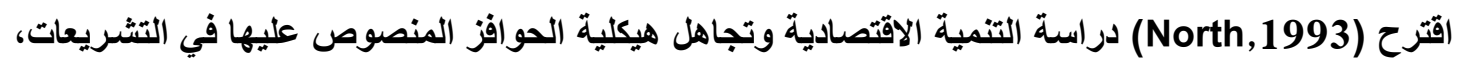

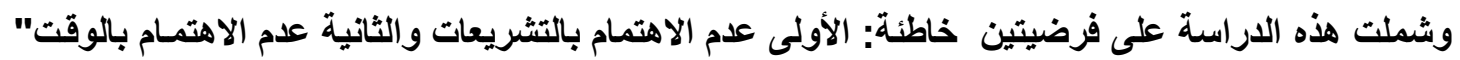

(Arndt, 1983:47)

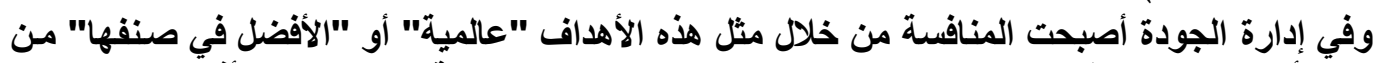

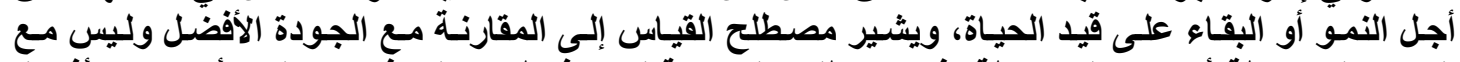

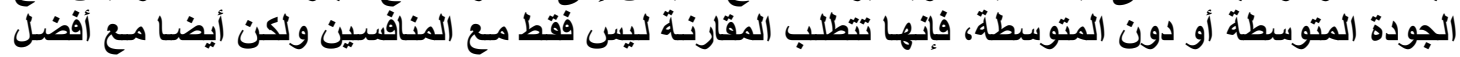

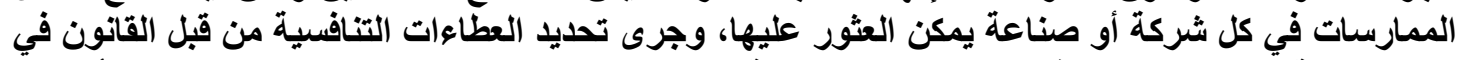

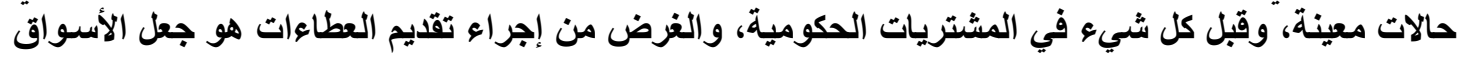

ميكانيكية وغير شخصية (Gummesson,2008:65).

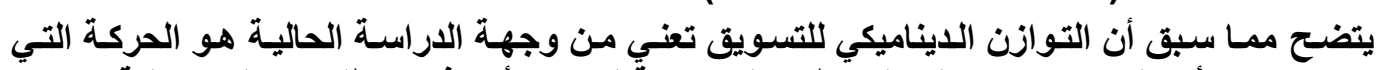

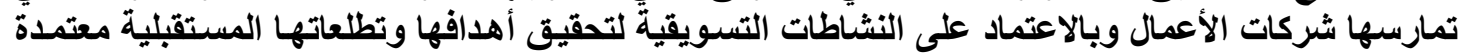

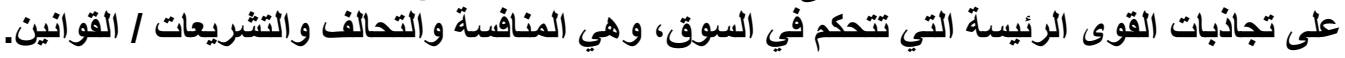

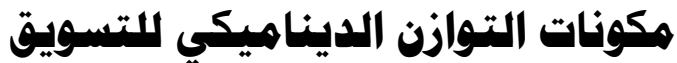

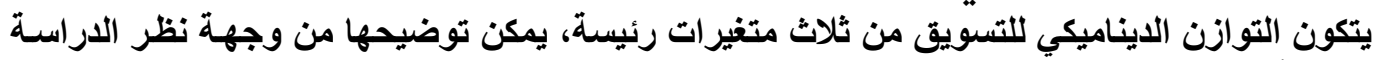
الحالية كما يأتي : التون

\section{: Strategic Collaboration التحالفات الستراتيجية}

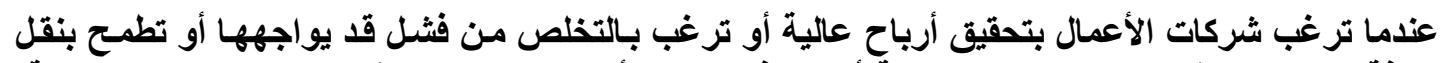

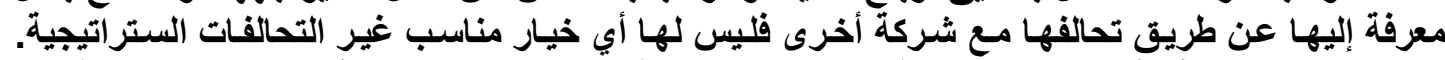

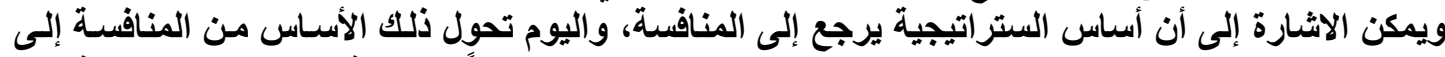

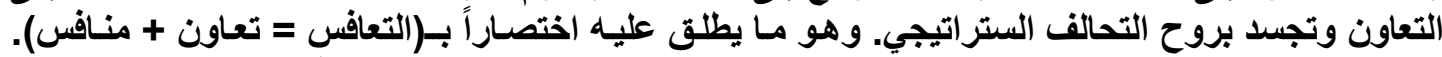

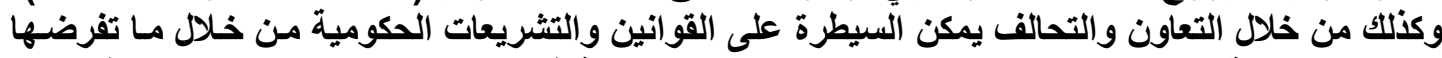

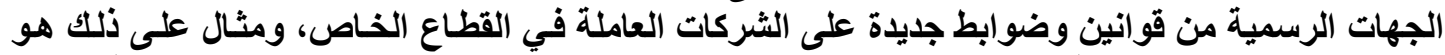

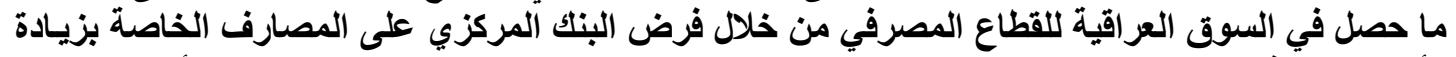

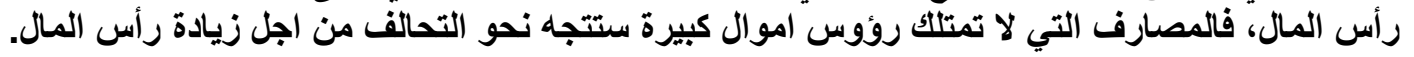




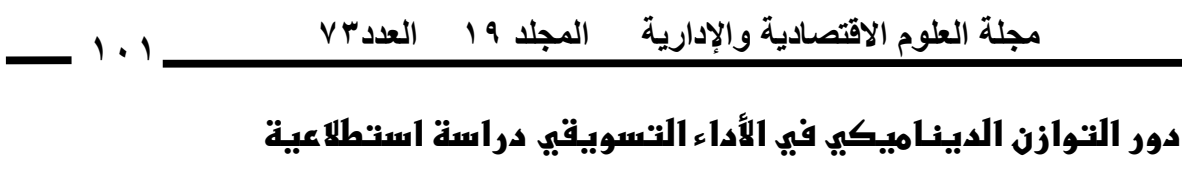

على عدد من المصارف العراقية الفاصة

منذ أكثر من عثر سنوات ماضية دخلت الثركات التحالفـات الستراتيجية من اجل خلق القيمـة وتوسيع

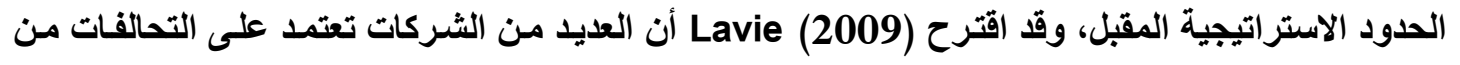

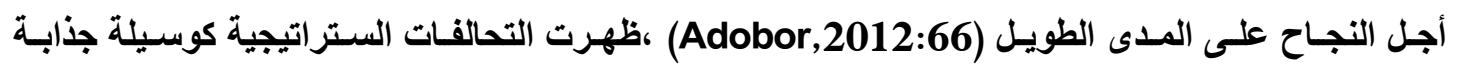

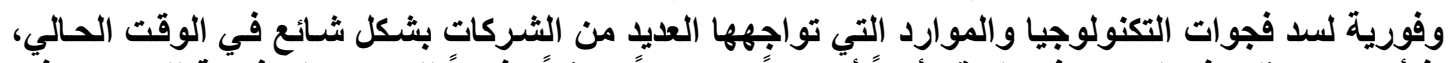

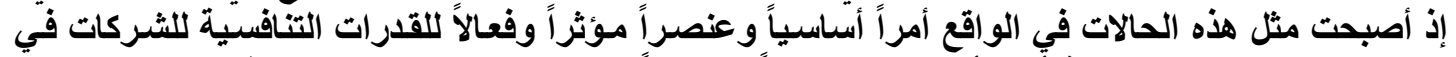

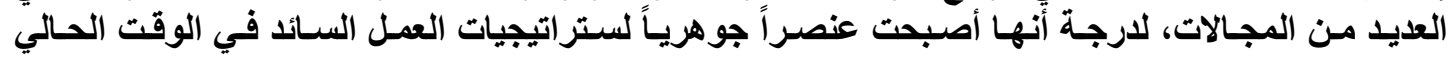

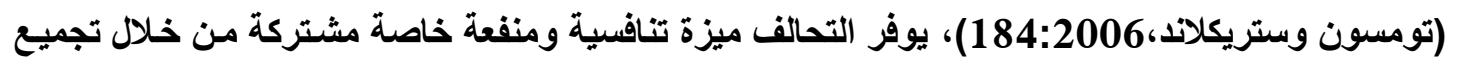

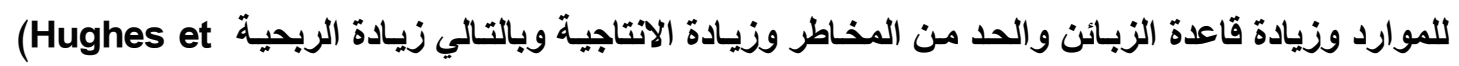

al.,2012:356)

لذلك نجد أن العديد من المصارف وجدت ضالتها في التحالفات الستراتيجية كبديل نـاجح عن ستراتيجية التئية

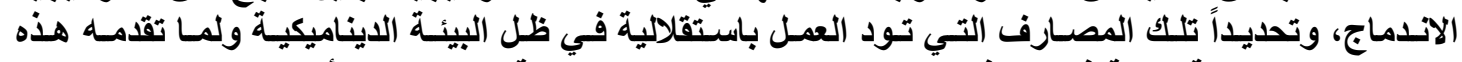

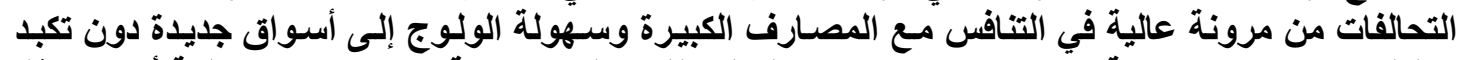

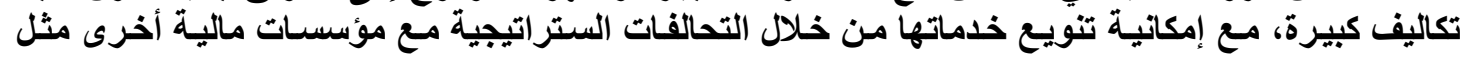

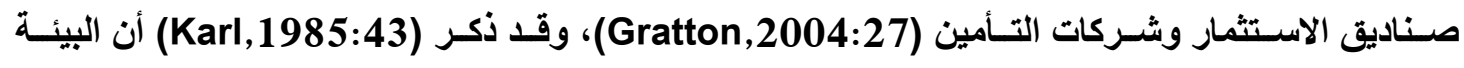
المحدثة أو (المدركة) (Enacted Environment) أي التي تحدثها المنظمة وتنافس فيها، هي البيئة التي

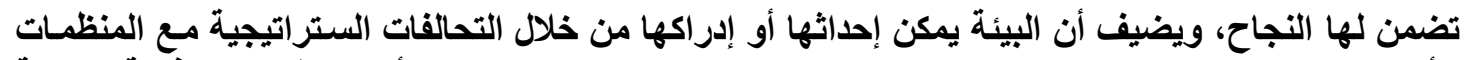

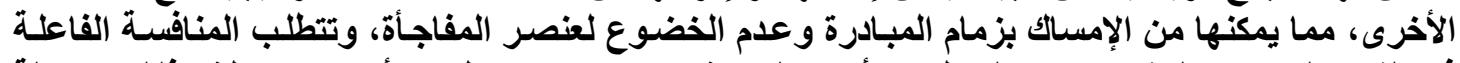

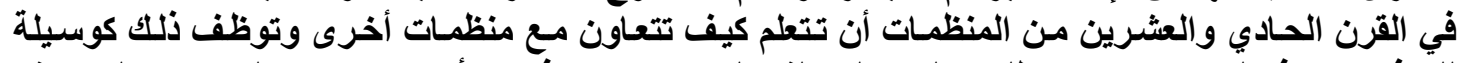

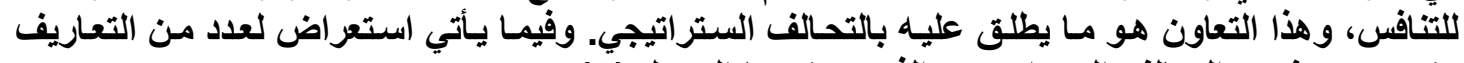

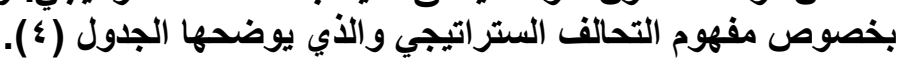




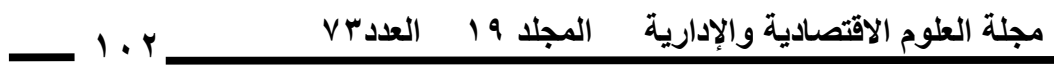 \\ دور التوازز الديناميكي في الأداء التسويقيي دراسة استطلا عية على عدد من المصارف العراقية الفاصة}

\begin{tabular}{|c|c|c|}
\hline \multicolumn{3}{|l|}{ الجدول ( ) يوضح المفاهيم الخاصة بالتحالفات الستراتيجية } \\
\hline المفهوم & الباحث & ت \\
\hline 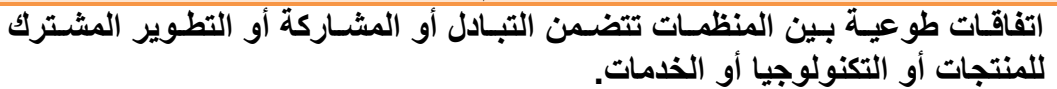 & (Gulati,1998:293) & 1 \\
\hline قيمة المنظمات المتحالفة. تلثلب جهوداً تعاونية طوعية من أجل خلق أو إضـافة أو تعظيم & $\begin{array}{l}\text { Willcocks\& ) } \\
\text { (Choi,1999:212 }\end{array}$ & r \\
\hline الإنتاج والتسويق. للتعاون بين منظمـات من القطاع نفسـه في مجال البحوث التقانة، تسـهيلات & $\begin{array}{c}\text { Thompson\& ) } \\
\text { (Strickland,2003 }\end{array}$ & $r$ \\
\hline 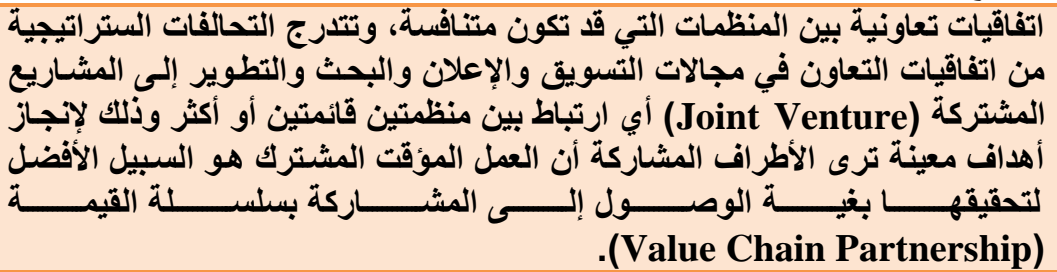 & (Hill\&,2001:423) & $\varepsilon$ \\
\hline 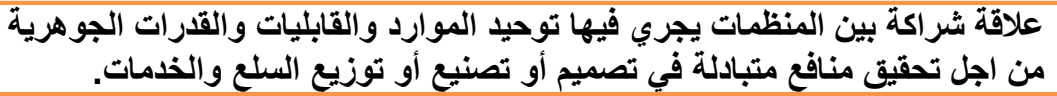 & (Hitt & 0 \\
\hline 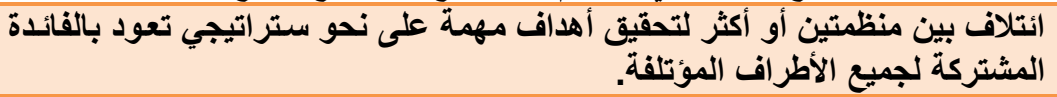 & $\begin{array}{c}\text { Kotabe\& ) } \\
\text { (Helsen,2007 }\end{array}$ & 9 \\
\hline 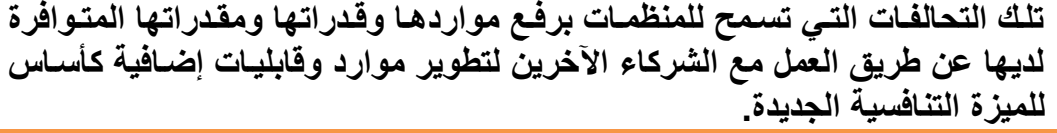 & (Hitt et al.,2007:303) & v \\
\hline 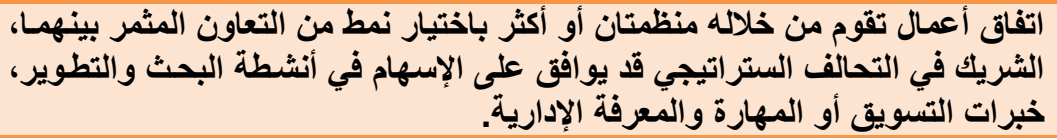 & (ياسين،2010: 000) & 9 \\
\hline 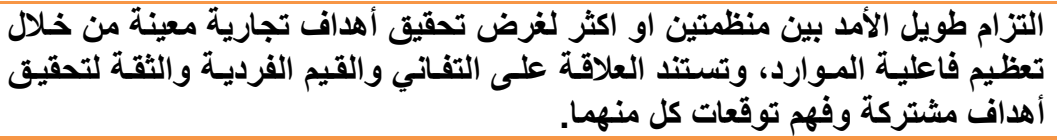 & $\begin{array}{l}\text { (Hughes et al., } \\
\text { 2012:358) }\end{array}$ & \\
\hline
\end{tabular}

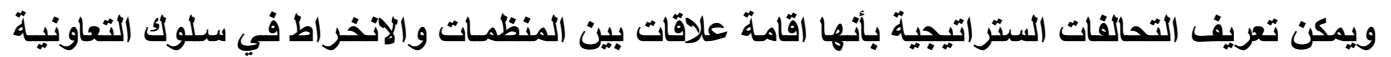

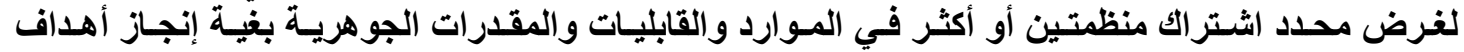

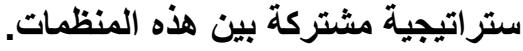

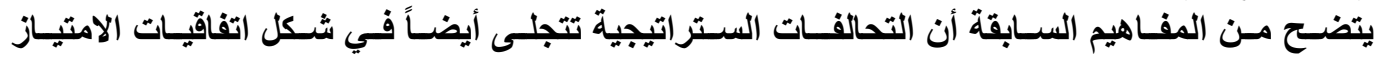

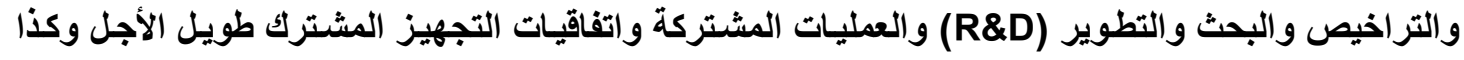

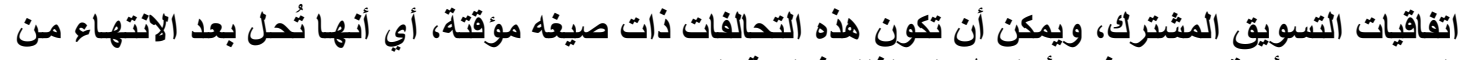

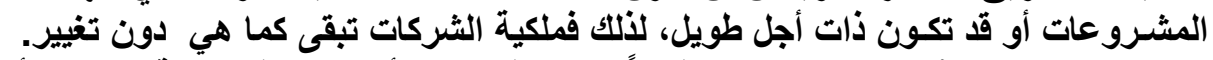

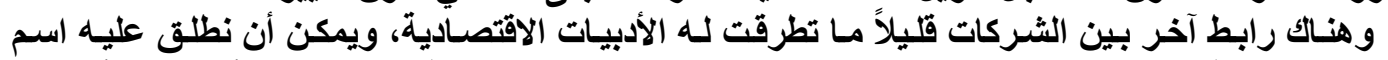

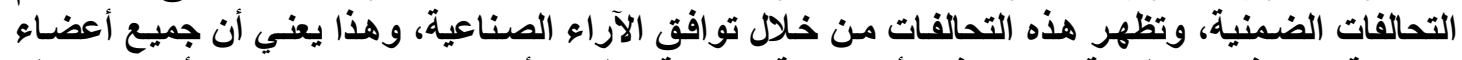

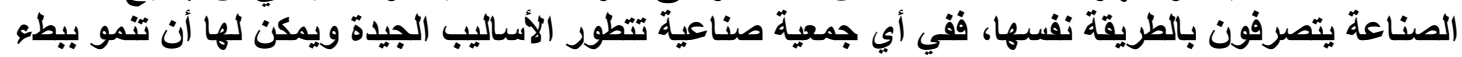

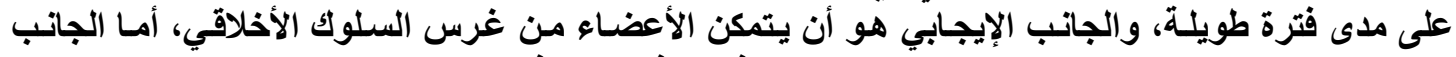

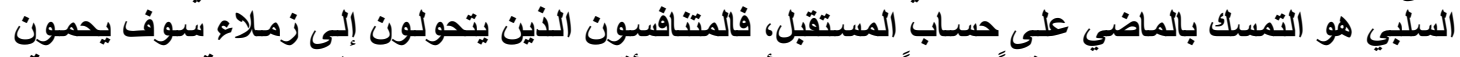

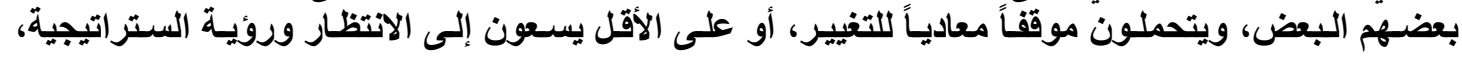

وبالتالي يتطلب الابتكار حدوث ثورة، وخرق التحالف ضمني (Gummesson,2008:185). 


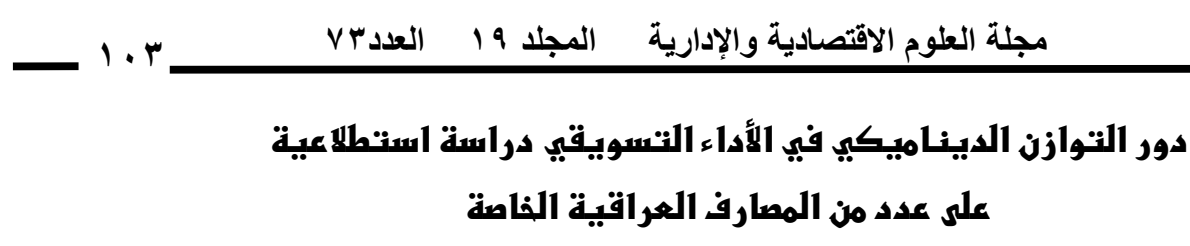

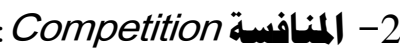

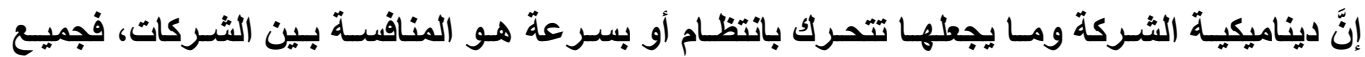

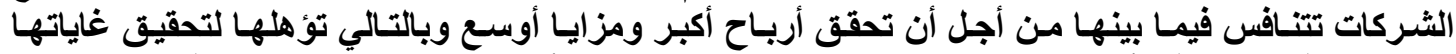

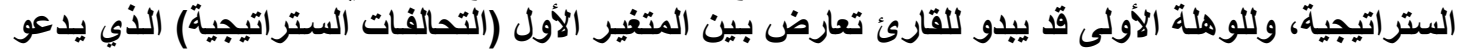

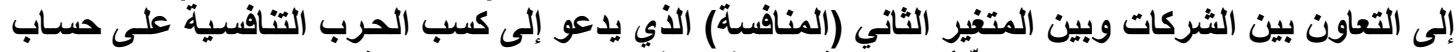

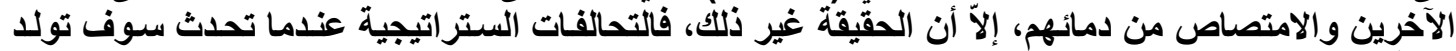

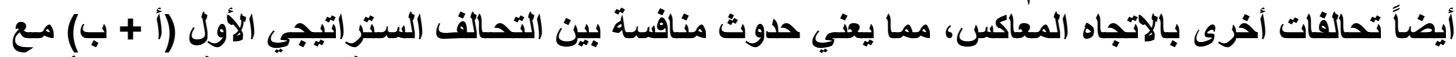

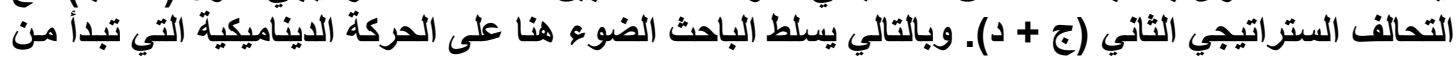

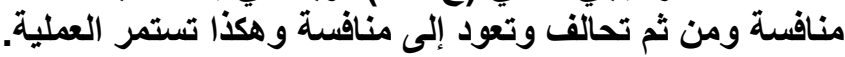

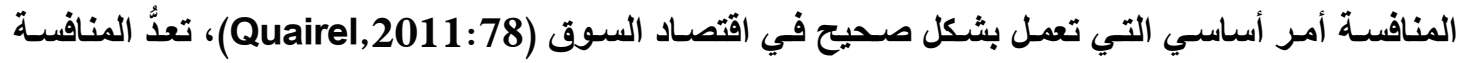

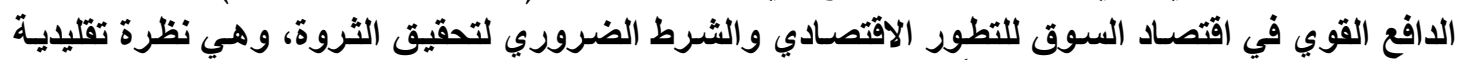

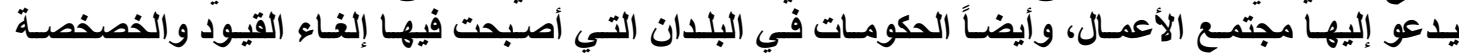

ستراتيجيات قوية (Gummesson, 2008:64).

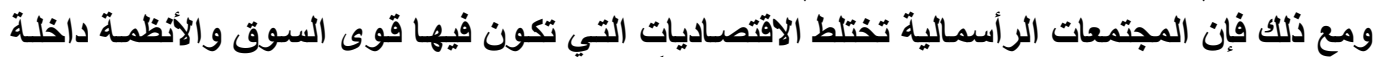

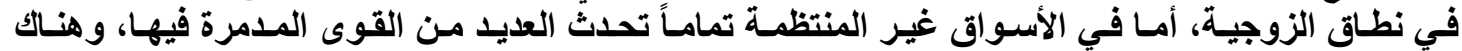

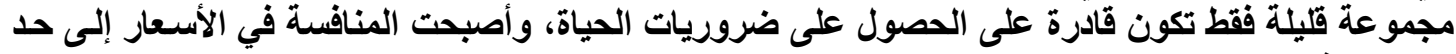

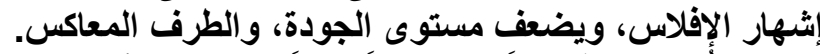

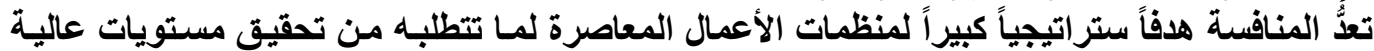

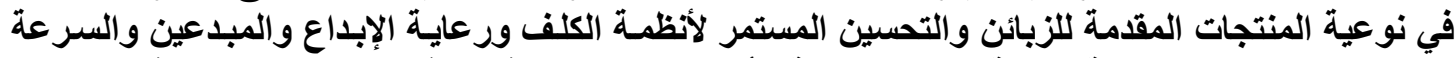

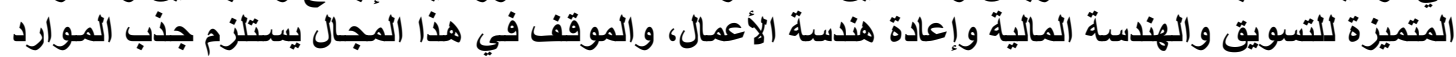

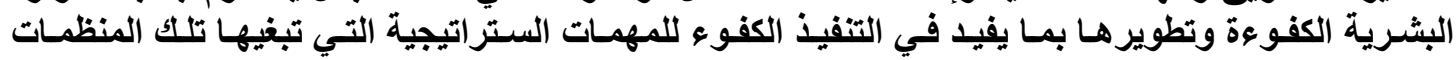

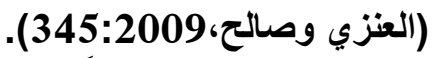

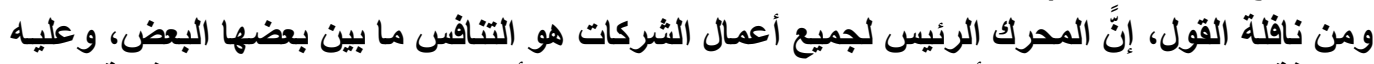

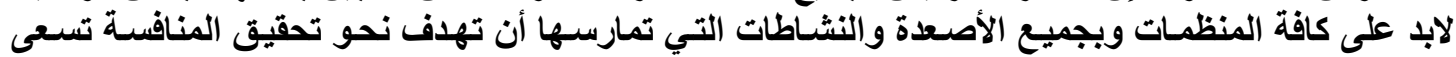

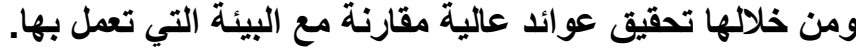

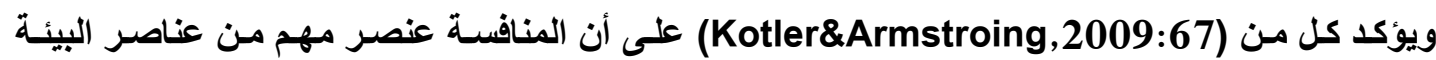

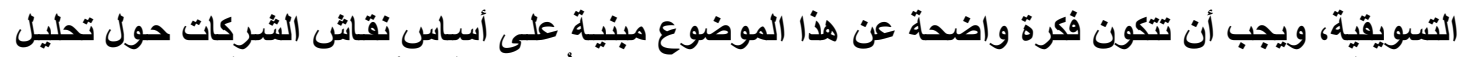

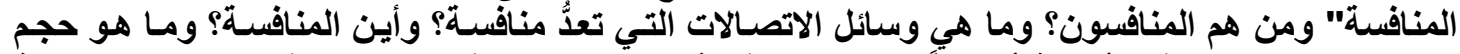

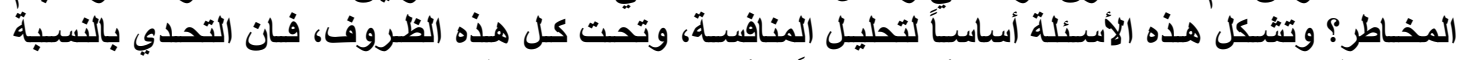

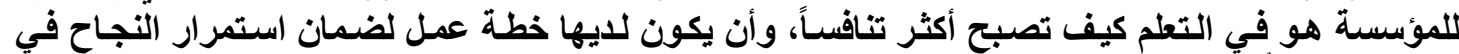

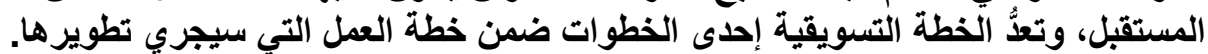

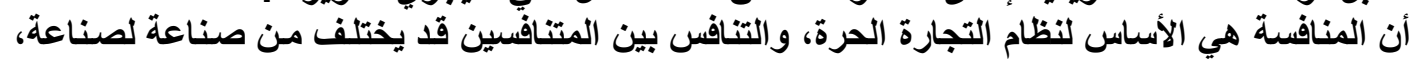

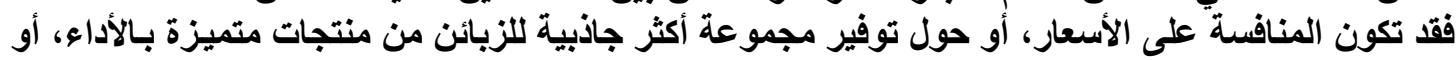

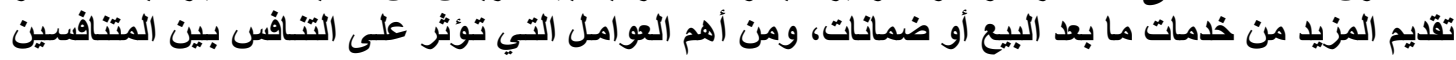

هي (Mullins et al.,2008:82):

- وجود شركات عددها صغير وعدم وجود شركات مهيمنة. - - نمو السوق ببطء وارتفاع التكاليف الثابتة للإنتاج.

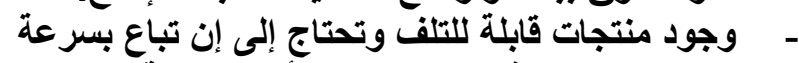
ـ المنتجات ليست فريدة من نوعها أو متجانسة. 


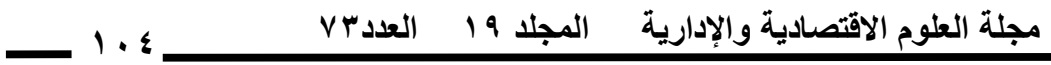 \\ دور التوازز الديناميكي في الأداء التسويقيي دراسة استطلا عية}

على عدد من المصارف العراقية الفاصة

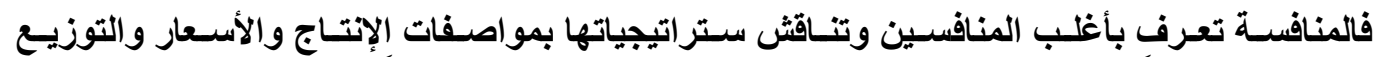

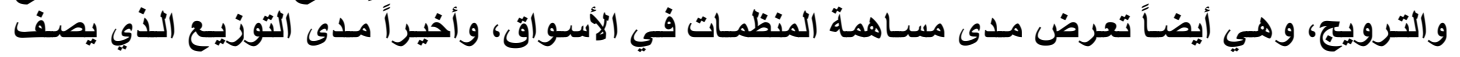

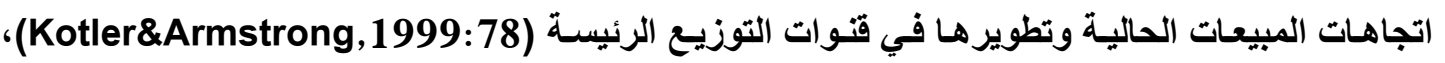

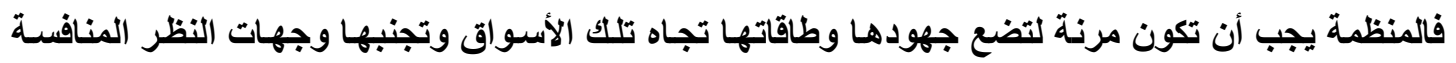
وبعدها تطور ستراتيجية تسويق لكل صنف مستهرف (Kotler\&Armstrong,2008:125). ويرى (Porter,1991:34) أن المنافسة تتحقق نتيجة قدرة المنظمة على إنجاز النشـاطات المطلوبـة

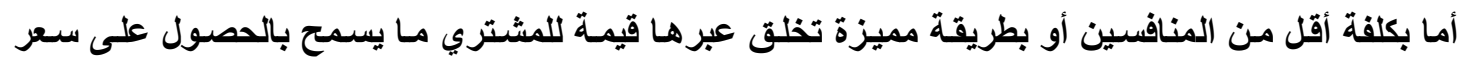

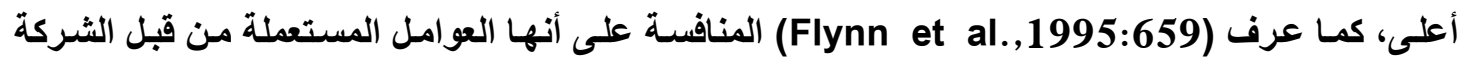

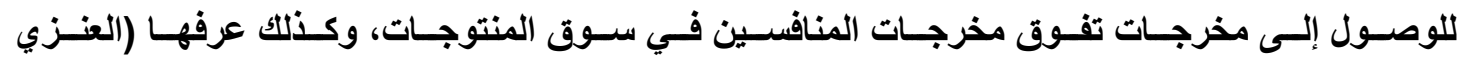

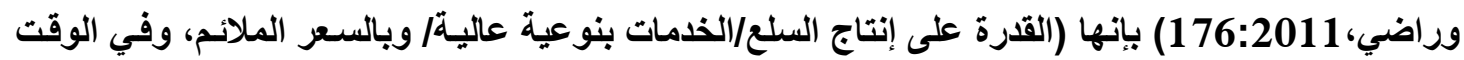

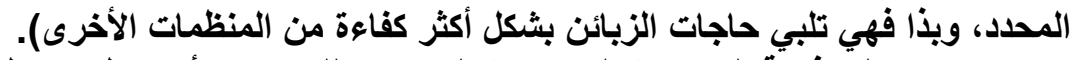

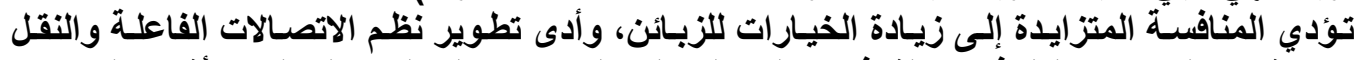

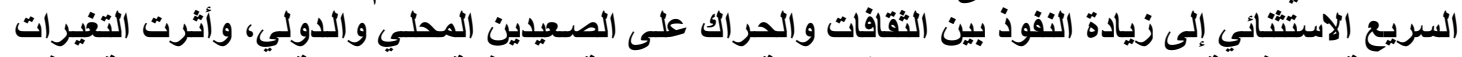

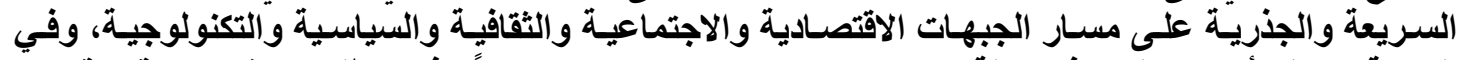

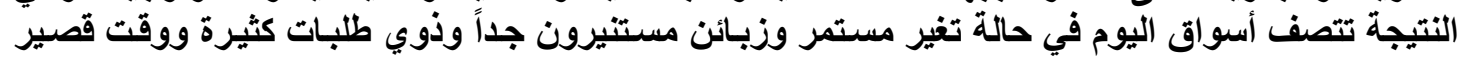

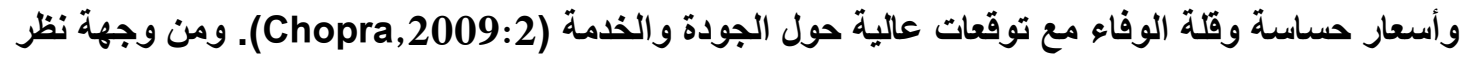
(Quairel,2011:80)

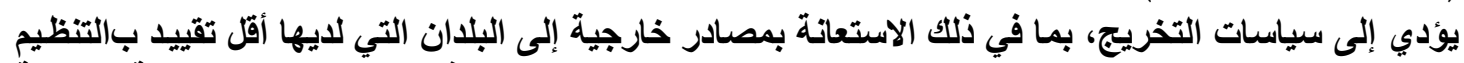

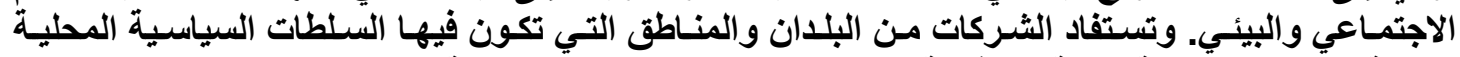

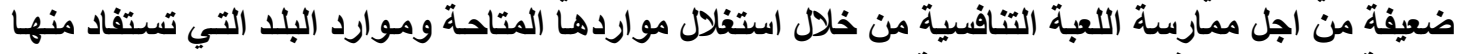
الشركة من اجل التنافس من حيث التكلفة التهبة

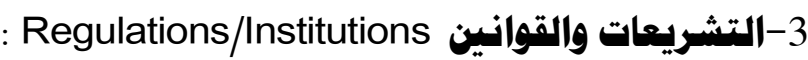

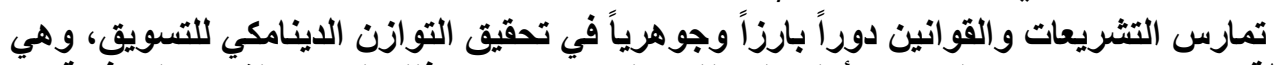

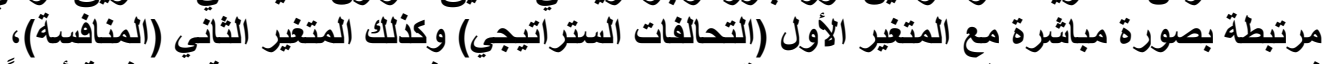

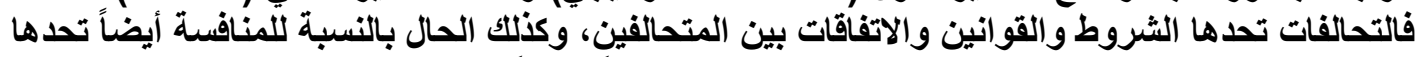

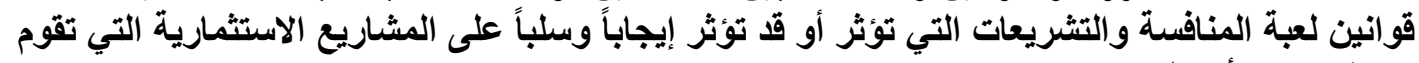

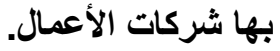

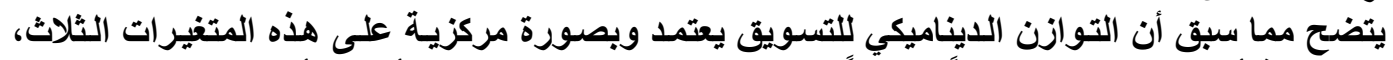

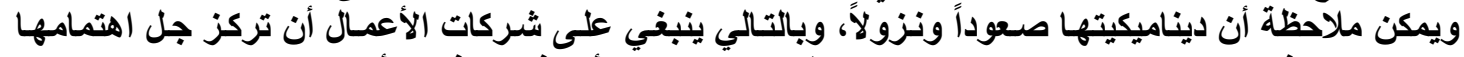

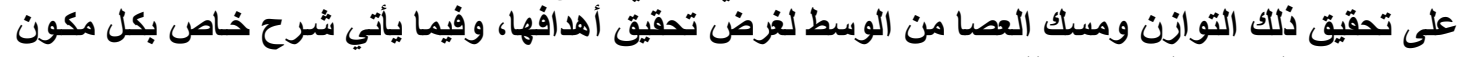

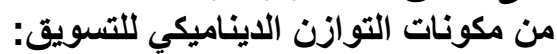

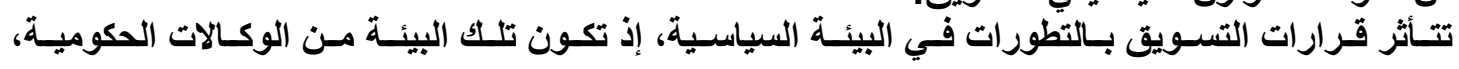

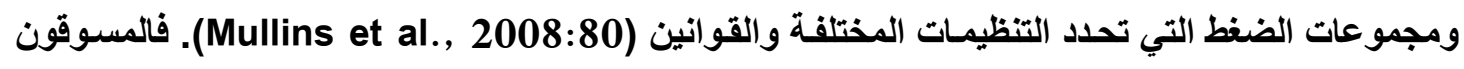

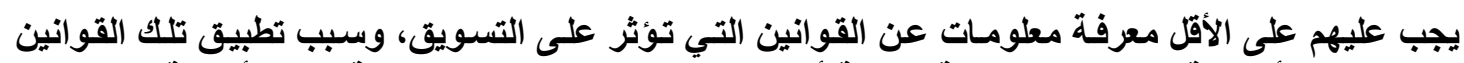
ونصوصها الأساسية والقواعد الراسخة الحالية أسستها التحاكم والهينئات التشرئ التريعية لإدارة أنشطة التسويق. 


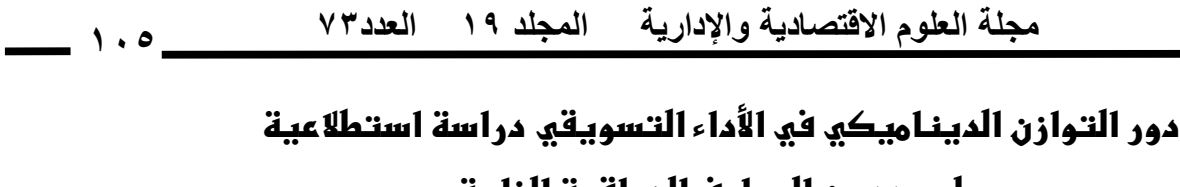 \\ على عدد من المصارف العراقية الفاصة}

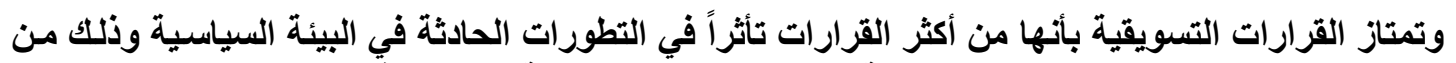

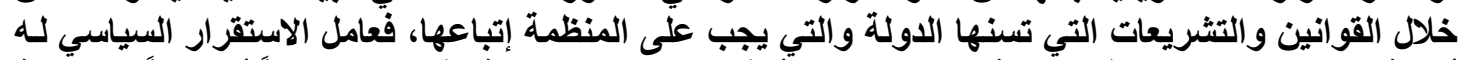

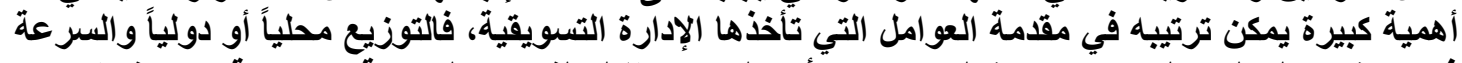

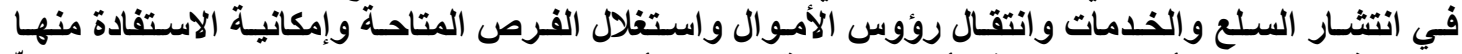

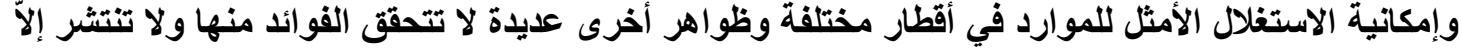

من خلال الاستقلال السياسي (Kotler\&Armstroing,2009:245).

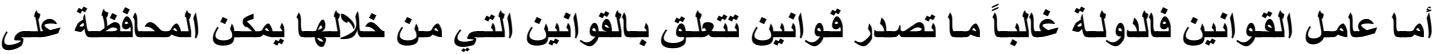

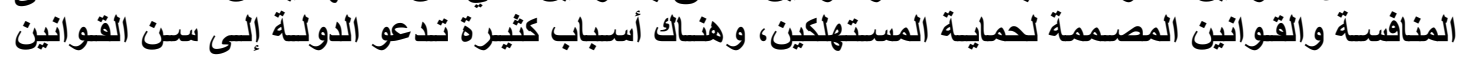

والتشريعات ذات الصلة بالجانب التسويقي منها (Kotler,1997:126):

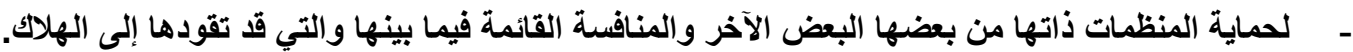

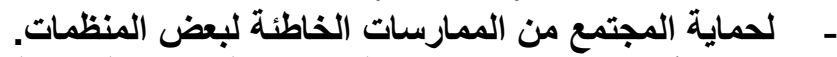

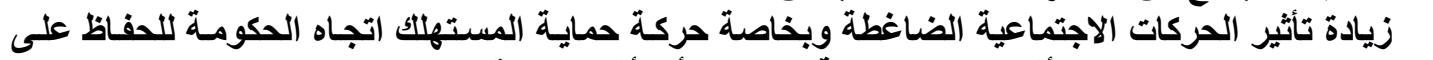

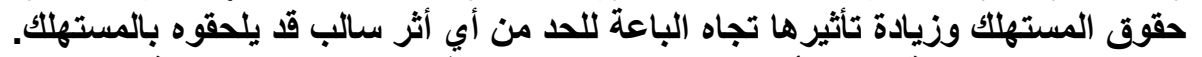

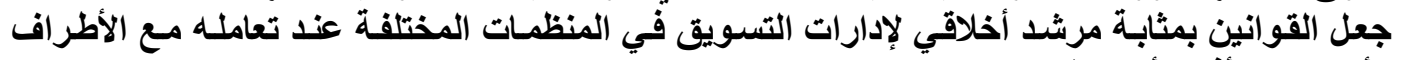
الأخرى من أفراد أو منظمات.

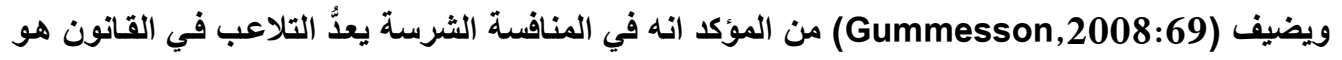

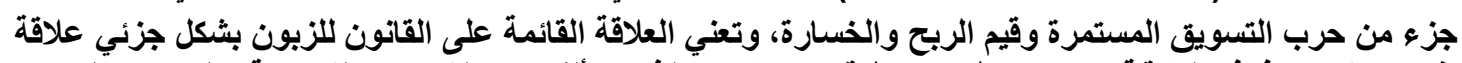

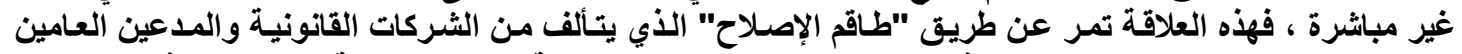

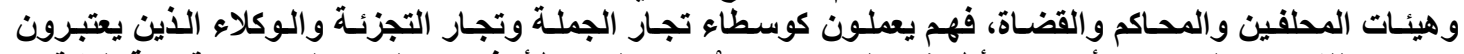

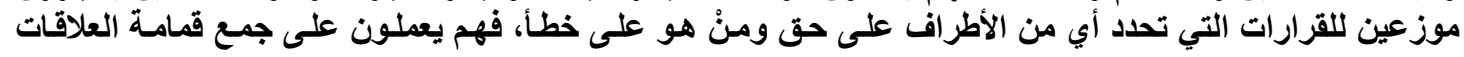

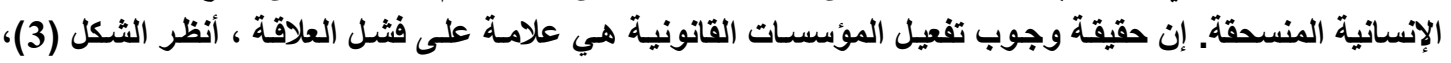

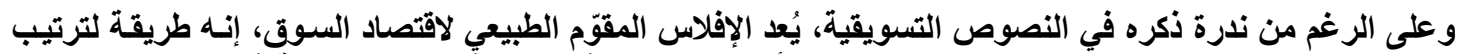

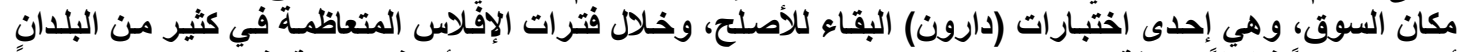

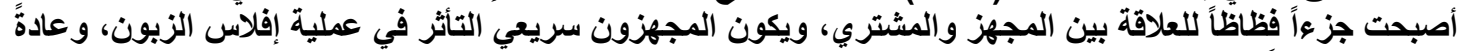

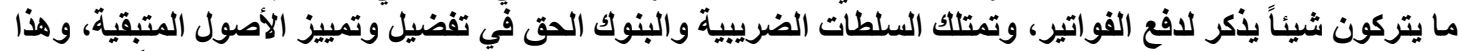

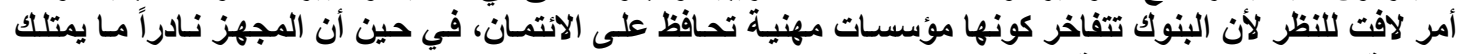
الفرصة لكي يتوقع بفشل شركة الزبون.

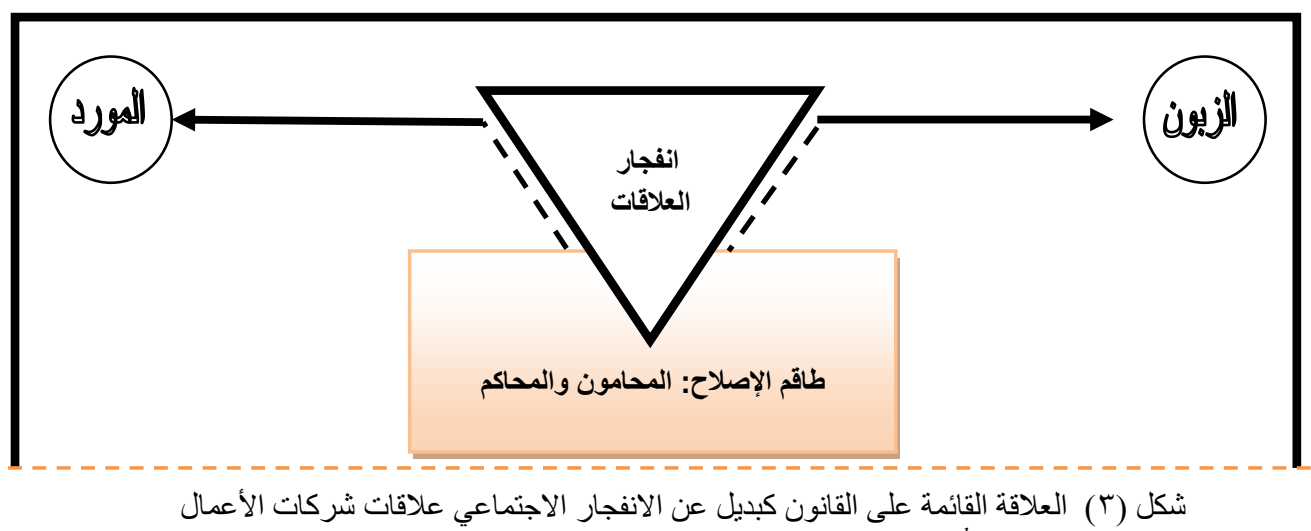

Source: Gummesson, Evert, (2008), "Total Relationship Marketing", $3^{\text {rd }}$ ed., Elsevier Ltd. USA, P:156. 


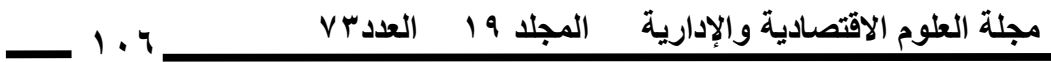 \\ دور التوازز الديناميكي في الأداء التسويقيي دراسة استطلا عية}

على عدد من المصارف العراقية الفاصة

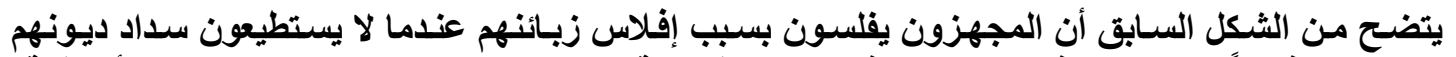

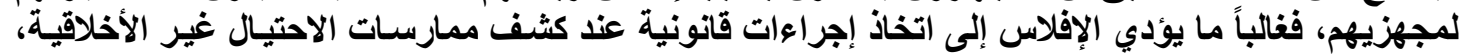
وبعض حالات الإفلاس هي اعتداء متعدد ومنهجي على النظام القانوني كوسيلة لكسب الماند المال،

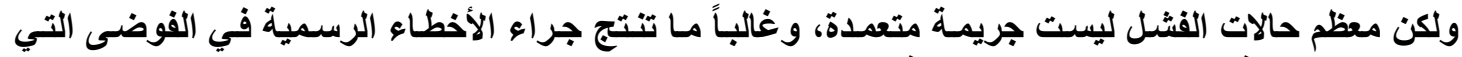

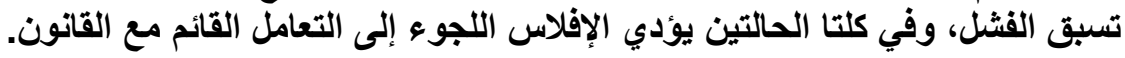

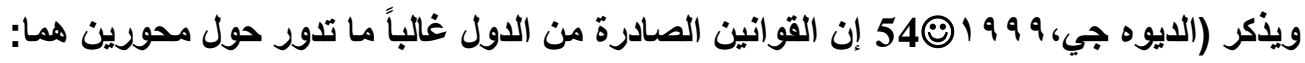

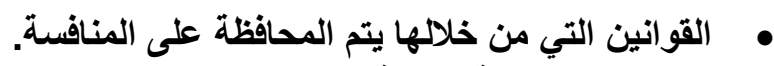
• القوانين المصممة لحماية المستهنك. ويضيف (Kotler,1997:76) بعداً ثاثثاً وهو حماية مصالح المجتمع.

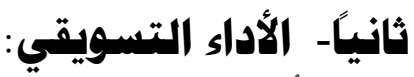

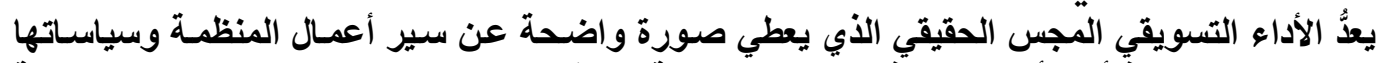

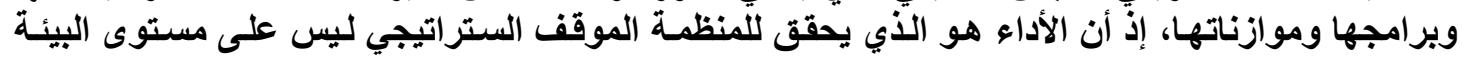

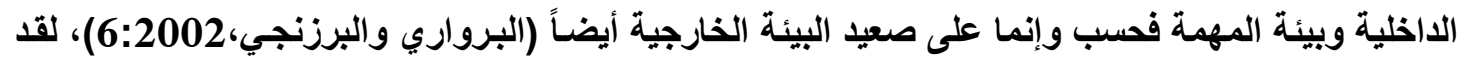

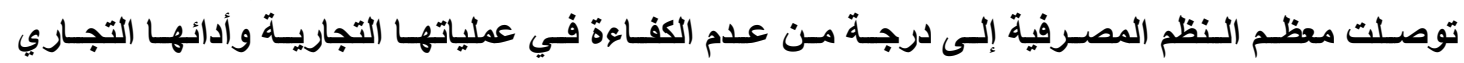

.(Islam et al.,2011:32) يعدُ التسويق العملية المحوريـة التي تكمن وراء التخطيط الستراتيجي والعمليات التجاريـة، وبهذا يُعدُّ

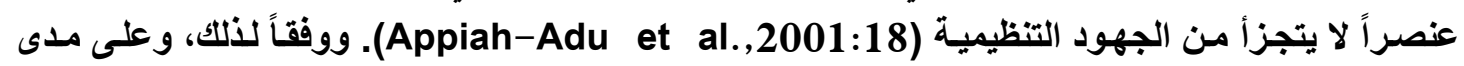

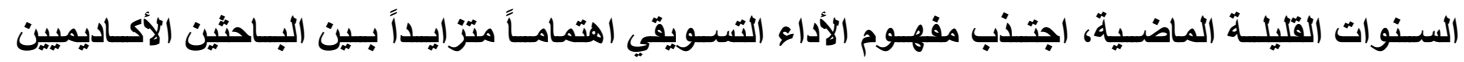

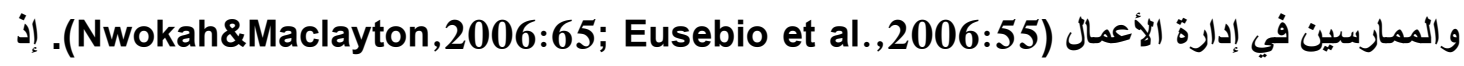

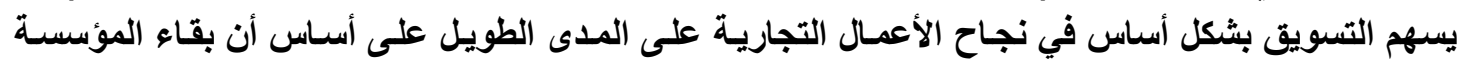
على قيد الحياة يعتمد على قدرتها على خلق القيمة (Nwokah,2009:23). لذا يعرف الأداء التسويقي من قبل (Kotler\&Armstrong,1999:45) بأنه مقابله أداء المنظمة بأداء

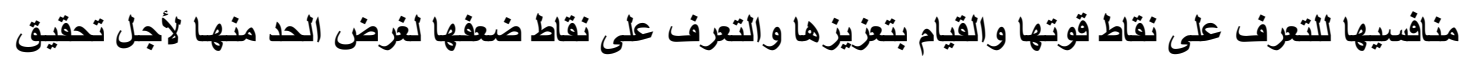

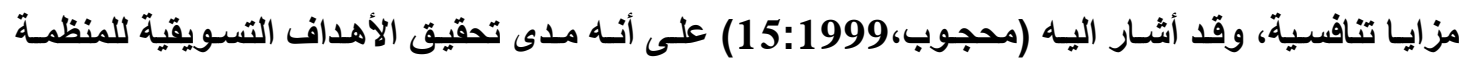
ونجاحها في كسب وإبقاء تفضيل الزبون وأصحاب المصـالح، ووصفه (da Gama,2011:661) Gأنسه

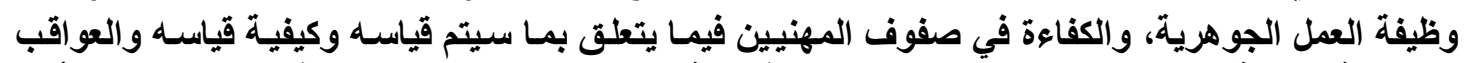

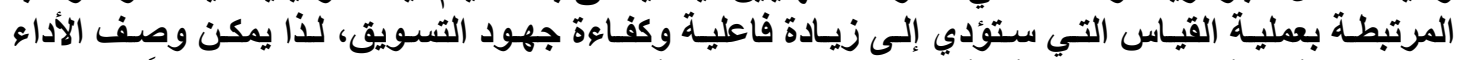

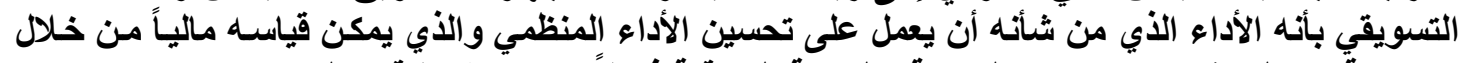

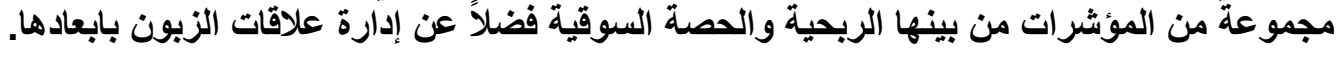




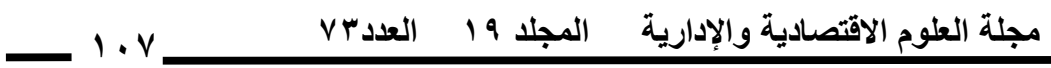 \\ دور التوازز الديناميكي في الأداء التسويقيي دراسة استطلا عية}

على عدد من المصارف العراقية الفاصة

أبعاد وقيساس الأداء التسويقي:

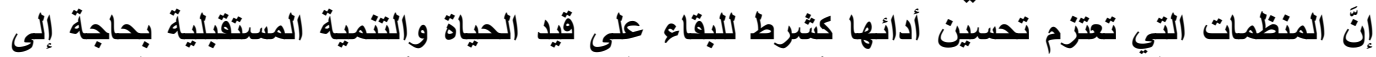

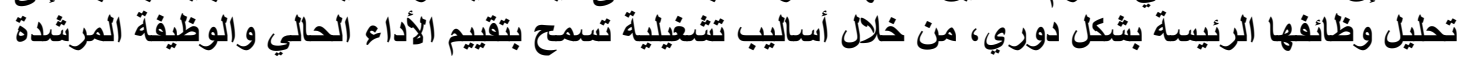

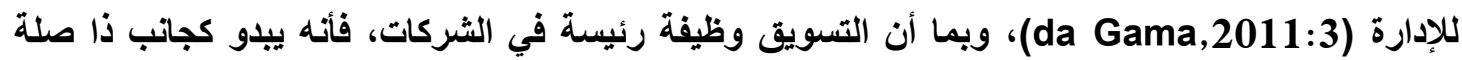

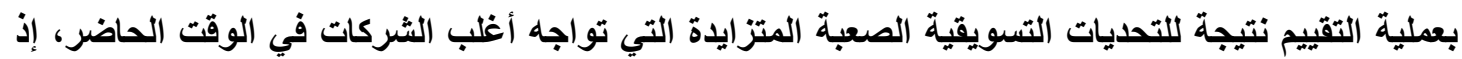

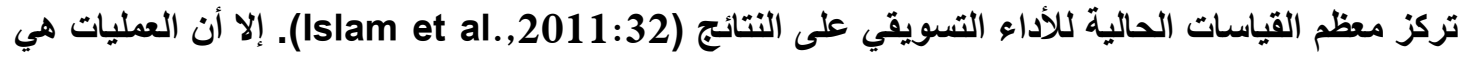
"المادة الصمغية" التي تلصق كل شيء تعمله الثركة، وعليه تستحق قياسات المدخلات مزيداً من الاهتمام الهام أيضاً (O'Sullivan \& Abela,2009:843).

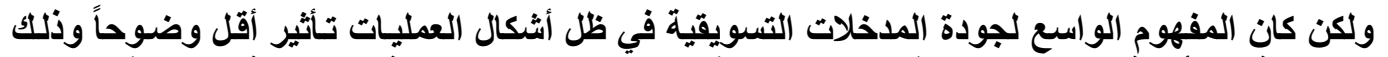

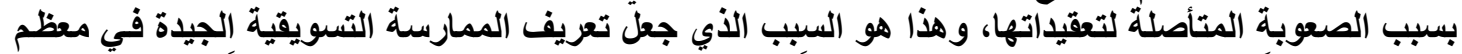

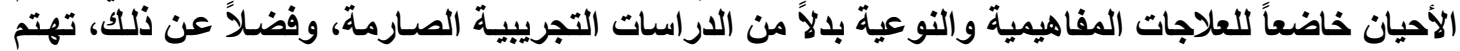

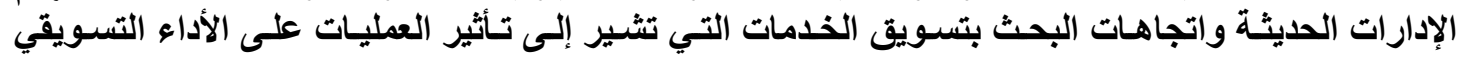

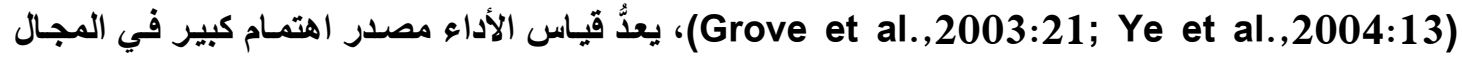

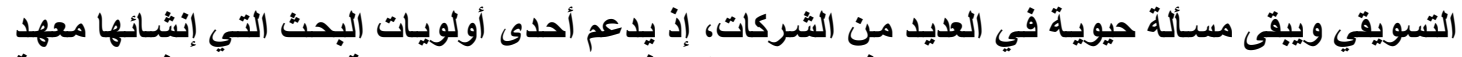

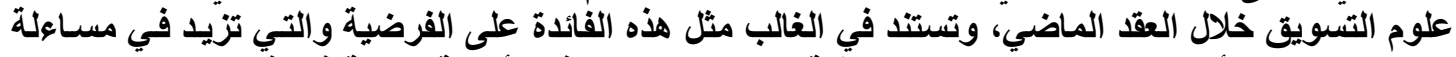

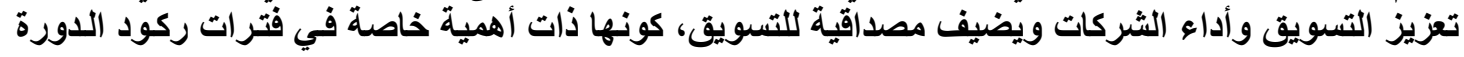

الاقتصادية (da Gama (B),2011:645).

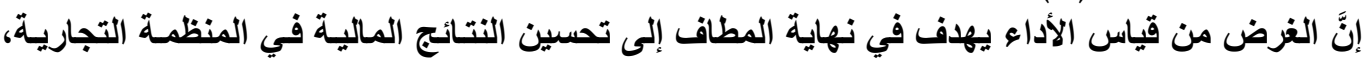

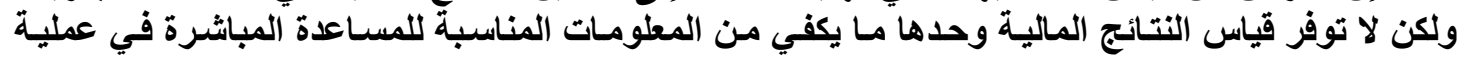

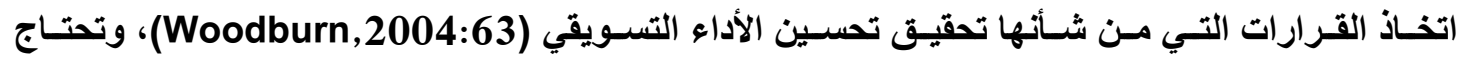
المنظمات لقياس عدة عوامل من أجل الحصول على فكرة حقيقية عن كيفية أداء المنظمة ومنى تتلدخل لتسوية

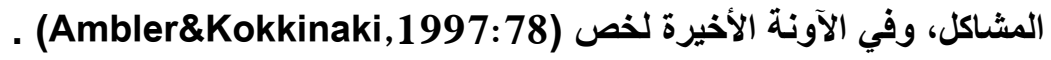

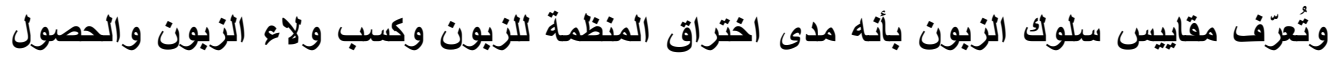

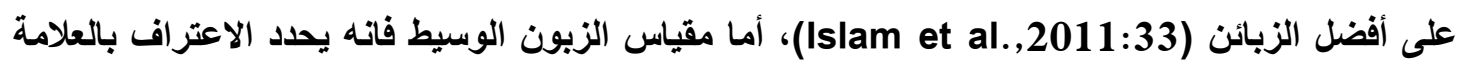

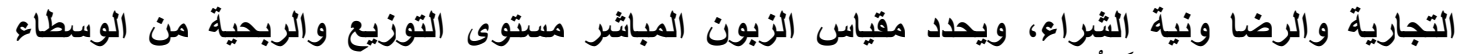

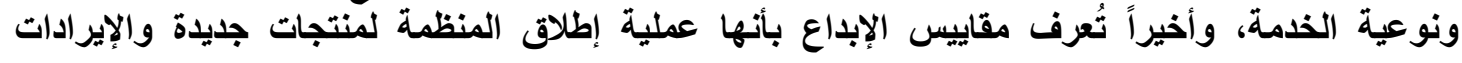

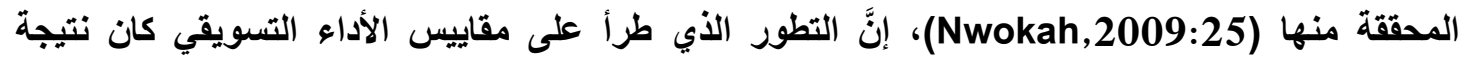

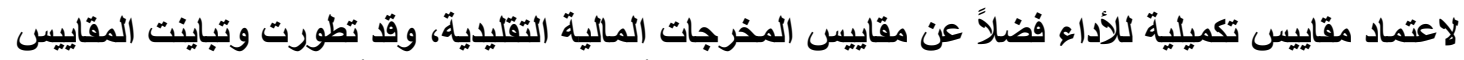

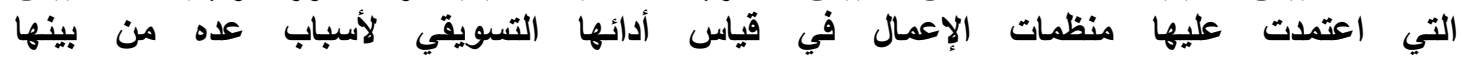

-:(Prid,2002:439)

• زيادة التركيز على التسويق بوصفه موجها للمبيعات المستقبلية ومن ثم النمو والربحية.

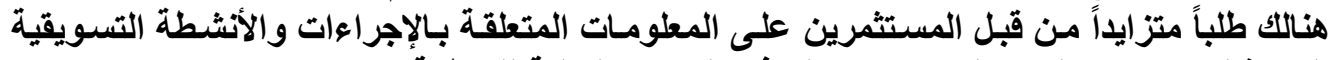

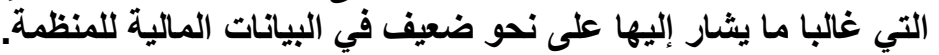

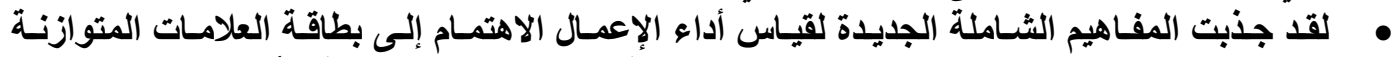
ونبهت المنظمات إلى ضرورة إدخال مقاييس تسويقية في التقسيمات الثائ الثاملة للأداء.

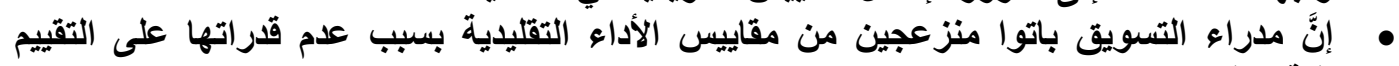
الدقيق لما يؤدونه. 


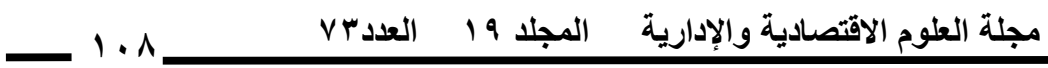 \\ دور التوازز الديناميكي في الأداء التسويقيي دراسة استطلا عية على عدد من المصارف العراقية الفاصة}

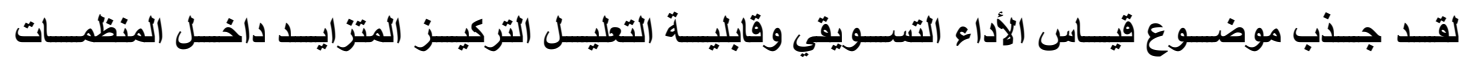

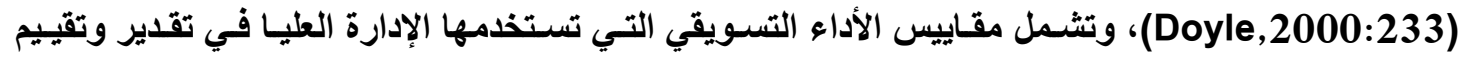

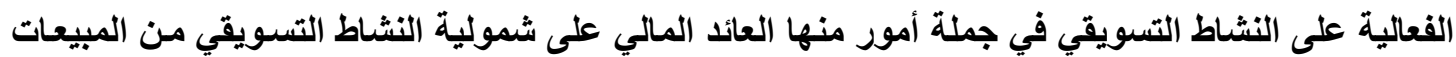

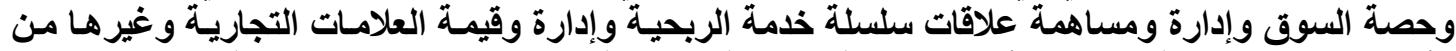

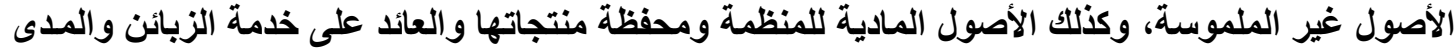

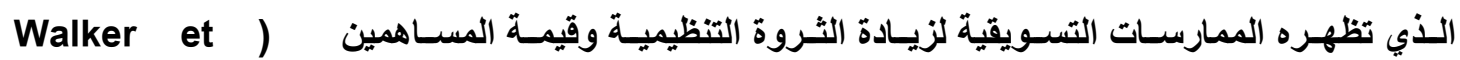

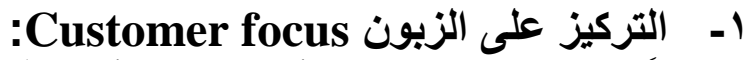

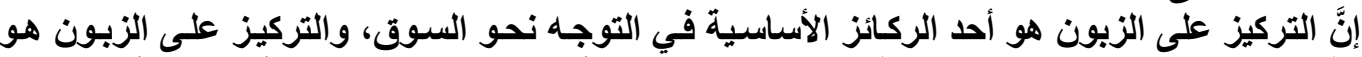

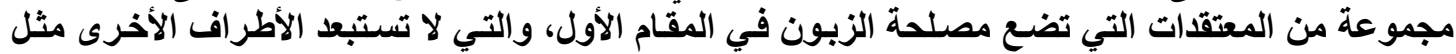

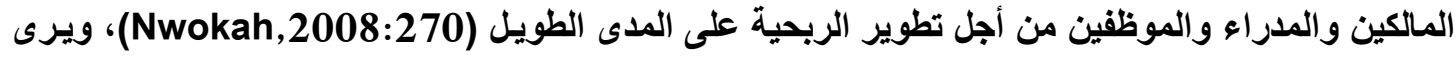
(Nwokah,2009:27)

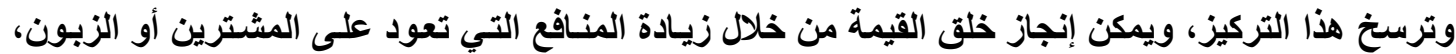

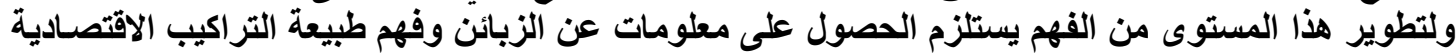

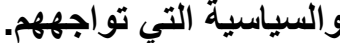

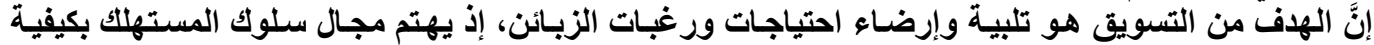

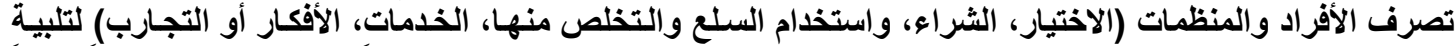

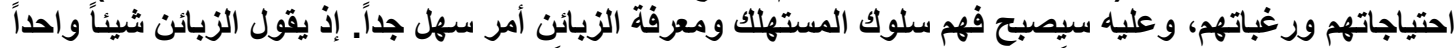

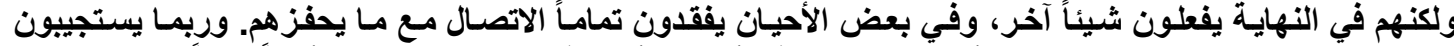

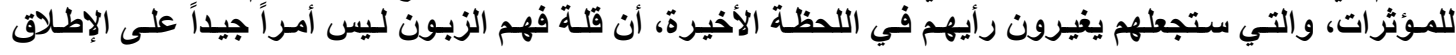

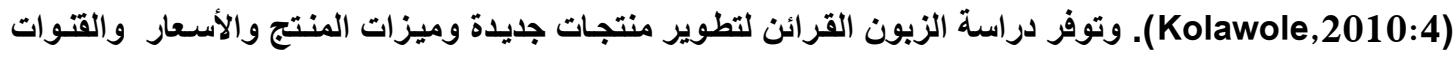

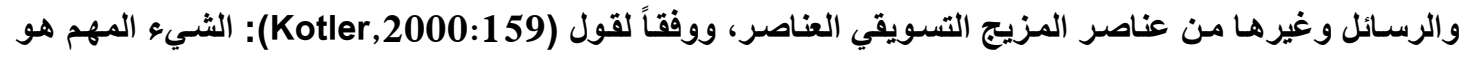
معرفة توقعات حركة الزبائن وأن تكون نصب أعنائن أعينه.

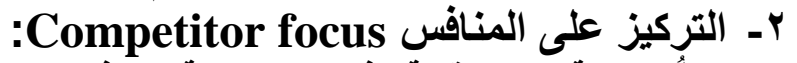

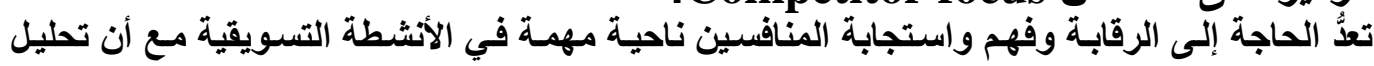

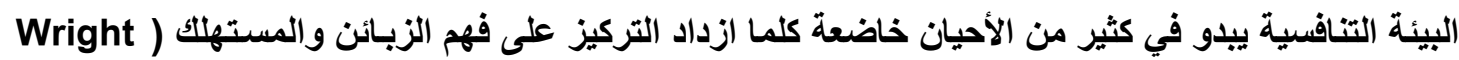

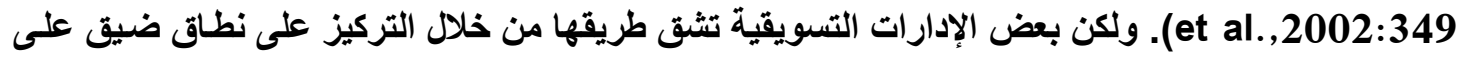

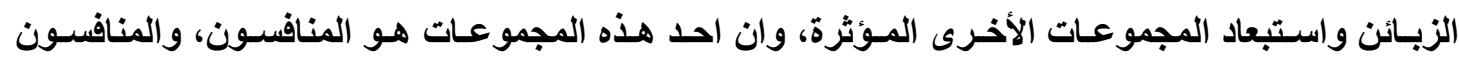
(Competitors)

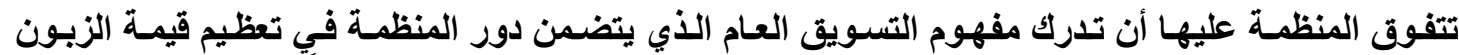

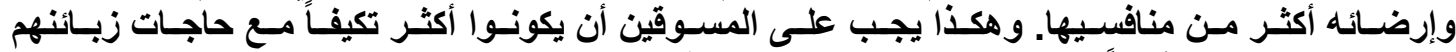

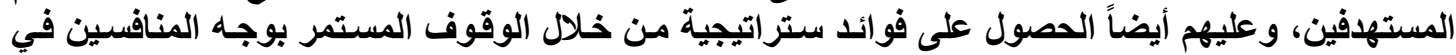

ذاكرة المستهلك (Kotler,1997:77).

وقد عُرَف التركيز على المنافس بأنه تلك الأنشطة التي تقوم بها إحدى الثركات لتحدد وتفهم صناعتها،

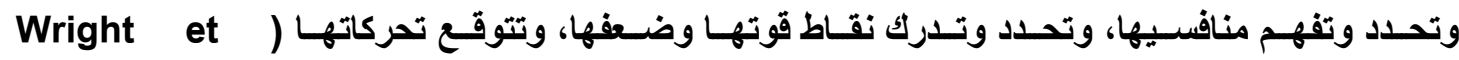

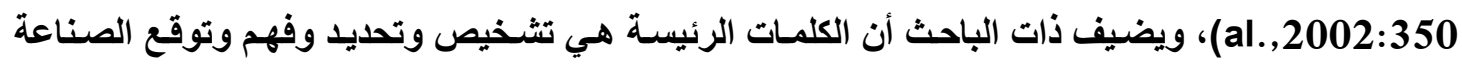

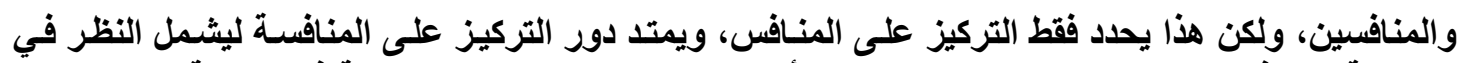

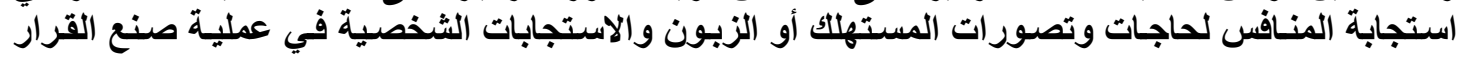




\section{مجلة العلوم الاقتصادية والإدارية المجلد 19 العددب V 19 \\ دور التوازز الديناميكي في الأداء التسويقيي دراسة استطلا عية}

على عدد من المصارف العراقية الفاصة

ثالثًا : العلاقات الرابطة

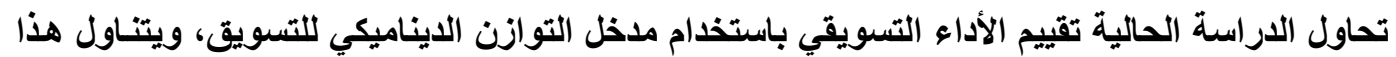

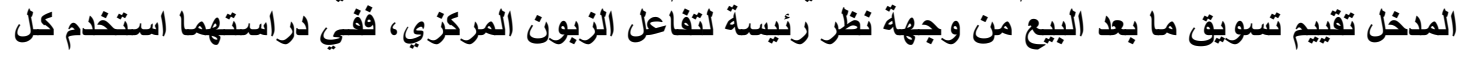

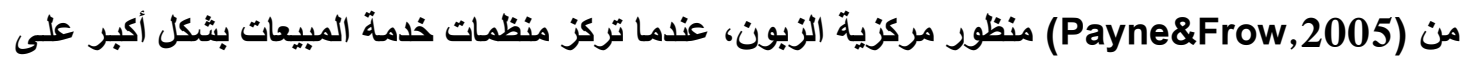

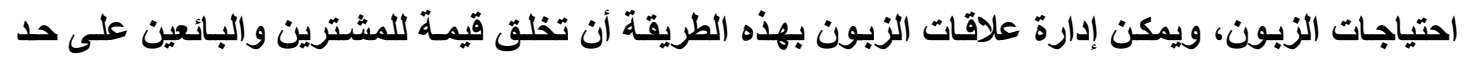

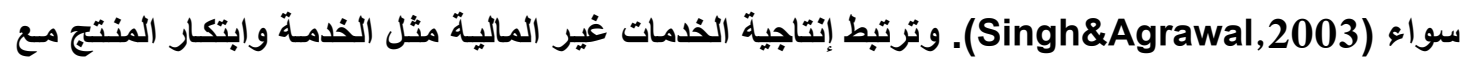

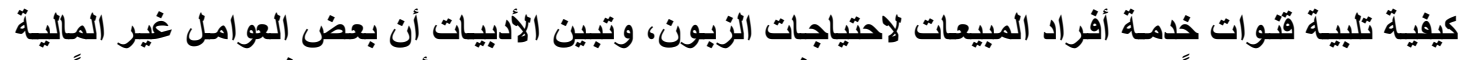

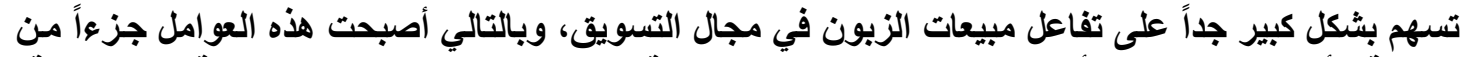

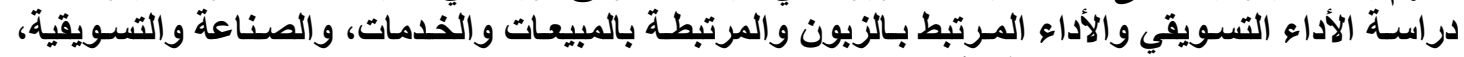

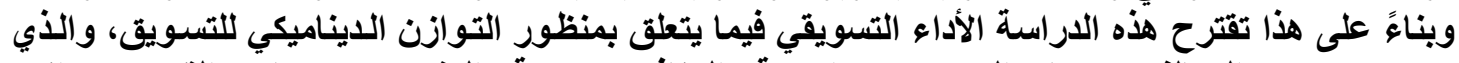

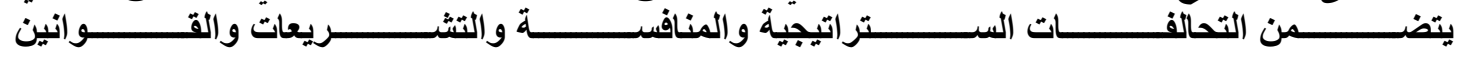
(Islam et al.,2011:40)

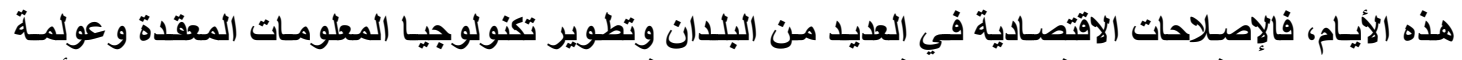

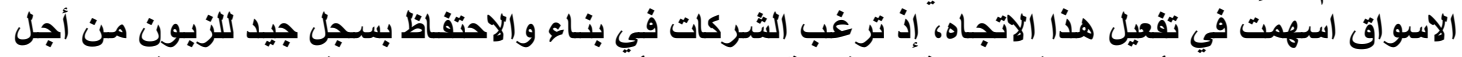

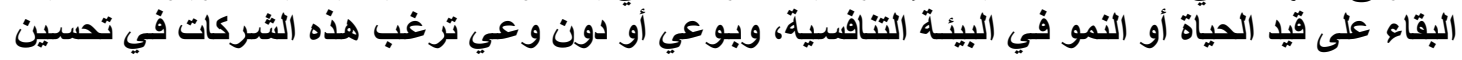

أدائها التسويقي (Lindgreen\&Shergill,2003:5)

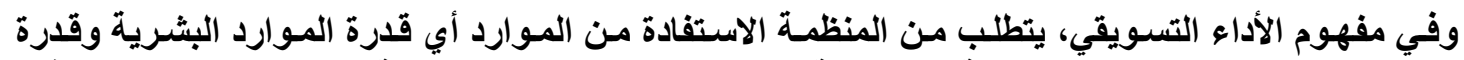

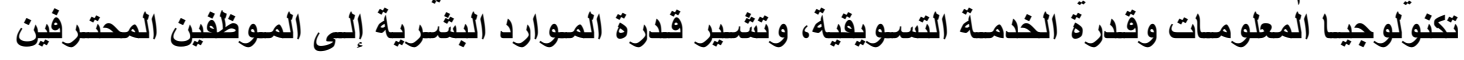

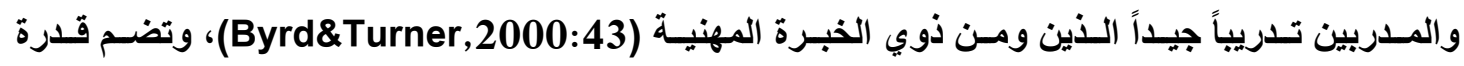

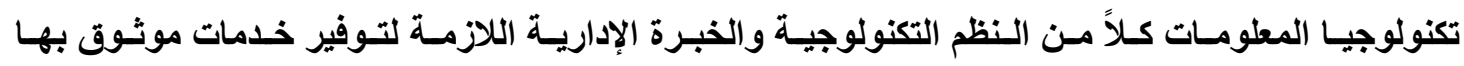

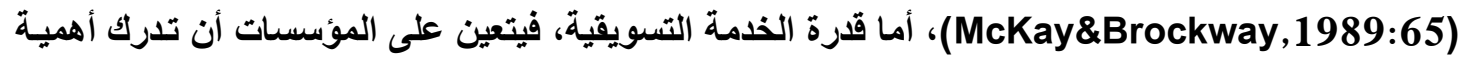

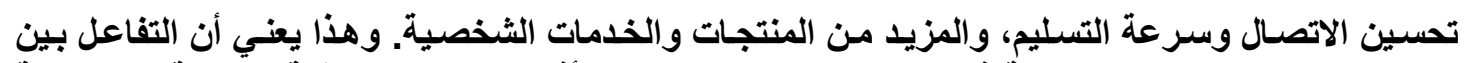

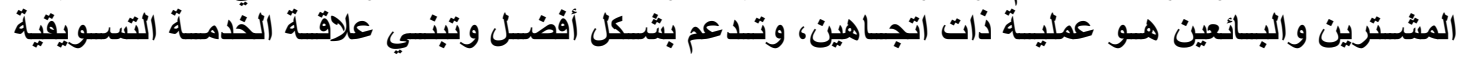

(Chen\&Popovich,2003:11)

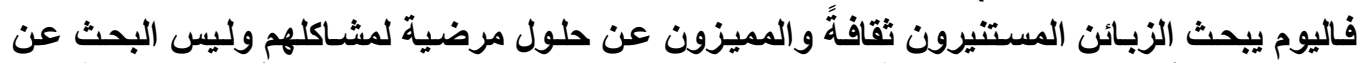

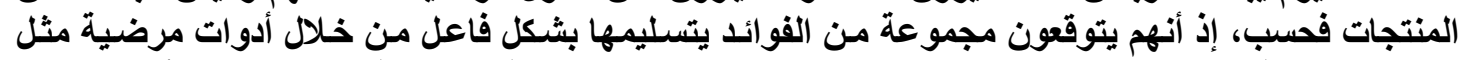

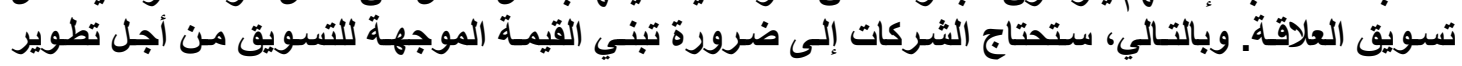

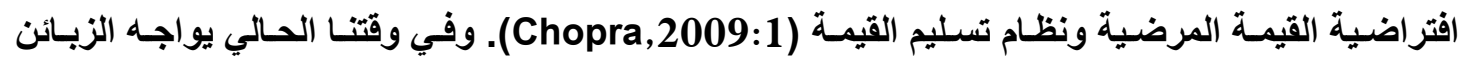

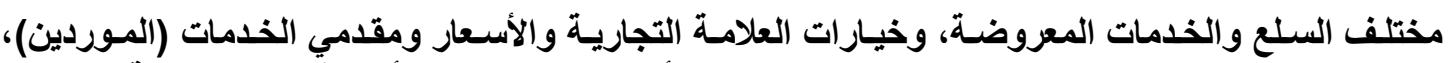

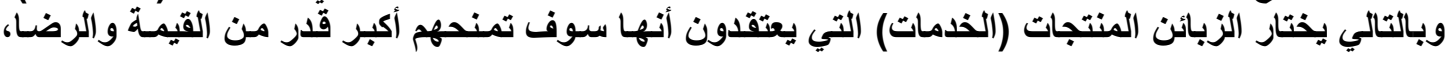

وحجر الأسساس لعلاقة الزبون هو قيمة الزبون ورضان الزبون (Awara,2008:5). 
دور التوازن الديناميكي في الأداء التسويقيى دراسة استطلا عية على عدد من المصارف العراقية الفاصة

يعدُ (Gomes-Gasseres) مسن أوائسل البـاحثين الـذين أسـهموا في بلـورة مفـاهيم التـوازن الـايناميكي

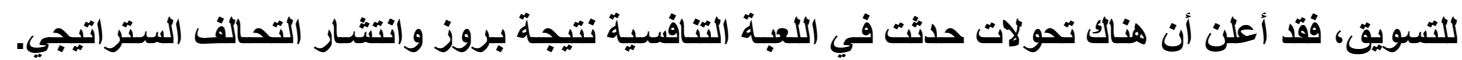

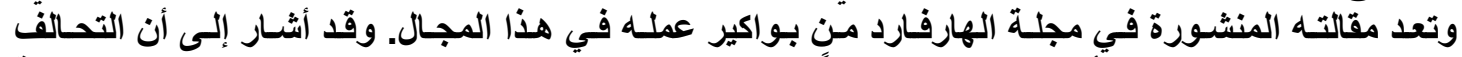

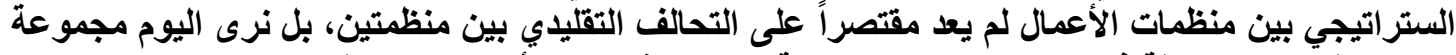

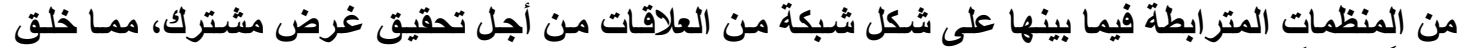

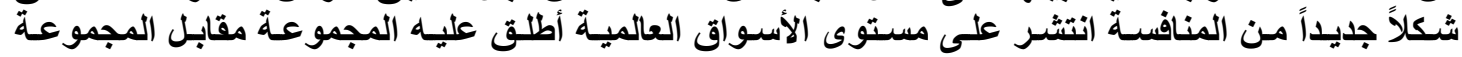
(Group Versus Group)

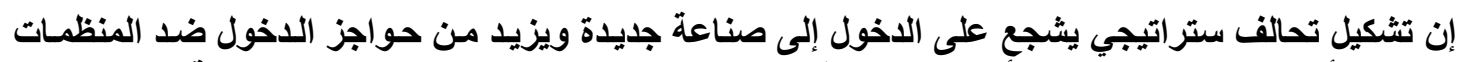

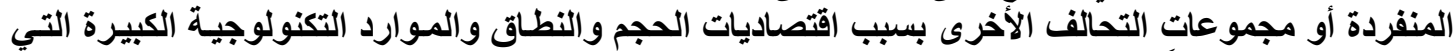

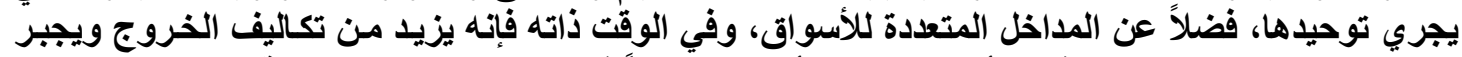

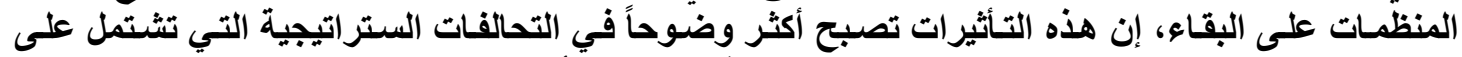

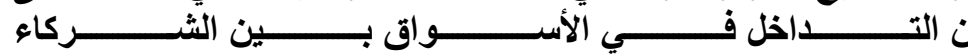
تبوى عـ البقاء

.(Gomes-Gasseres, 1996:36)

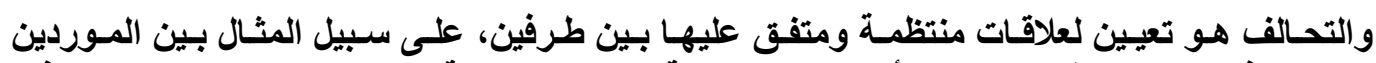

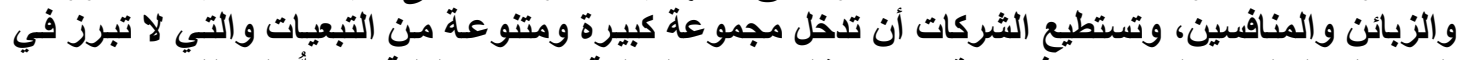

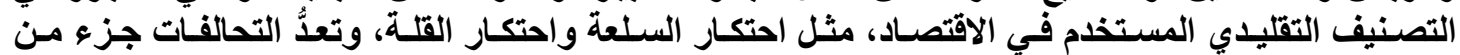

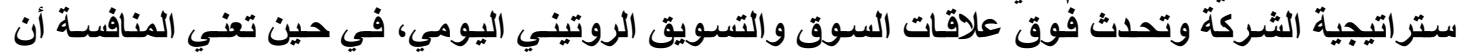

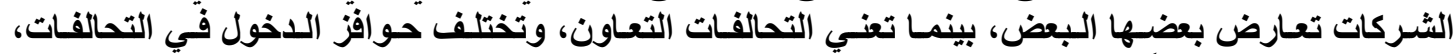

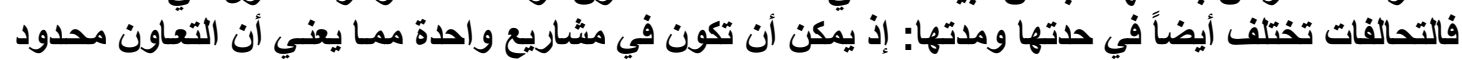

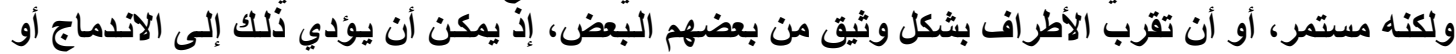

الاستحواذ، (Gummesson, 2008:184).

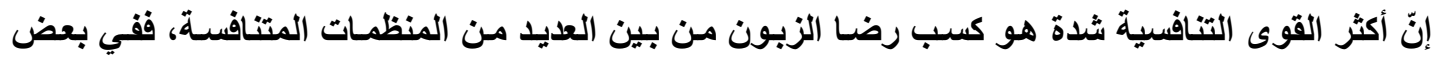

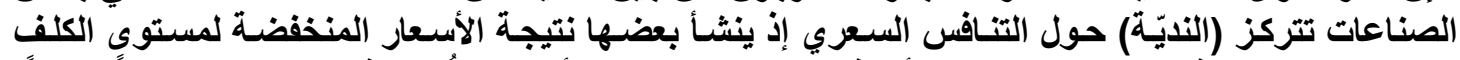

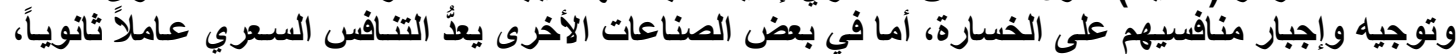

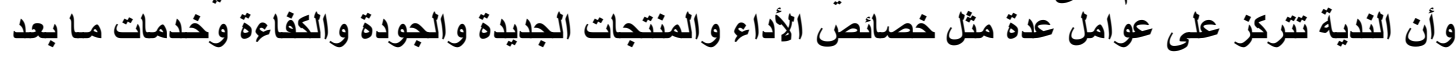

البيع والضمان والعلامة التجارية (Thompson,2000:43).

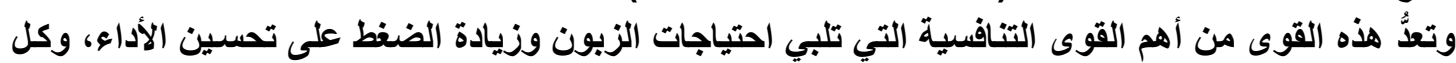

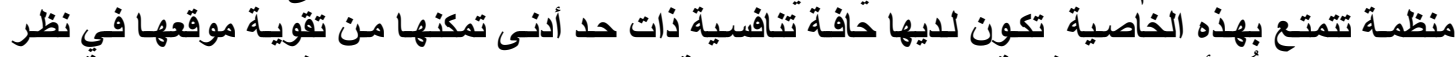

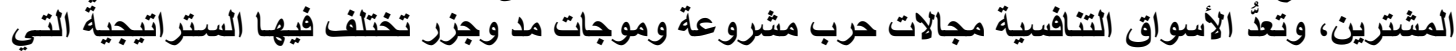

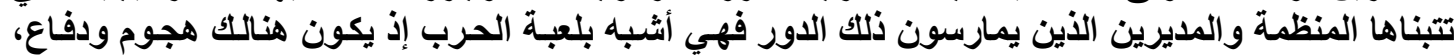

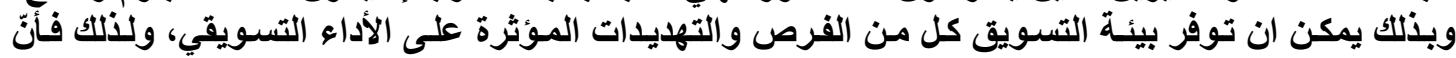

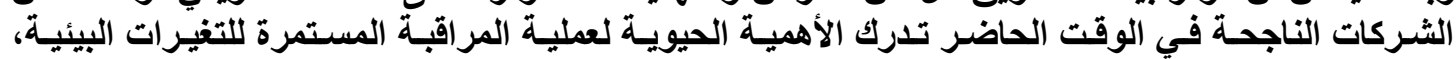




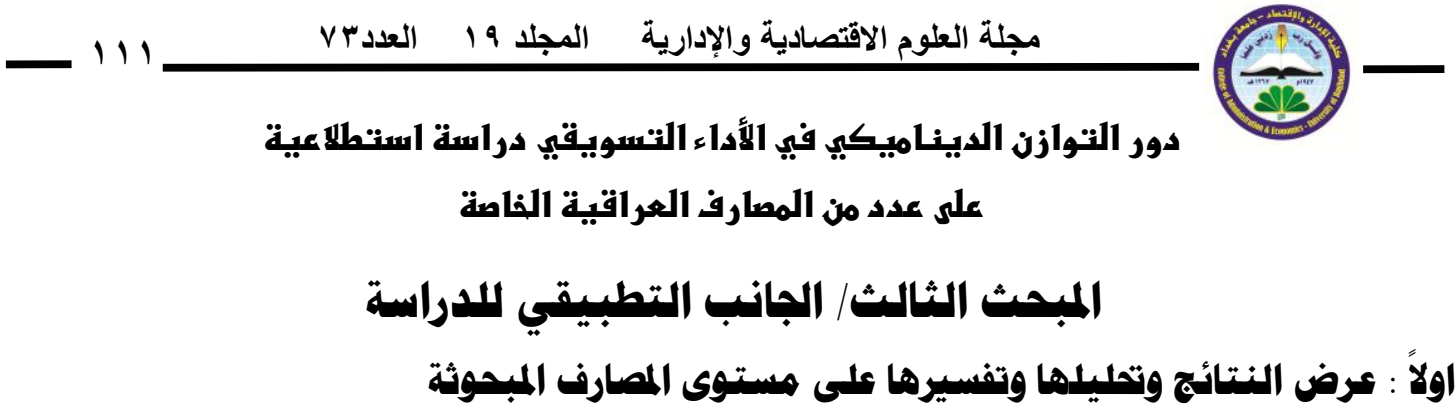

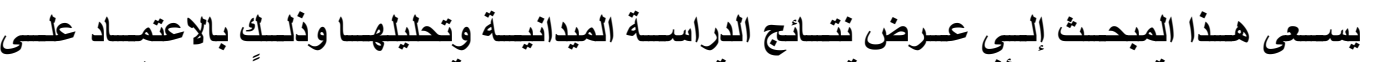

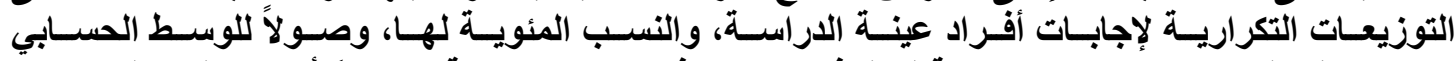

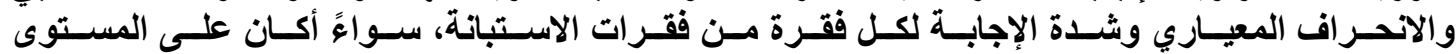

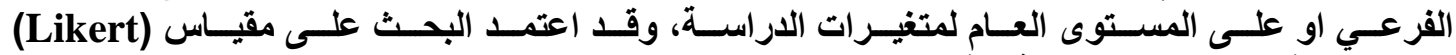

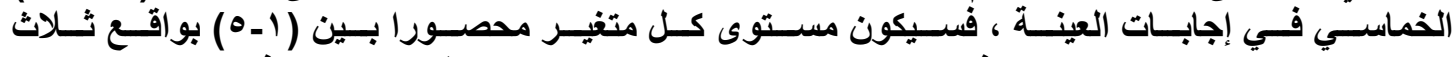

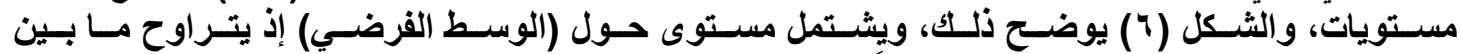

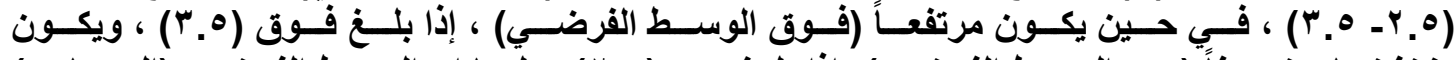

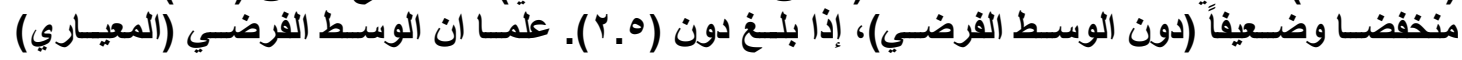

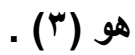

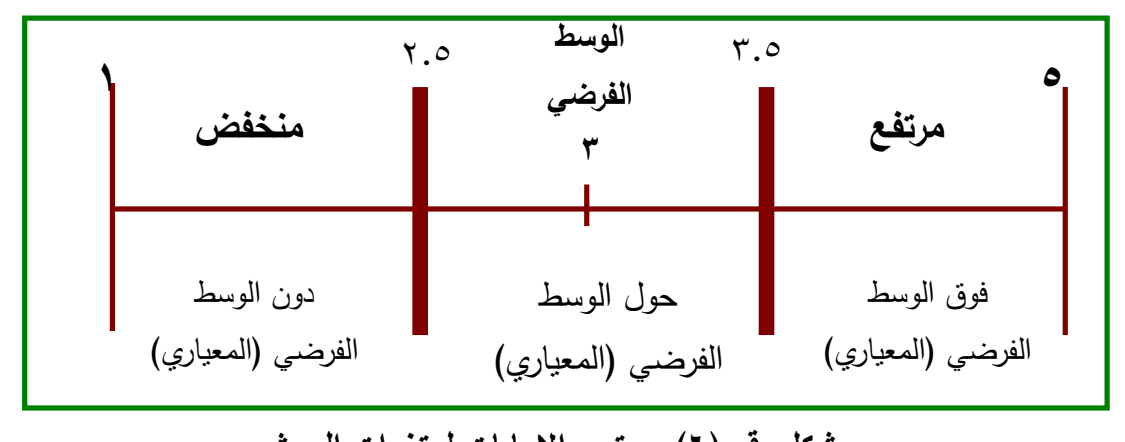

شكل رقم (؟) مستوى الإجابات لمتغيرات البحث

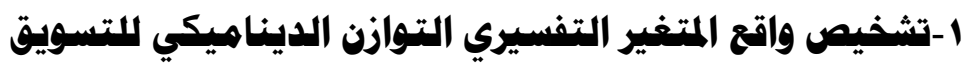

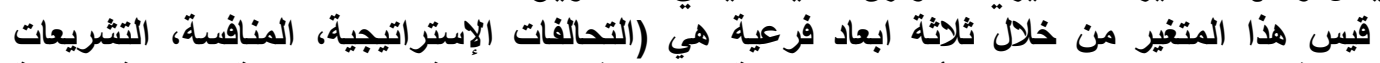

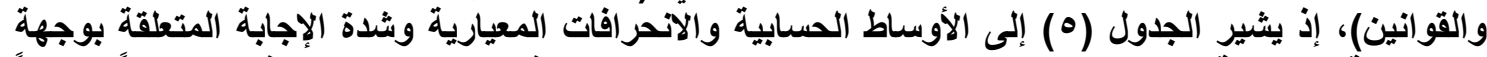

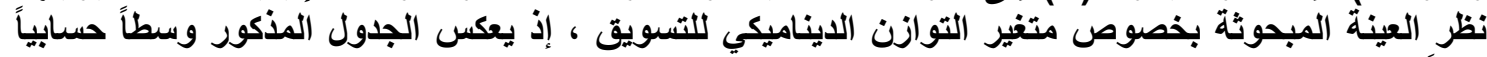

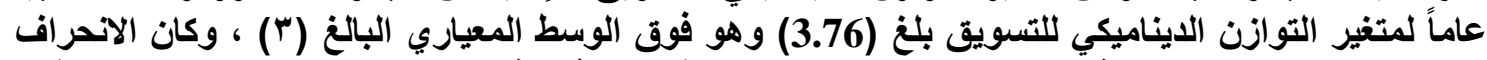

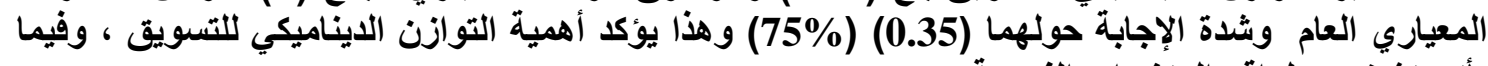

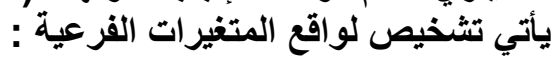


دور النوازن الديناميكي في الأداء النسويقيى دراسة استطلا عية

على عدد من المصارف العراقية الفاصة

\section{(التحالفات الإستراتيجية الإنية}

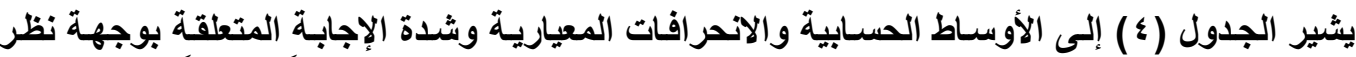

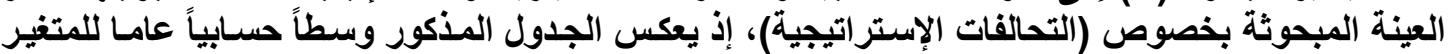

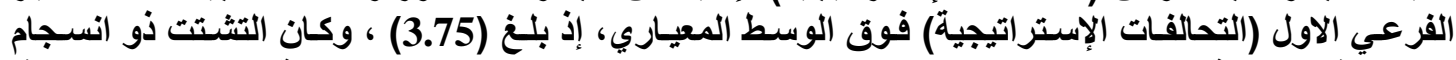

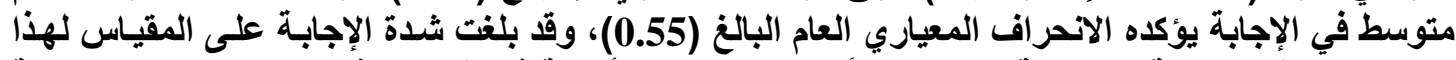

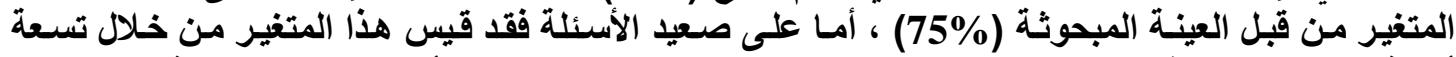

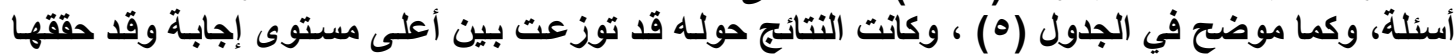

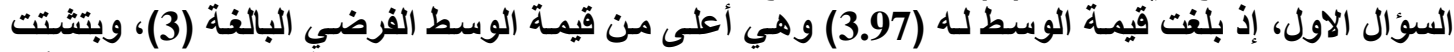

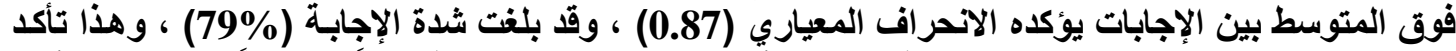

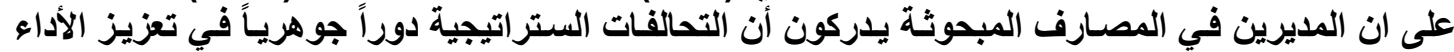

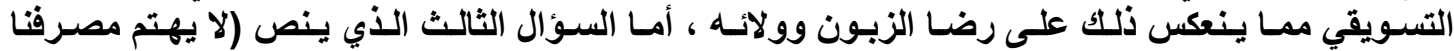

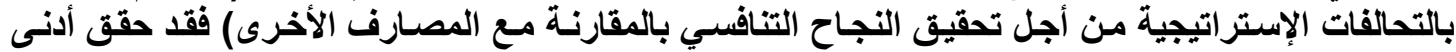

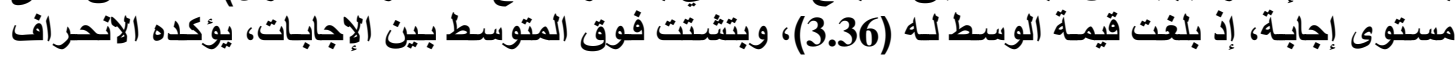

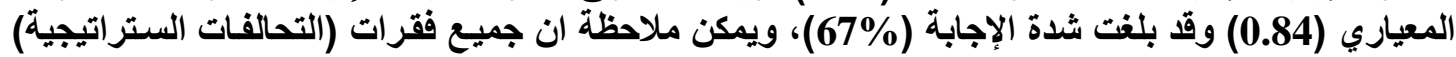

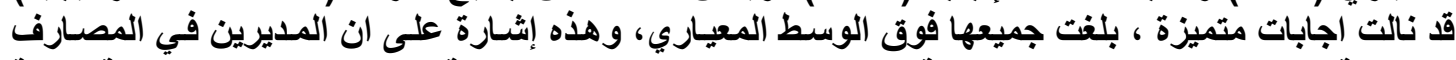

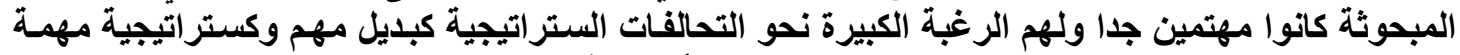
نحو تحقيق التوازن الديناميكي للتسويق من اجل تحقيق الأداء الافضل. 


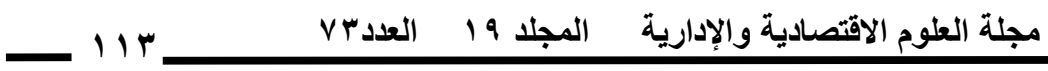

\section{دور التوازن الديناميكي في الأداء التسويقي دراسة استطلا عية}

\section{على عدد من المصارف العراقية الفاصة}

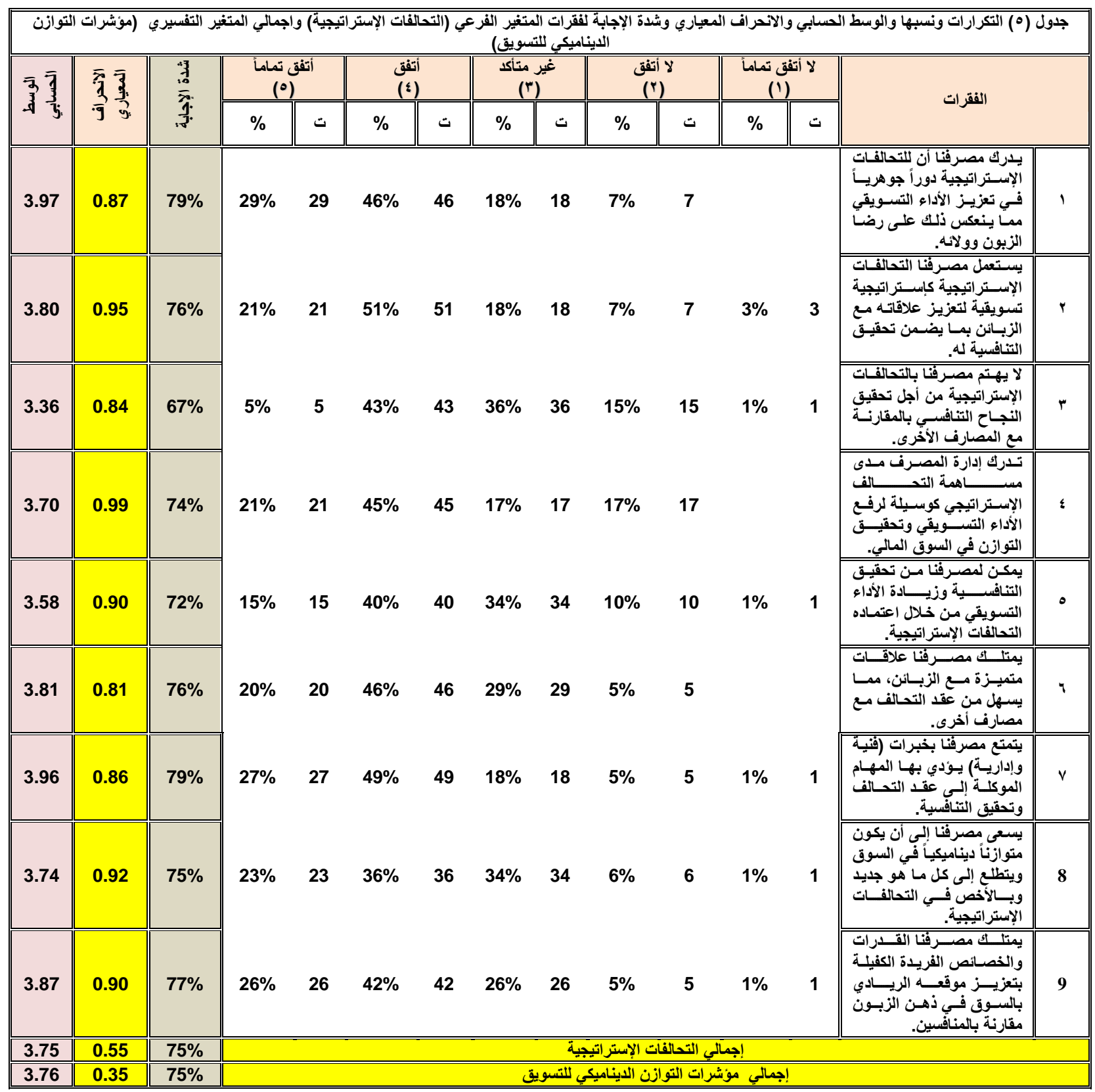




\section{دور التوازن الديناميكي في الأداء التسويقي دراسة استطلا عية}

\section{على عدد من المصارف العراقية الفاصة}

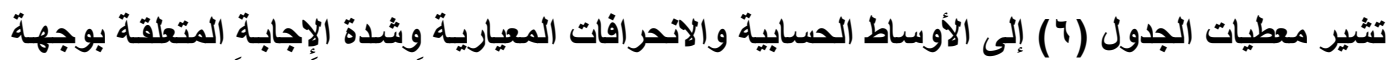

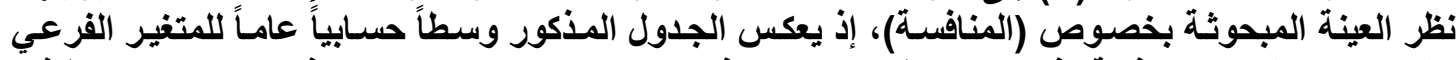

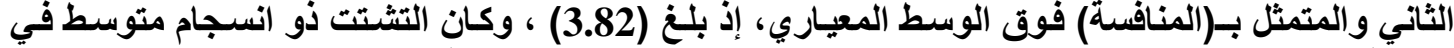

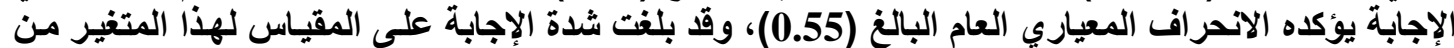

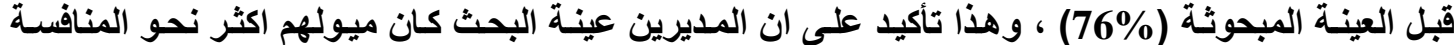

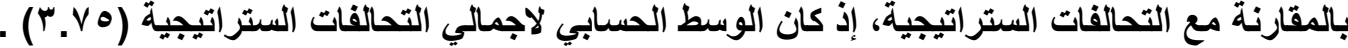

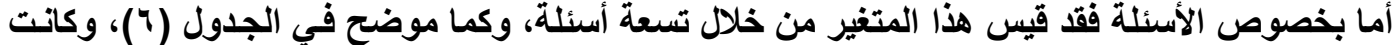

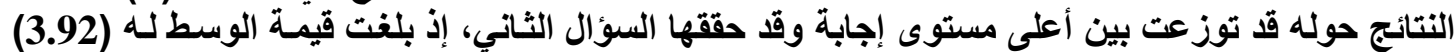

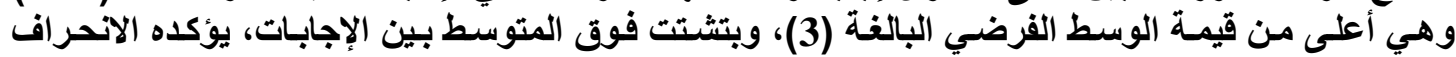

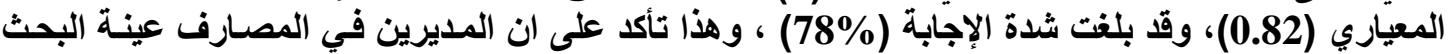

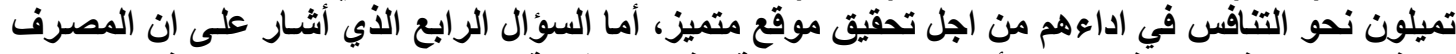

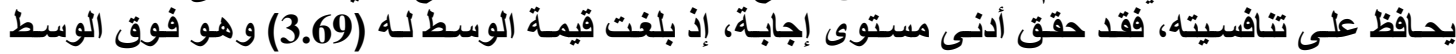

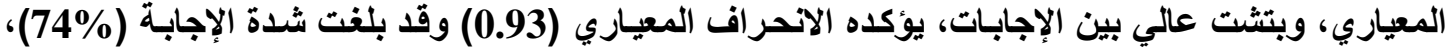

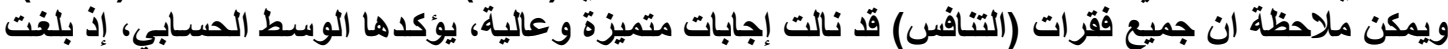

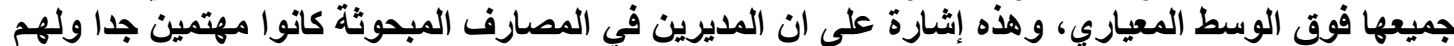

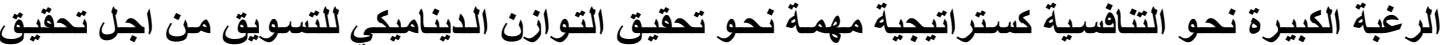

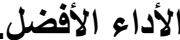

التشريعات والقوانين

يبين الجدول (V) الأوسـاط الحسـابية والانحرافات المعياريـة وشدة الإجابـة المتعلقة بوجهة نظر العينة

\begin{tabular}{|c|c|c|c|c|c|c|c|c|c|c|c|c|c|c|}
\hline \multicolumn{15}{|c|}{ جدول (T) التكرارات ونسبها والوسط الحسابي والانحراف المعياري وشدة الإجابة لفقرات المتغير الفرعي (المنافسة) } \\
\hline \multirow{2}{*}{$\overline{\overline{3}} \overline{3}$} & \multirow{2}{*}{$\begin{array}{l}\bar{x} \\
. \overline{9} \\
\overline{9}\end{array}$} & \multirow{2}{*}{ ב: } & \multicolumn{2}{|c|}{$\begin{array}{l}\text { أتفق تماماً } \\
(0) \\
\end{array}$} & \multicolumn{2}{|c|}{ أنتفتى } & \multicolumn{2}{|c|}{ 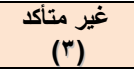 } & \multicolumn{2}{|c|}{ لا أتفقتى } & \multicolumn{2}{|c|}{$\begin{array}{l}\text { لا أتفقى تماماً } \\
\text { (1) } \\
\end{array}$} & \multirow{2}{*}{\multicolumn{2}{|c|}{ الفقرات }} \\
\hline & & & $\%$ & $ت$ & $\%$ & $ت$ & $\%$ & $ت$ & $\%$ & $ت$ & $\%$ & $ت$ & & \\
\hline 3.89 & 1.00 & $78 \%$ & $30 \%$ & 30 & $42 \%$ & 42 & $17 \%$ & 17 & $9 \%$ & 9 & $2 \%$ & 2 & 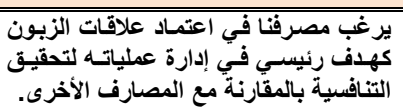 & 1 \\
\hline 3.92 & 0.82 & $78 \%$ & $25 \%$ & 25 & $45 \%$ & 45 & $26 \%$ & 26 & $4 \%$ & 4 & & & 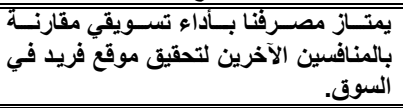 & $r$ \\
\hline 3.91 & 0.90 & $78 \%$ & $29 \%$ & 29 & $40 \%$ & 40 & $24 \%$ & 24 & $7 \%$ & 7 & & & 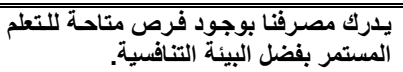 & $r$ \\
\hline 3.69 & 0.93 & $74 \%$ & $17 \%$ & 17 & $49 \%$ & 49 & $21 \%$ & 21 & $12 \%$ & 12 & $1 \%$ & 1 & 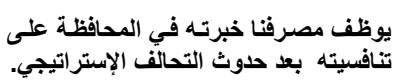 & ؛ \\
\hline 3.78 & 0.76 & $76 \%$ & $16 \%$ & 16 & $\mathbf{5 0 \%}$ & 50 & $30 \%$ & 30 & $4 \%$ & 4 & & & 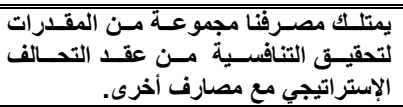 & 。 \\
\hline 3.70 & 1.01 & $74 \%$ & $25 \%$ & 25 & $35 \%$ & 35 & $25 \%$ & 25 & $15 \%$ & 15 & & & 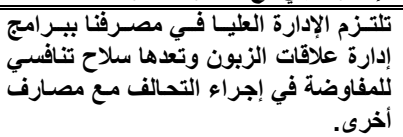 & 1 \\
\hline 3.86 & 0.91 & $77 \%$ & $25 \%$ & 25 & $46 \%$ & 46 & $19 \%$ & 19 & $10 \%$ & 10 & & & 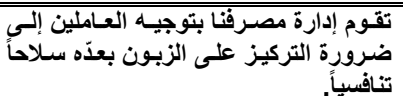 & v \\
\hline 3.87 & 0.81 & $77 \%$ & $21 \%$ & 21 & $51 \%$ & 51 & $22 \%$ & 22 & $6 \%$ & 6 & & & 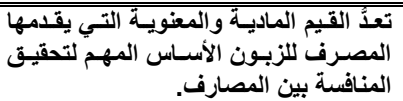 & 8 \\
\hline 3.77 & 0.89 & $75 \%$ & $19 \%$ & 19 & $49 \%$ & 49 & $23 \%$ & 23 & $8 \%$ & 8 & $1 \%$ & 1 & 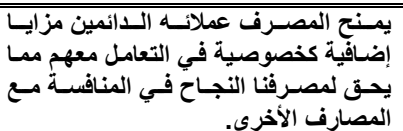 & 9 \\
\hline 3.82 & 0.55 & $76 \%$ & & & & & & & & & & & & \\
\hline
\end{tabular}

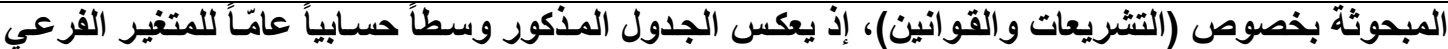

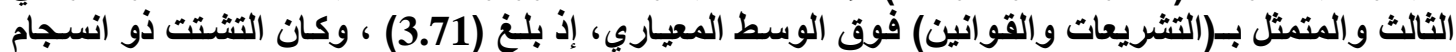




\section{دور التوازن الديناميكي في الأداء التسويقي دراسة استطلا عية}

\section{على عدد من المصارف العراقية الفاصة}

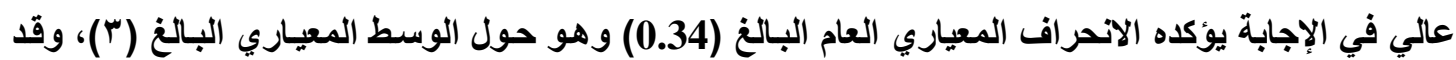

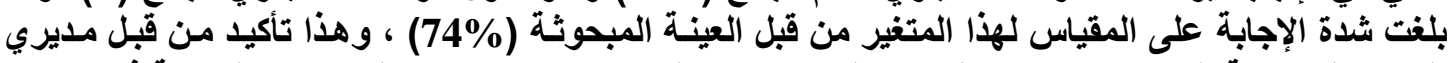

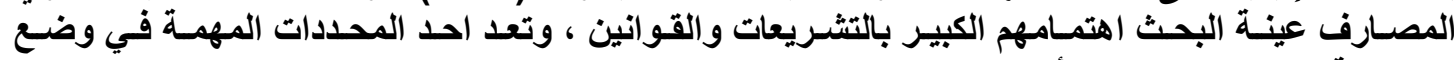
ستراتيجة المصرف لتحقيق الأداء المتميز.

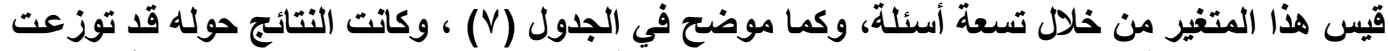

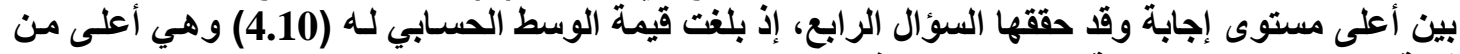

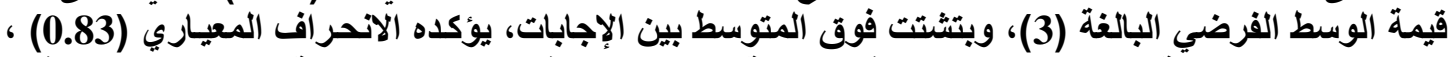

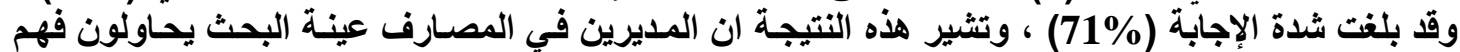

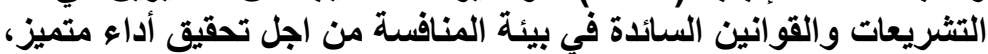

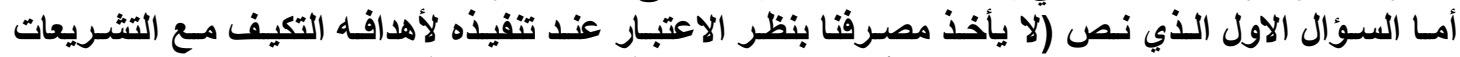

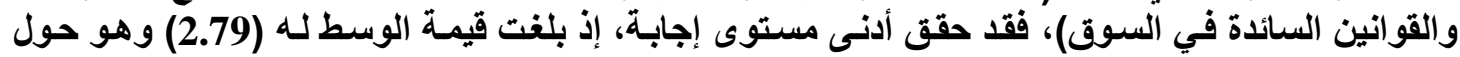

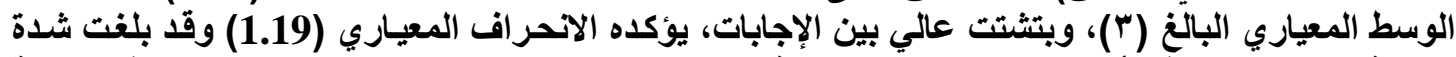

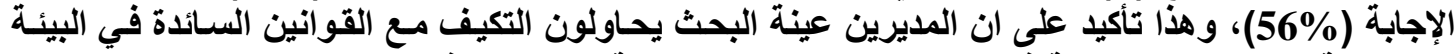

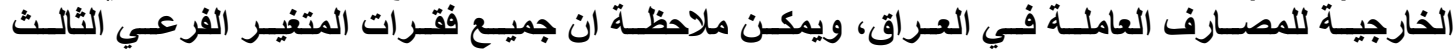

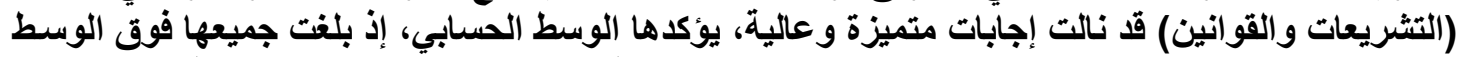

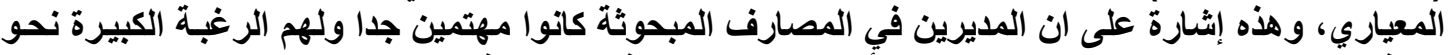

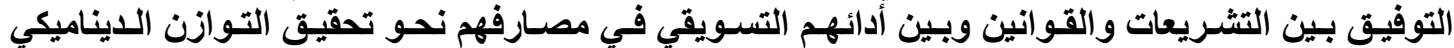
للتسويق ، وبالتالي تحقيق الأداء الأفضل 


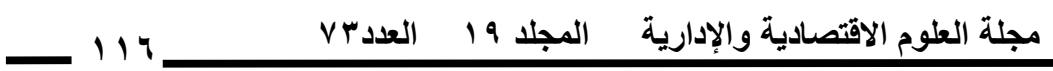 \\ دور التوازن الديناميكي في الأداء التسويقيي دراسة استطلا عية}

على عدد من المصارف العراقية الخاصة

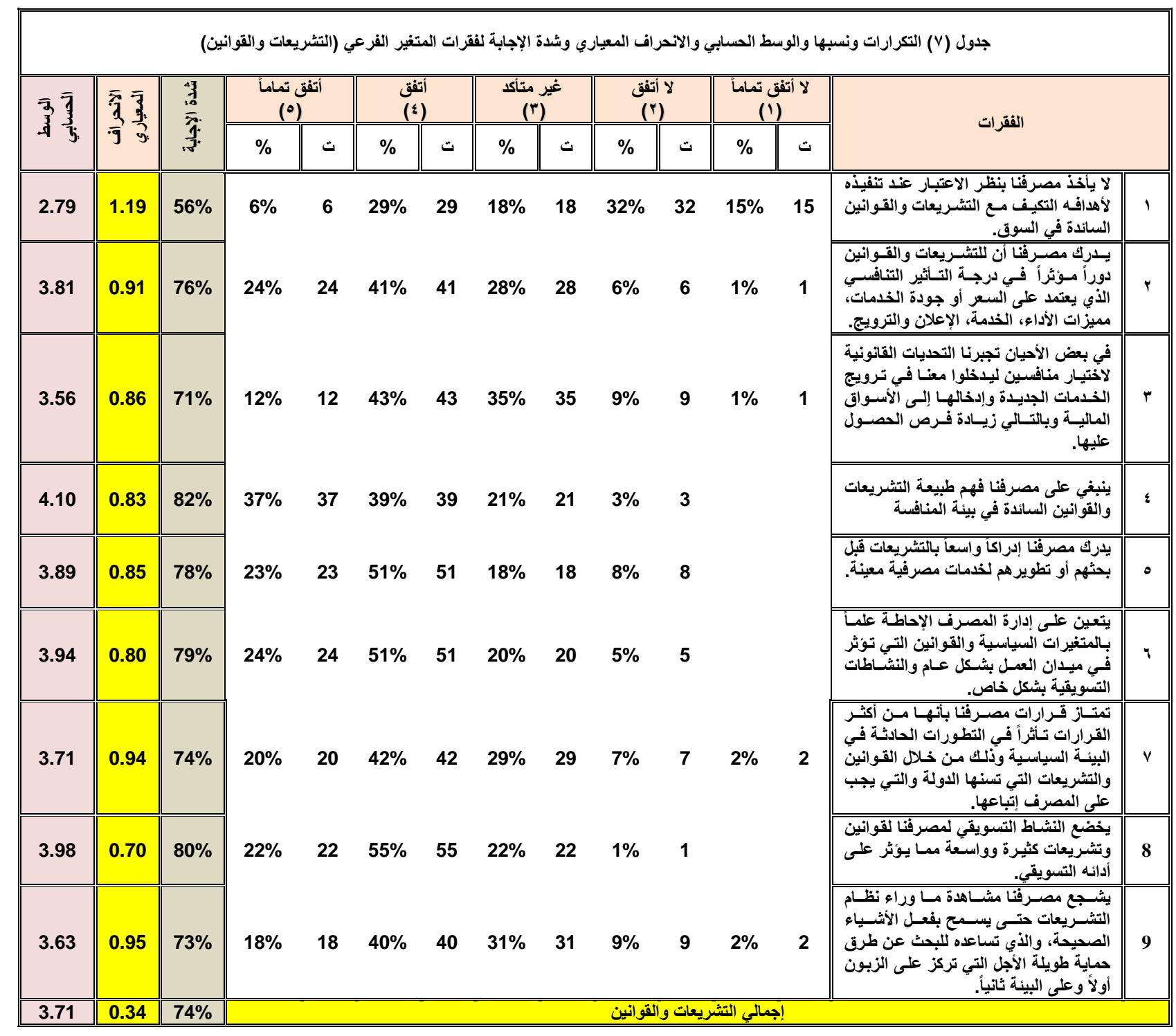




\section{دور التوازن الديناميكي في الأداء التسويقي دراسة استطلا عية}

\section{على عدد من المصارف العراقية الفاصة}

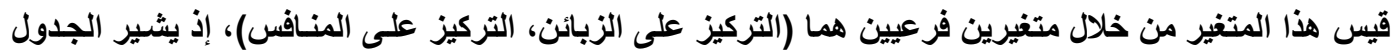

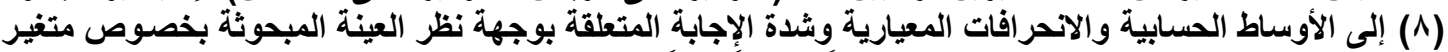

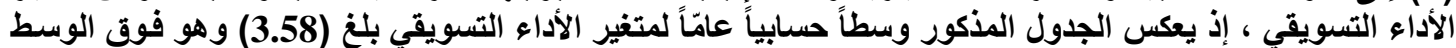

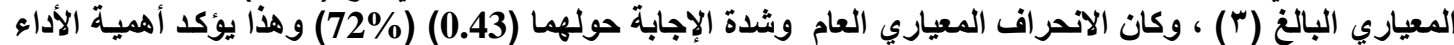

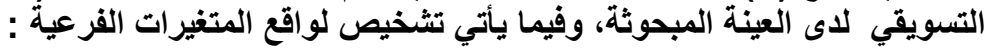

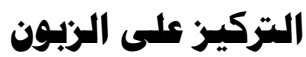

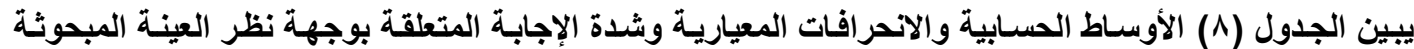

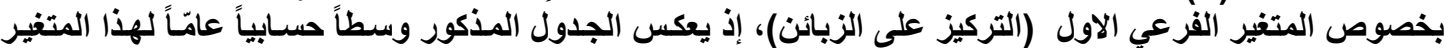

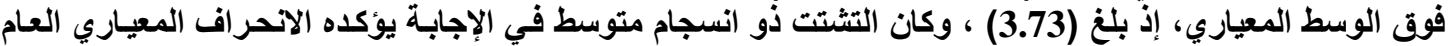

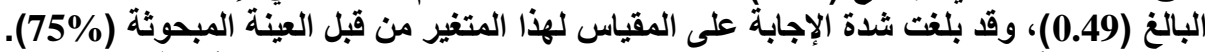

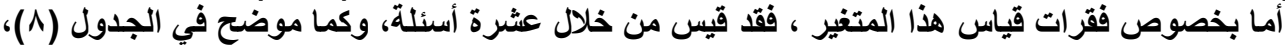

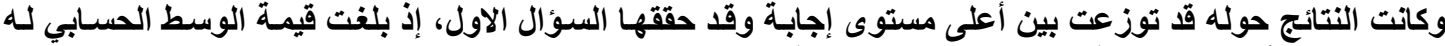

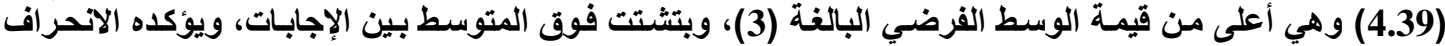

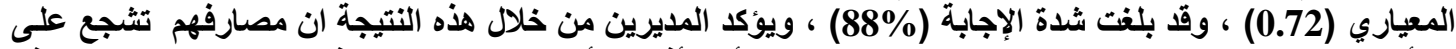

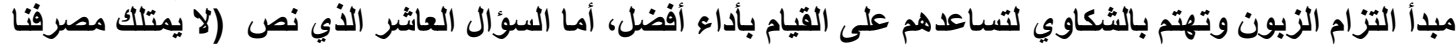

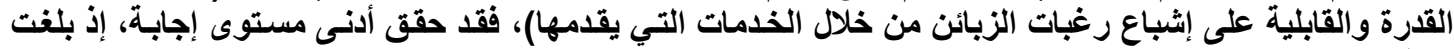

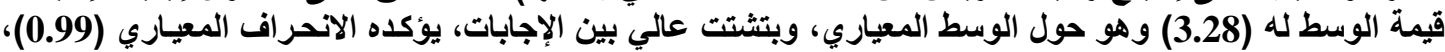

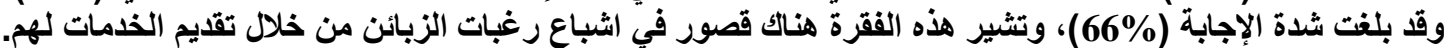

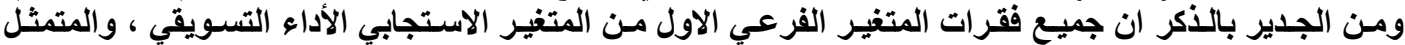

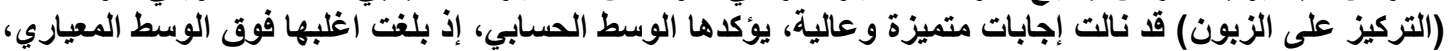

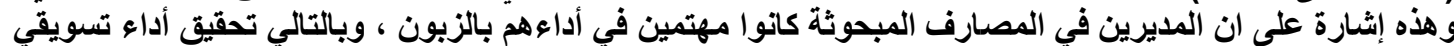

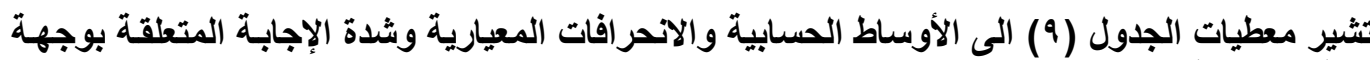

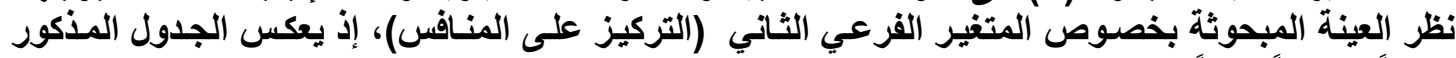

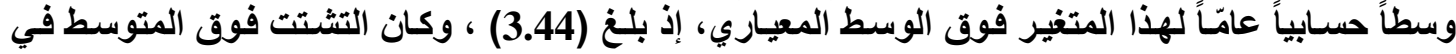

\begin{tabular}{|c|c|c|c|c|c|c|c|c|c|c|c|c|c|c|}
\hline \multicolumn{15}{|c|}{ 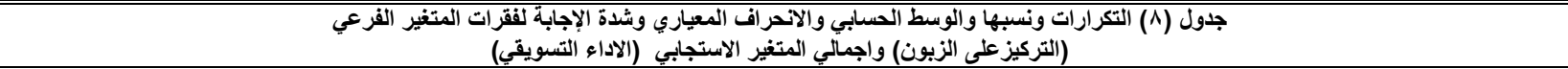 } \\
\hline \multirow{2}{*}{$\overline{\bar{y}} \overline{\frac{1}{3}}$} & \multirow{2}{*}{ 高高 } & \multirow{2}{*}{ 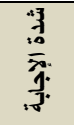 } & \multicolumn{2}{|c|}{$\begin{array}{l}\text { أتفق تماما } \\
(0) \\
\end{array}$} & \multicolumn{2}{|c|}{ أنقق } & \multicolumn{2}{|c|}{ غير متأكلد } & \multicolumn{2}{|c|}{ لا أتفق } & \multicolumn{2}{|c|}{ لا أتفق تماماً } & \multirow{2}{*}{\multicolumn{2}{|c|}{ الفقرات }} \\
\hline & & & $\%$ & $ت$ & $\%$ & $ت$ & $\%$ & $ت$ & $\%$ & $ت$ & $\%$ & $ت$ & & \\
\hline 4.39 & 0.72 & $88 \%$ & $53 \%$ & 53 & $33 \%$ & 33 & $14 \%$ & 14 & \multirow[b]{2}{*}{$12 \%$} & \multirow[b]{2}{*}{12} & \multirow{6}{*}{$3 \%$} & \multirow{6}{*}{3} & 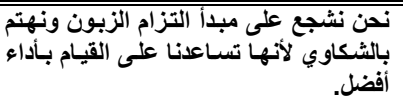 & 1 \\
\hline 3.87 & 0.98 & $77 \%$ & $30 \%$ & 30 & $39 \%$ & 39 & $19 \%$ & 19 & & & & & ليس لاينا التزام قوي مع زبانتنا. & $\bar{r}$ \\
\hline 3.84 & 0.92 & $77 \%$ & $27 \%$ & 27 & $38 \%$ & 38 & $27 \%$ & 27 & $8 \%$ & 8 & & & 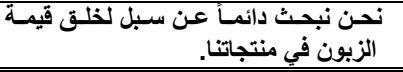 & $r$ \\
\hline 3.94 & 0.85 & $79 \%$ & $26 \%$ & 26 & $49 \%$ & 49 & $18 \%$ & 18 & $7 \%$ & 7 & & & نقيس رضا الزيون على أساس منتظل. & $\xi$ \\
\hline 3.51 & 0.96 & $70 \%$ & $14 \%$ & 14 & $39 \%$ & 39 & $34 \%$ & 34 & $10 \%$ & 10 & & & 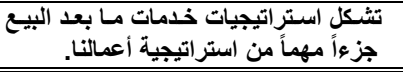 & 0 \\
\hline 4.02 & 0.79 & $80 \%$ & $30 \%$ & 30 & $44 \%$ & 44 & $24 \%$ & 24 & $2 \%$ & 2 & & & 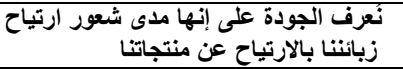 & 1 \\
\hline 3.36 & 0.92 & $67 \%$ & $12 \%$ & 12 & $30 \%$ & 30 & $40 \%$ & 40 & $18 \%$ & 18 & & & 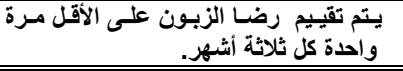 & v \\
\hline 3.60 & 1.10 & $72 \%$ & $20 \%$ & 20 & $41 \%$ & 41 & $25 \%$ & 25 & $7 \%$ & 7 & $7 \%$ & 7 & 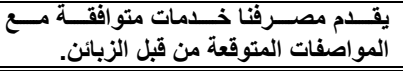 & 8 \\
\hline 3.48 & 0.86 & $70 \%$ & $15 \%$ & 15 & $27 \%$ & 27 & $49 \%$ & 49 & $9 \%$ & 9 & & & الحدقى خذمات مصرفي توقعات الزبائن غير & 9 \\
\hline 3.28 & 0.99 & $66 \%$ & $7 \%$ & 7 & $42 \%$ & 42 & $26 \%$ & 26 & $22 \%$ & 22 & $3 \%$ & 3 & 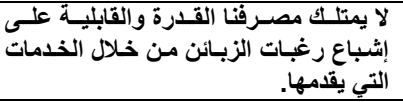 & $\begin{array}{l}1 \\
\mathbf{0}\end{array}$ \\
\hline 3.73 & 0.49 & $75 \%$ & & & & & & & & & 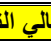 & & & \\
\hline 3.58 & 0.43 & $72 \%$ & & & & & & & & & & & & \\
\hline
\end{tabular}




\section{$-$

\section{دور التوازن الديناميكي في الأداء التسويقي دراسة استطلا عية}

\section{على عدد من المصارف العراقية الفاصة}

الإجابة يؤكده الانحراف المعياري العام البالغ (0900)، وقد بلغت شدة الإجابة على المقياس لهذا المتغير من

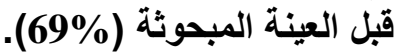

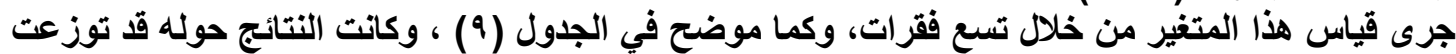

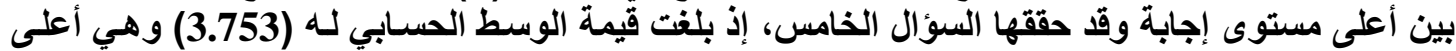

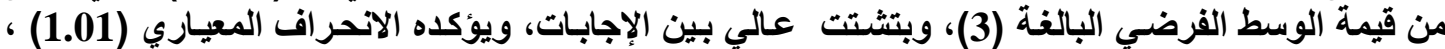

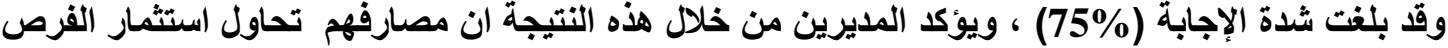

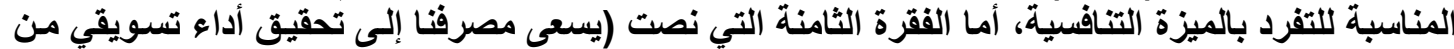

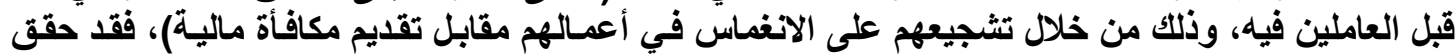

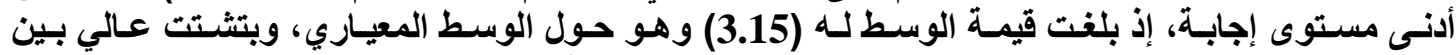

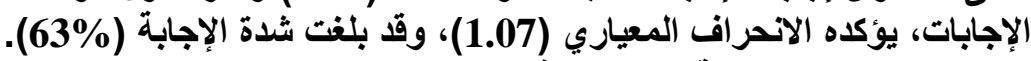

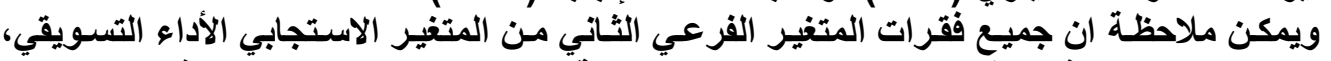

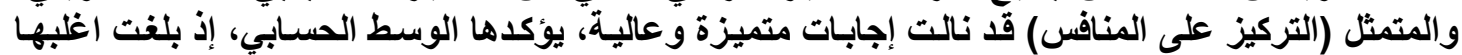

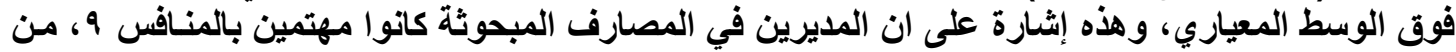
اجل تحقيق أداء تسويقي عالي.

\begin{tabular}{|c|c|c|c|c|c|c|c|c|c|c|c|c|c|c|}
\hline \multicolumn{15}{|c|}{ جدول (9) التكرارات ونسبها و الوسط الحسابي والانحراف المعياري وشدة الاجابة لفقرات المتغير الفرعي ( التركيز على المنافس) } \\
\hline \multirow{2}{*}{$\overline{\bar{y}} \overline{3}$} & \multirow{2}{*}{ 高事: } & \multirow{2}{*}{ 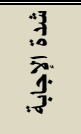 } & \multicolumn{2}{|c|}{$\begin{array}{l}\text { آتفق تماماً } \\
\text { (0) }\end{array}$} & \multicolumn{2}{|c|}{ أتفق } & \multicolumn{2}{|c|}{ غير متأكلد } & \multicolumn{2}{|c|}{ لا آنفق } & \multicolumn{2}{|c|}{$\begin{array}{l}\text { لا أتفق تماماً } \\
\text { (1) }\end{array}$} & \multirow{2}{*}{\multicolumn{2}{|c|}{ الفقرات }} \\
\hline & & & $\%$ & $ت$ & $\%$ & $ت$ & $\%$ & $ت$ & $\%$ & $ت$ & $\%$ & 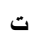 & & \\
\hline 3.38 & 1.02 & $68 \%$ & $13 \%$ & 13 & $38 \%$ & 38 & $24 \%$ & 24 & $24 \%$ & 24 & $1 \%$ & 1 & 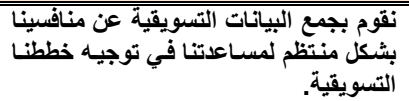 & 1 \\
\hline 3.29 & 0.95 & $66 \%$ & $8 \%$ & 8 & $38 \%$ & 38 & $30 \%$ & 30 & $23 \%$ & 23 & $1 \%$ & 1 & 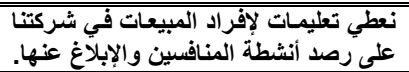 & r \\
\hline 3.47 & 0.88 & $69 \%$ & $11 \%$ & 11 & $40 \%$ & 40 & $34 \%$ & 34 & $15 \%$ & 15 & & & فعل منجاسب. سريعاً لإجراءات المنافسين برد & $r$ \\
\hline 3.47 & 0.93 & $69 \%$ & $15 \%$ & 15 & $32 \%$ & 32 & $38 \%$ & 38 & $15 \%$ & 15 & & & 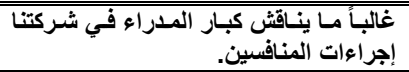 & $\varepsilon$ \\
\hline 3.753 & 1.01 & $75 \%$ & $27 \%$ & 27 & $34 \%$ & 34 & $27 \%$ & 27 & $11 \%$ & 11 & $1 \%$ & 1 & نستثمر الفزص للتفرد بالميزة التنافسية. & 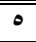 \\
\hline 3.751 & 1.02 & $75 \%$ & $24 \%$ & 24 & $43 \%$ & 43 & $19 \%$ & 19 & $12 \%$ & 12 & $2 \%$ & 2 & 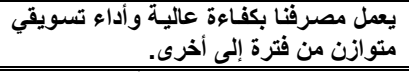 & 1 \\
\hline 3.34 & 1.05 & $67 \%$ & $11 \%$ & 11 & $41 \%$ & 41 & $22 \%$ & 22 & $23 \%$ & 23 & $3 \%$ & 3 & 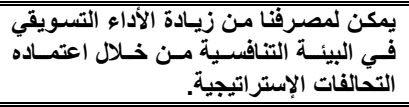 & $v$ \\
\hline 3.15 & 1.07 & $63 \%$ & $12 \%$ & 12 & $22 \%$ & 22 & $42 \%$ & 42 & $17 \%$ & 17 & $7 \%$ & 7 & 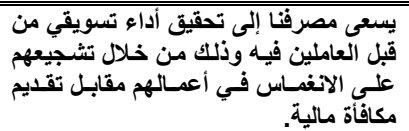 & 8 \\
\hline 3.35 & 1.10 & $67 \%$ & $14 \%$ & 14 & $38 \%$ & 38 & $21 \%$ & 21 & $23 \%$ & 23 & $4 \%$ & 4 & 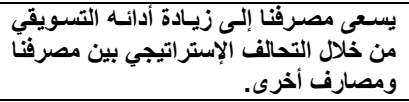 & 9 \\
\hline 3.44 & 0.60 & $69 \%$ & & & & & & & كاصس & & كالي & & & \\
\hline
\end{tabular}


دور التوازن الديناميكي في الأداء التسويقيى دراسة استطلا عية على عدد من المصارف العراقية الفاصة

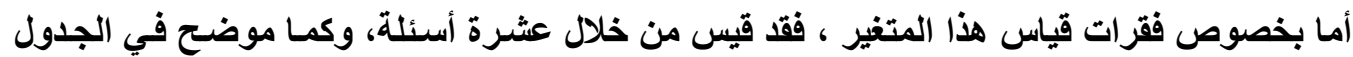

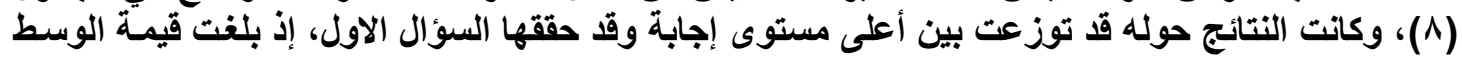

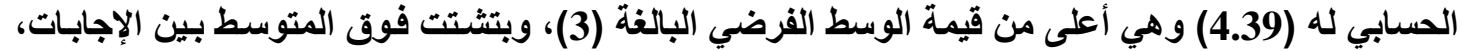

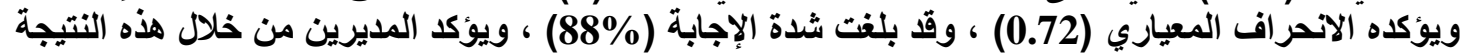

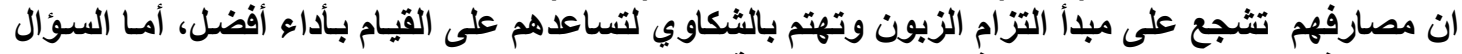

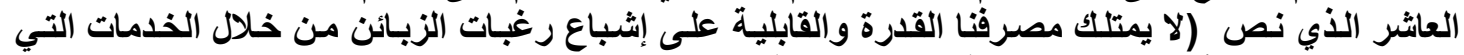

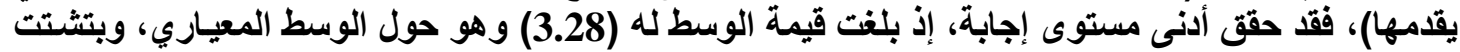

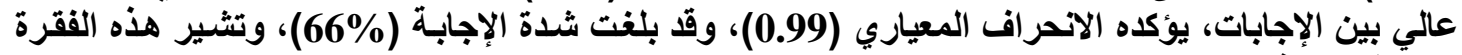

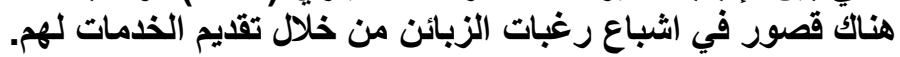

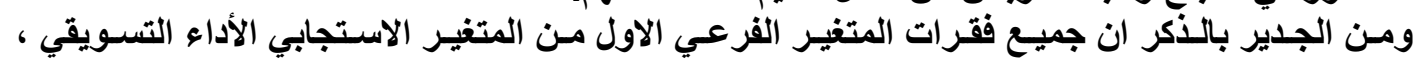

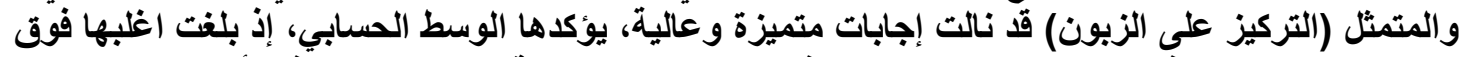

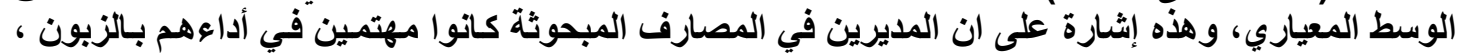
ويالتالي تحقيق أداء تسويقي عادي.

\section{3- تحديد الأهمية لمتغيرات التوازن الديناهيكي للتسويق على وفق الوسط الحسابي والانسراف}

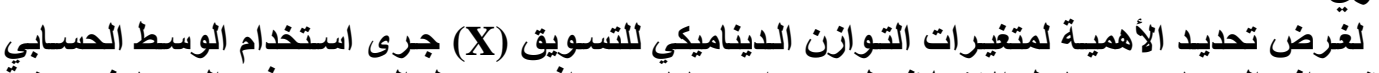

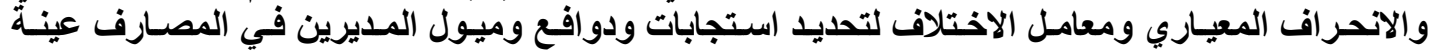

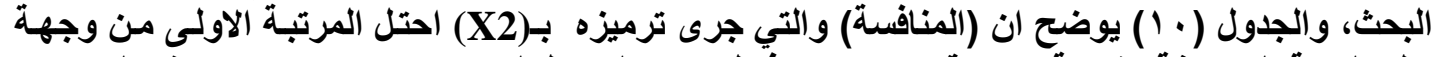

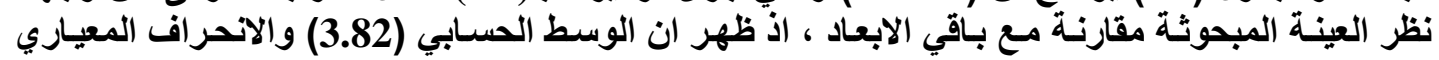

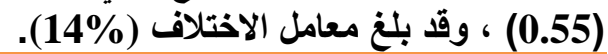

\begin{tabular}{|c|c|c|c|c|}
\hline حسابي و الانحر اف & ، بالاعتماد على & ري وي ومعائن & عديد اهمب & جدول \\
\hline تحديد الاهمية & Std. Deviation & Mean & الابعاد & \\
\hline الثاني & 0.55 & 3.75 & التحالفات الإستراتيجية & $\mathrm{x} 1$ \\
\hline 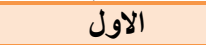 & 0.55 & 3.82 & المنافسة & $\mathrm{x} 2$ \\
\hline الثالث & 0.34 & 3.71 & التشريعات والقوانين & $\mathrm{x} 3$ \\
\hline & 0.35 & 3.76 & التوازن الديناميكي للتسويق & $\mathbf{x}$ \\
\hline
\end{tabular}

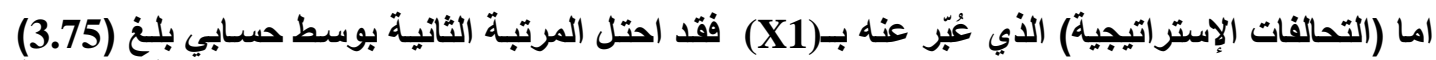

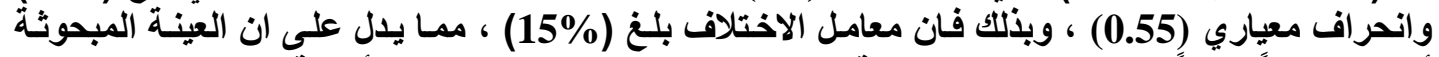

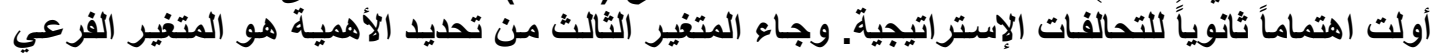

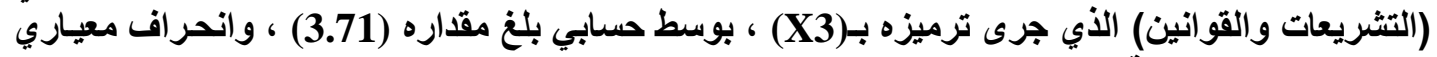
(0.34) ، وكانت نتيجة معامل الاختلاف ( 


\section{$-1 \mathrm{r}$ \\ دور التوازن الديناميكي في الأداء التسويقي دراسة استطلا عية}

على عدد من المصارف العراقية الفاصة

ثالثًا : اختبار فرضيات الدراسة

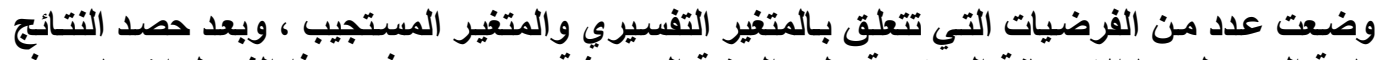

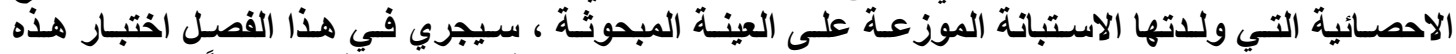
الفرضيات على محورين ، الاول فرضيات الارتباط ، الثاني فرضيات التانية التأثير، وفيما يأئي تفصيلاً لهذه النتائج:

الفرضية الرئيسة الاولى : اثثرت في الاراسة الحالية الفرضية الرئيسة الاولى والتي مفادهي التاديا (تزداد مسـاهمة

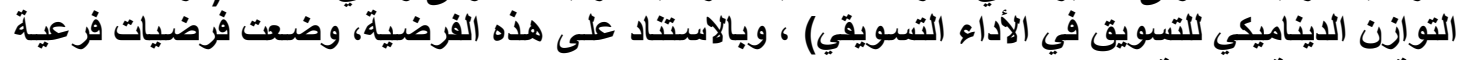

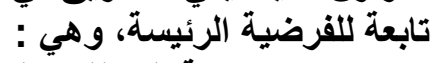

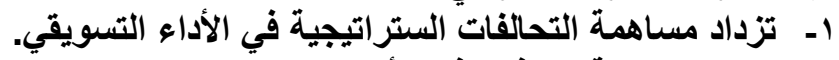

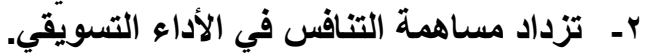

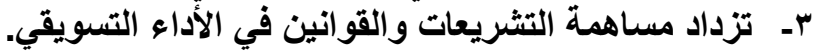

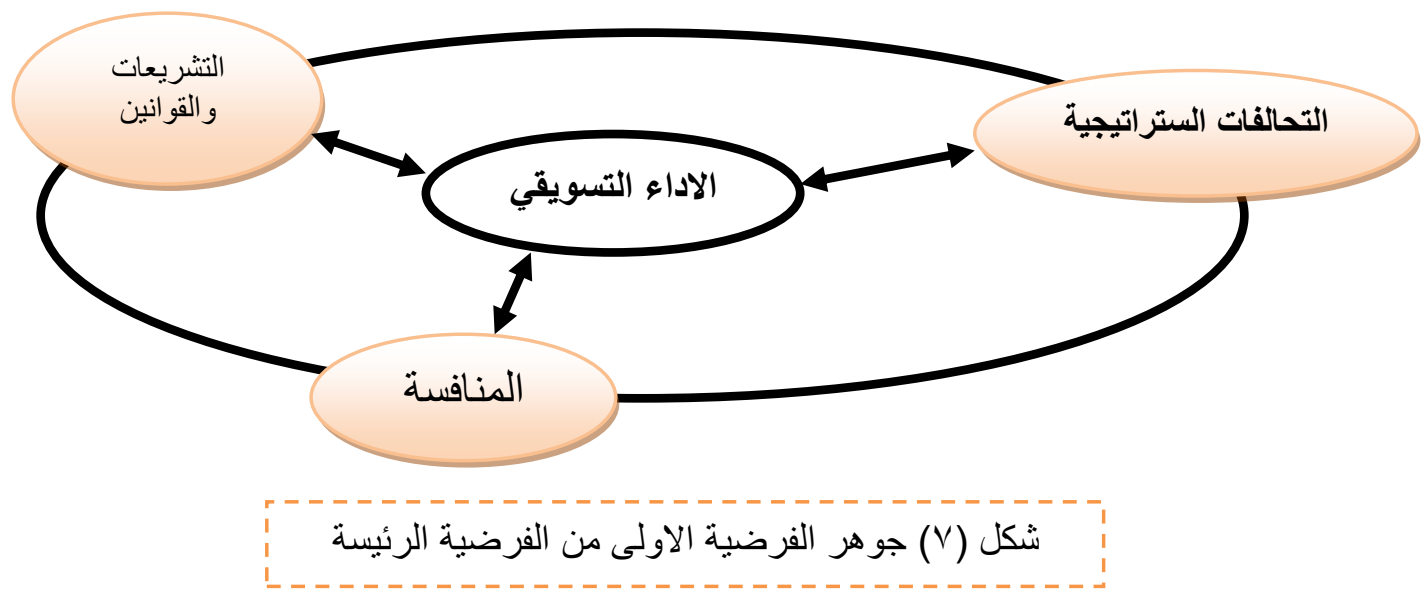

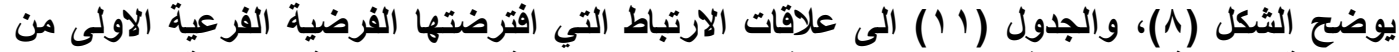

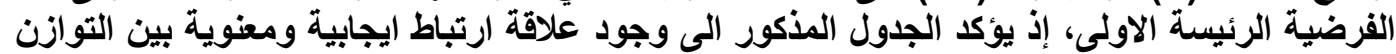

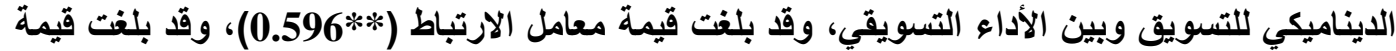
(t) المحتسبة (7.3) وهي أكبر من قيمها الجدولية والبالغة (2.3) بمستوى دلائة (1 (1) . •).

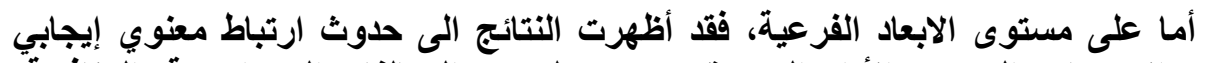

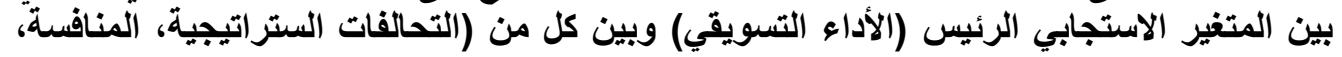

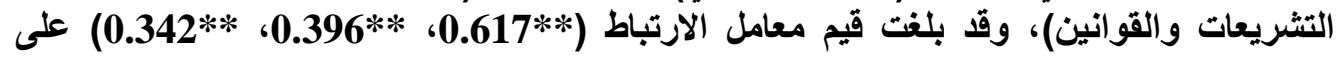


دور التوازز الديناميكي في الأداء التسويقيي دراسة استطلا عية

\section{على عدد من المصارف العراقية الفاصة}

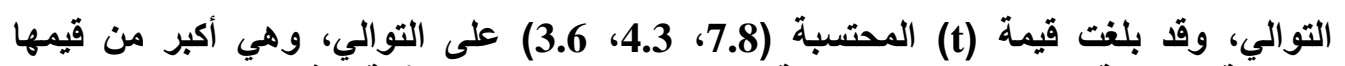

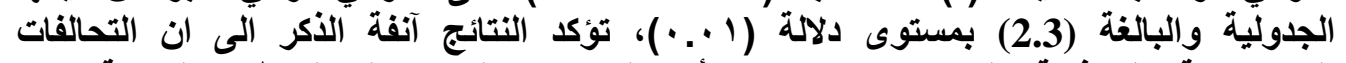

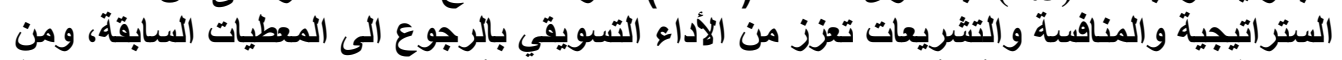

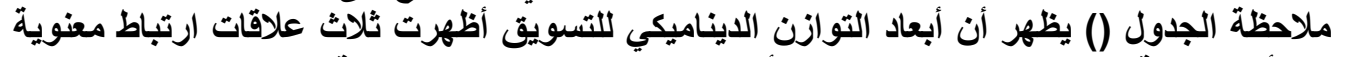

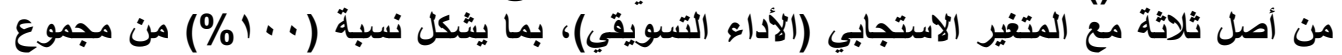

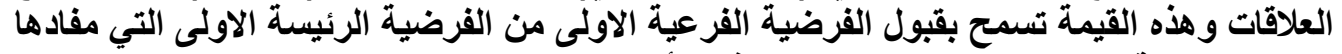

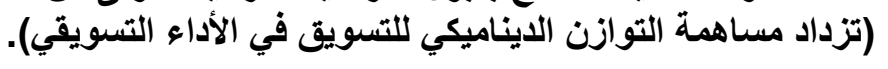

جدول (1 1 ) معاملات الارتباط وقيم (t) بين متغيرات التوازن الديناميكي للتسويق وبين الأداء التسويقي

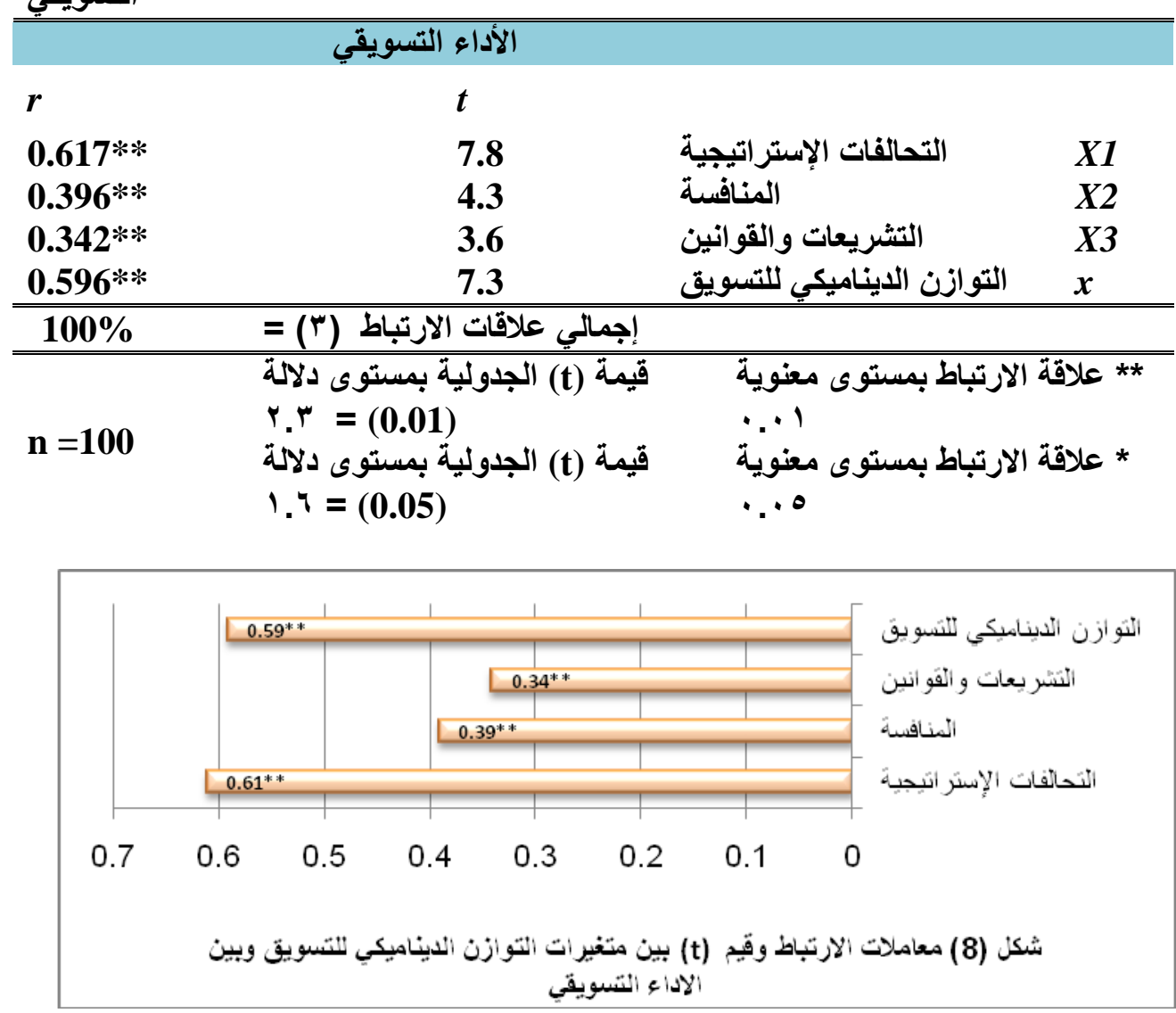

فرضيات التأثير البسيط (Simple Regression Analysis)

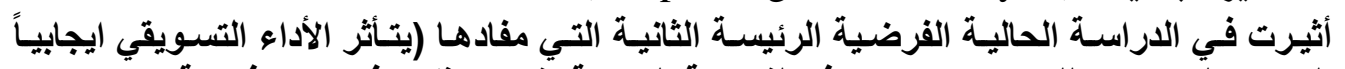

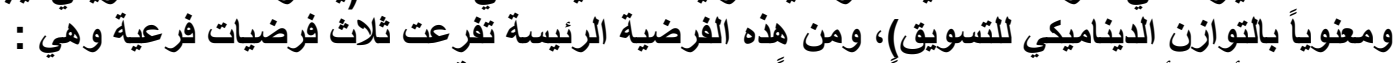

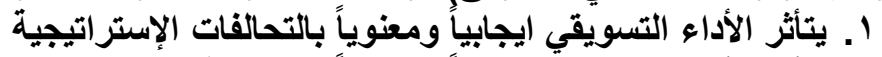

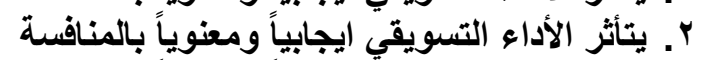

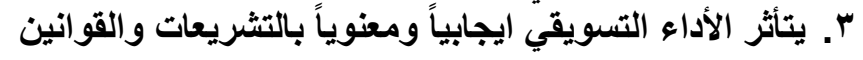

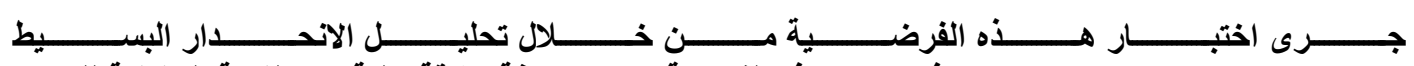

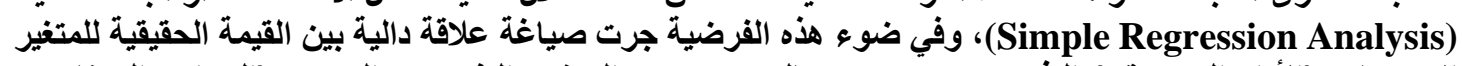

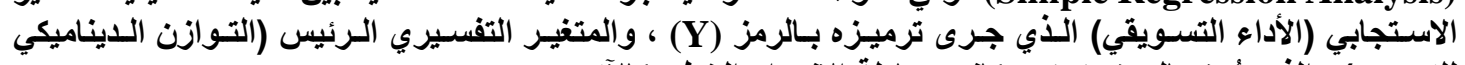
للتسويق) و الذي رُمز بالرمز (X)، وكانت معادلة الانحدار الخطي كالآتي: $\mathbf{Y}=\alpha+\beta \mathbf{X}$ 


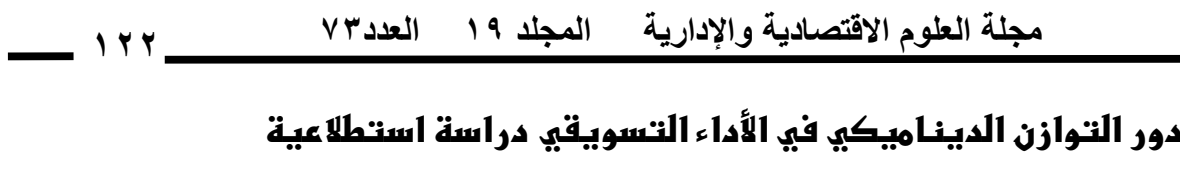

على عدد من المصارف العراقية الفاصة

وفيما يأتي القيم لمعادلة الانحدار:

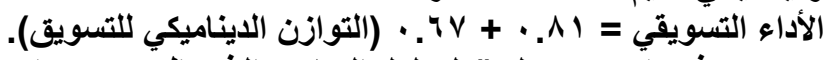

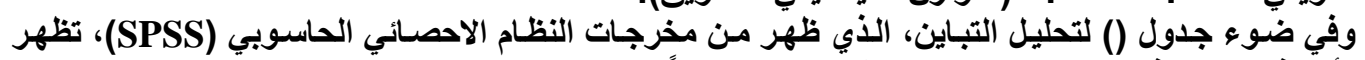

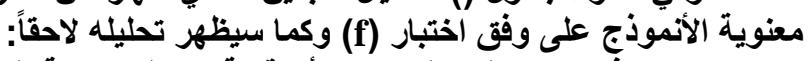

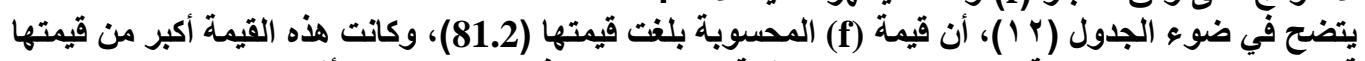

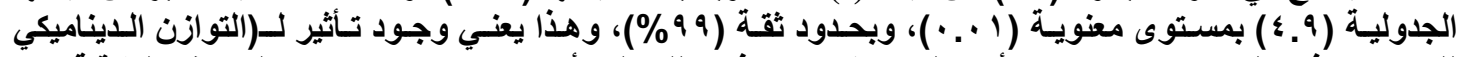

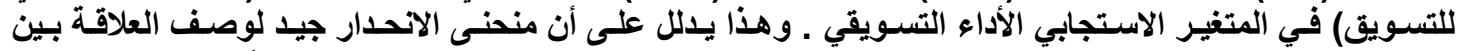

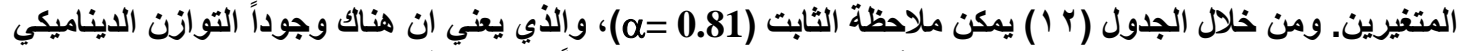

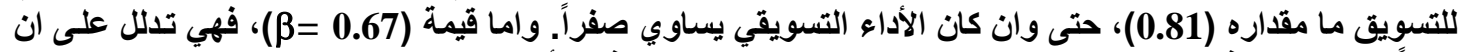

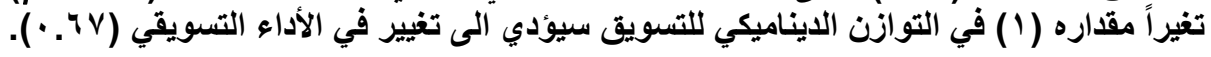

جدول (r I I) تحليل تأثير أبعاد المتغير التوازن الايناميكي للتسويق في المتغير الأداء التسويقي

\begin{tabular}{|c|c|c|c|c|c|c|}
\hline \multirow{2}{*}{ المستجيب } & \multirow{2}{*}{ قمنيمة (P) } & \multirow{2}{*}{ قالمصلة (Fلة } & \multirow{2}{*}{$\begin{array}{c}\text { التحديد }\left(\mathbf{R}^{2}\right) \\
\text { معامل }\end{array}$} & \multicolumn{2}{|c|}{ الثوابت } & \multirow{2}{*}{ المتغير التفسيري وأبعاده } \\
\hline & & & & $\alpha$ & $\boldsymbol{\beta}$ & \\
\hline \multirow{4}{*}{ الأداء التسويقي } & $\cdot .000$ & 81.2 & .45 & .81 & .67 & \multirow{4}{*}{ 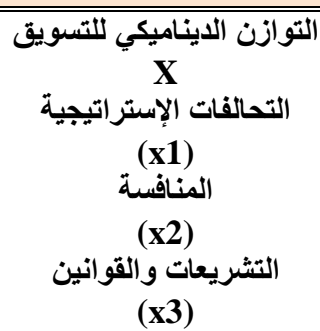 } \\
\hline & $\cdot .000$ & 97.9 & .50 & .55 & .71 & \\
\hline & $\cdot .000$ & 19.8 & .27 & .32 & .41 & \\
\hline & $\cdot .002$ & 10.4 & .19 & .39 & .31 & \\
\hline
\end{tabular}

$\mathrm{n}=\mathbf{1 0 0}$

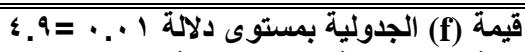

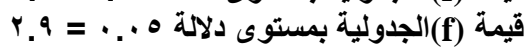

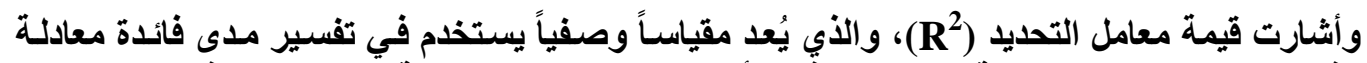

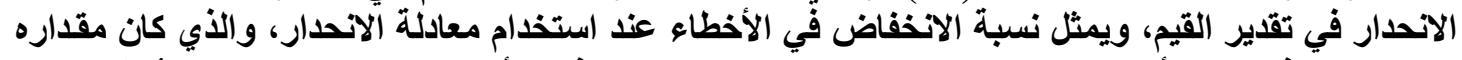

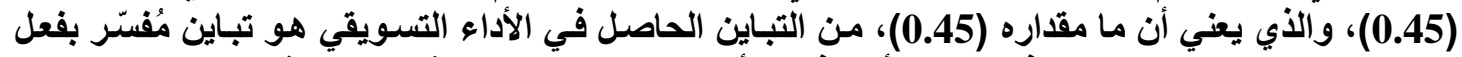

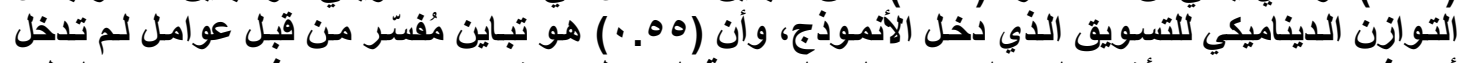

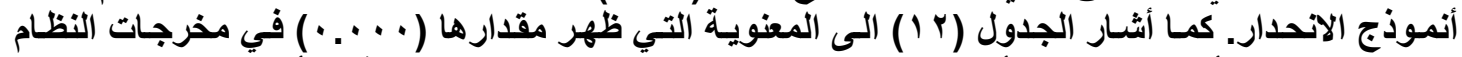

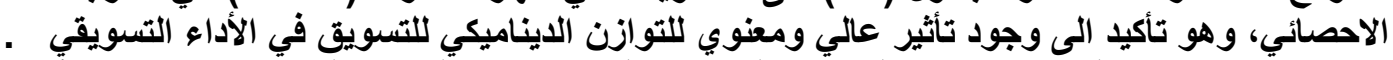

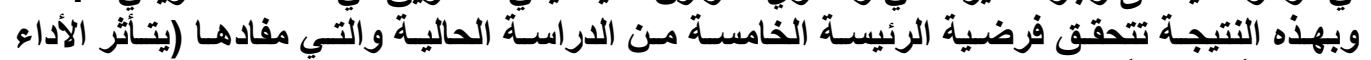

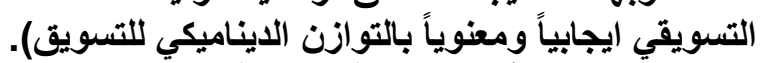

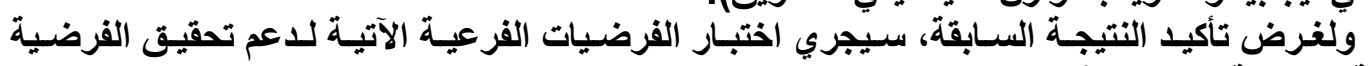

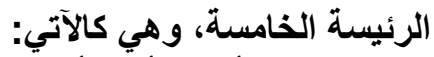

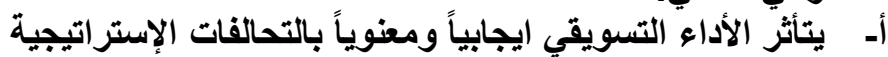

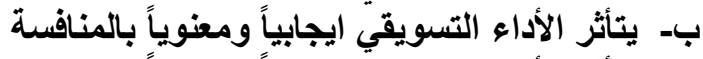
ج- يتأثر الأداء التسويقي ايجابياً ومعنوياً بالتشريعات التينة والقوانين 


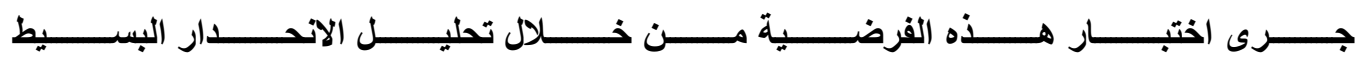

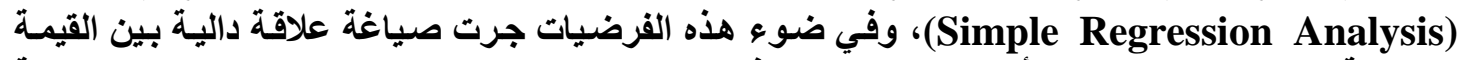

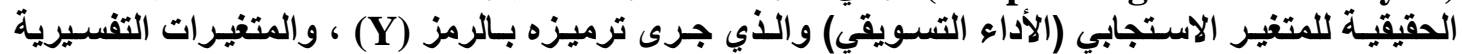

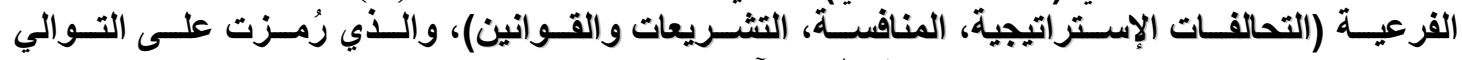
بـ (X3,X2,X1) وكاتت معادلات الانحدار الخطي كالآتي:

$$
\begin{aligned}
& \mathrm{Y}=\alpha+\beta \mathbf{X 1} \\
& \mathrm{Y}=\alpha+\beta \mathbf{X} 2 \\
& \mathrm{Y}=\alpha+\beta \mathbf{X} 3
\end{aligned}
$$

وفيما يأتي القيم لمعادلة الانحدار:

الأداء التسويقي = 0.55 + 0.71 (التحالفات الإستراتيجية). الألداء التسويقي = 0.32 + 0.41 (المنافسة).

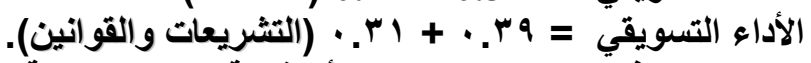

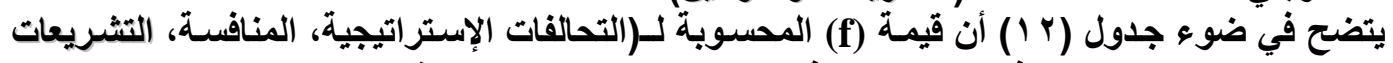

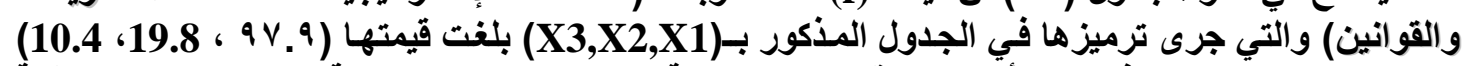

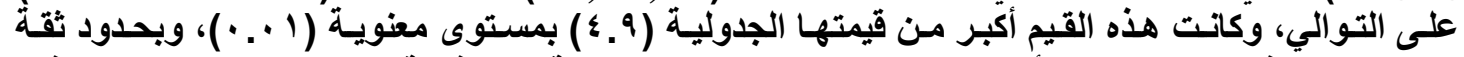

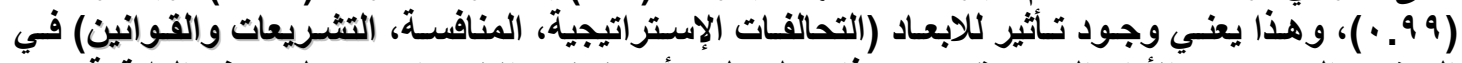

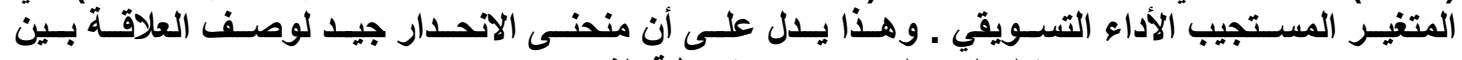

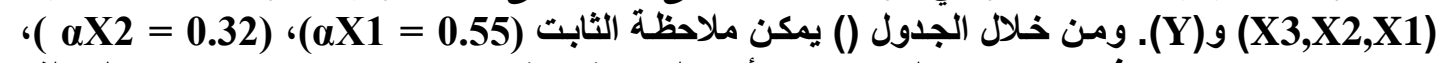

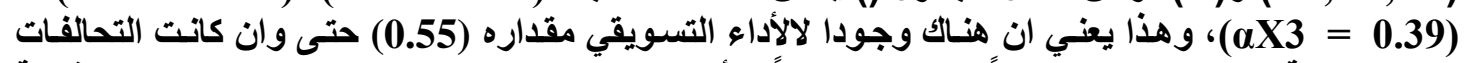

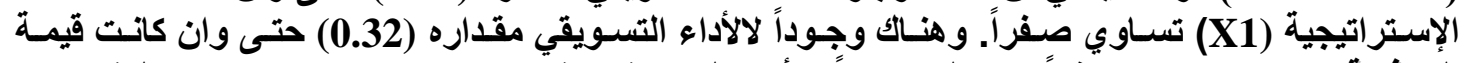

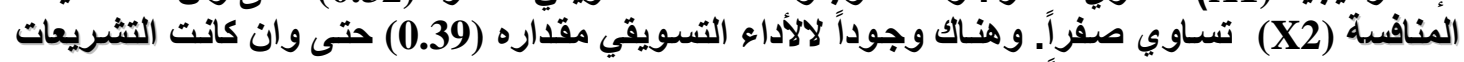

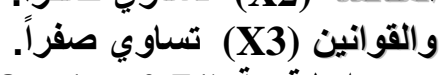

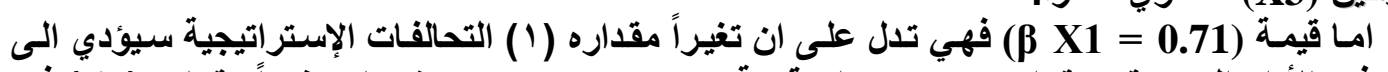

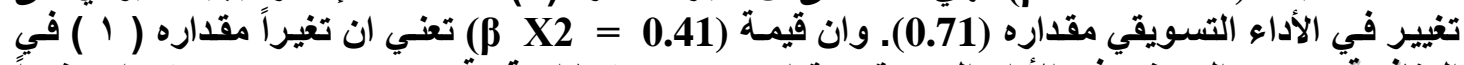

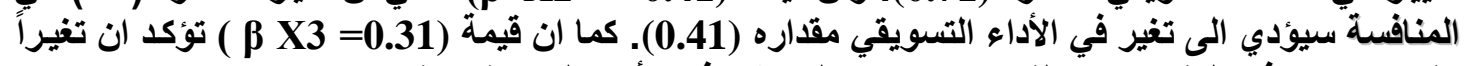

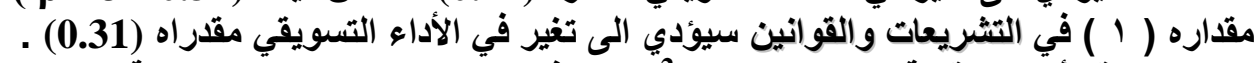

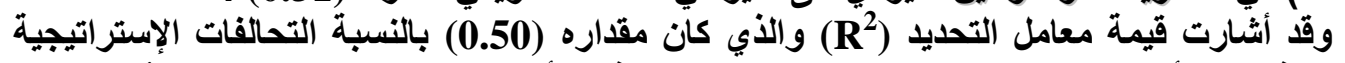

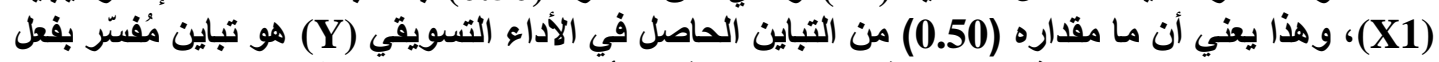

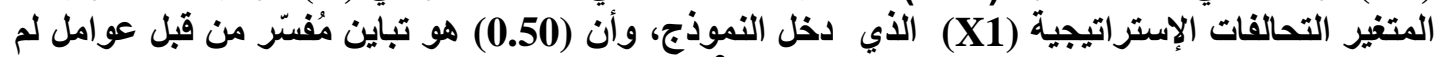

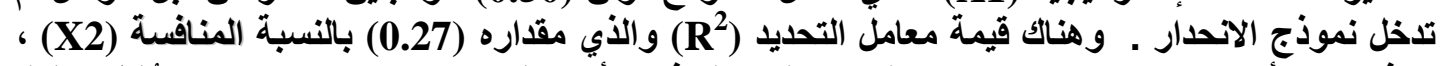

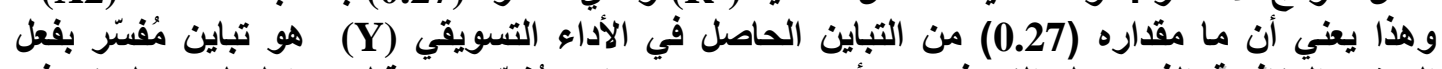

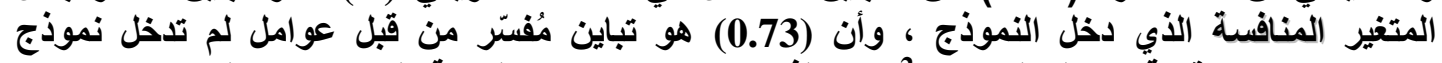

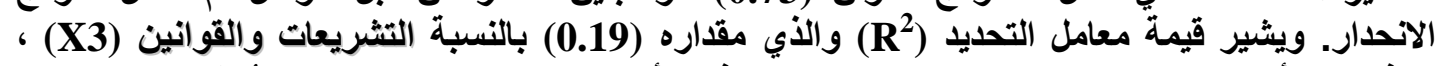

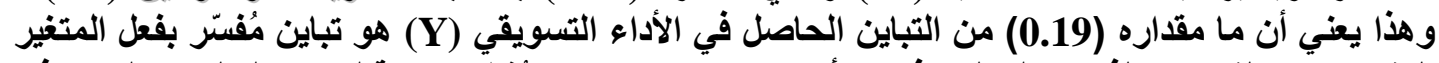

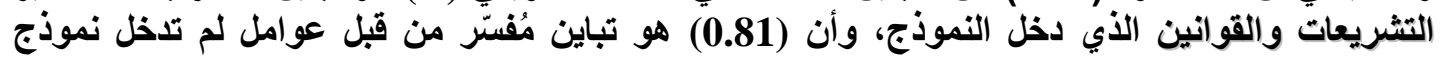

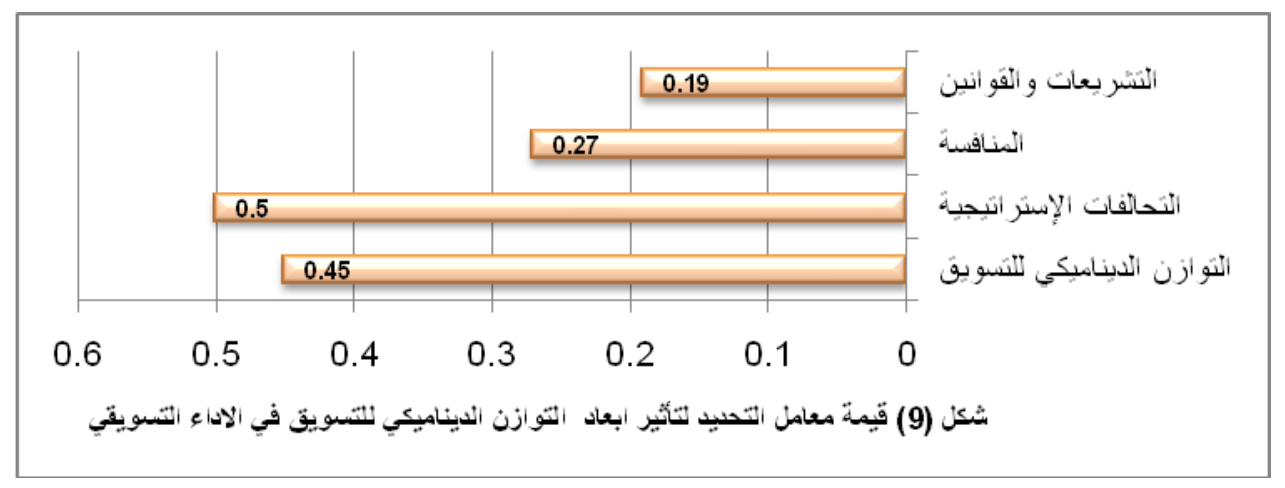




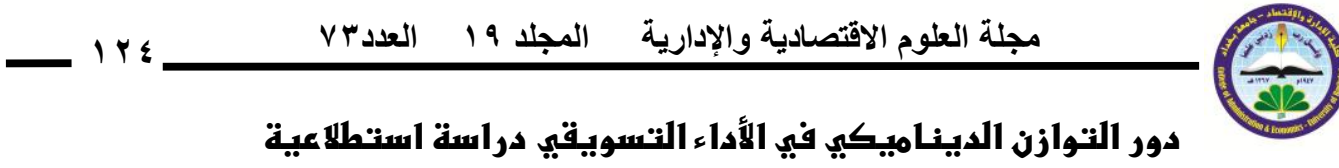 على عدد من المصارف العراقبة الفاصة}

كما أشار الجدول () الى المعنوية التي ظهر مقدارها ( . . . . ) في مخرجات النظام الاحصائي لجميع

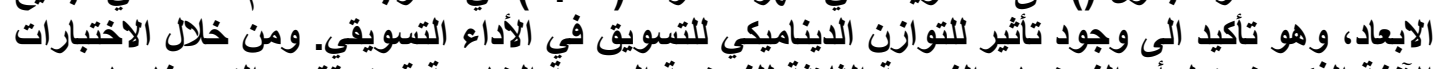

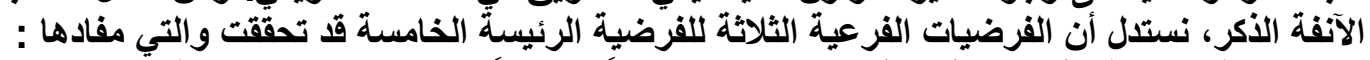

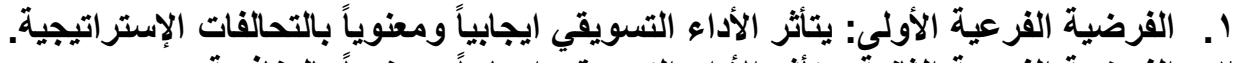

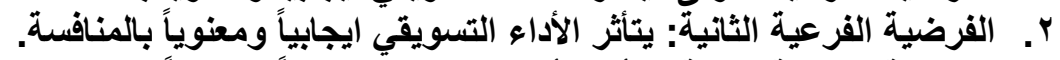

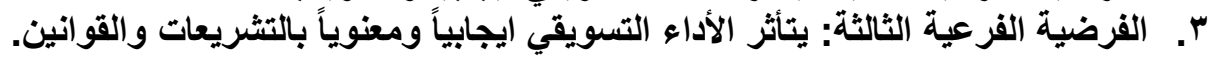




\section{المبحث الرابع/ الاستنتاجات والتوصيات}

اولاً : الاستنتتاجات

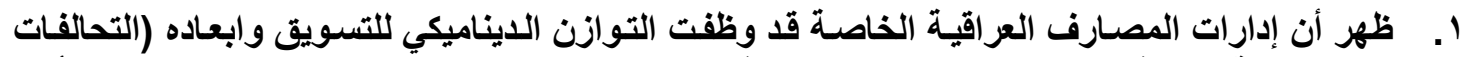

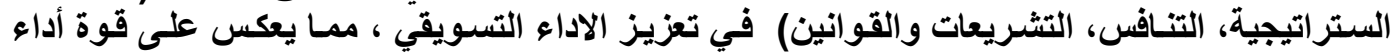

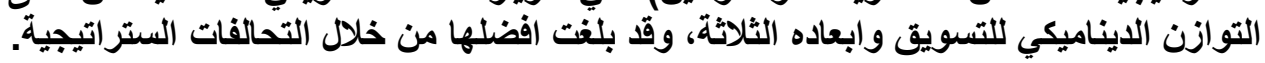

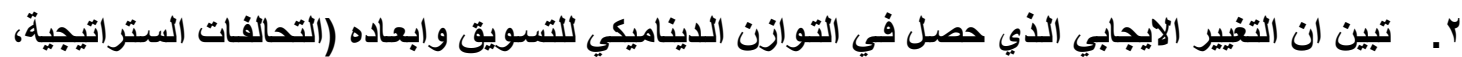

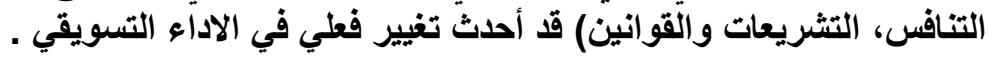

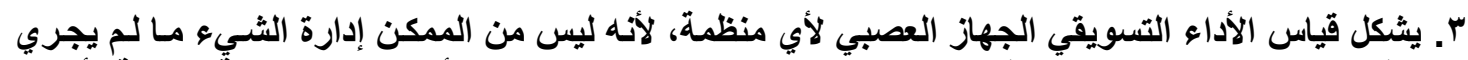

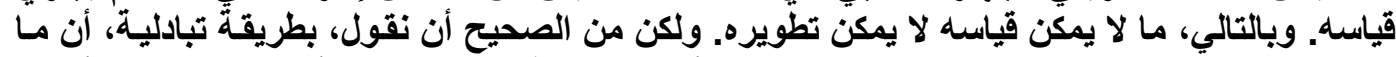

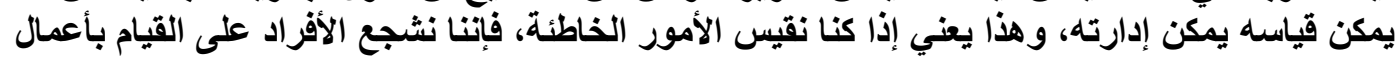

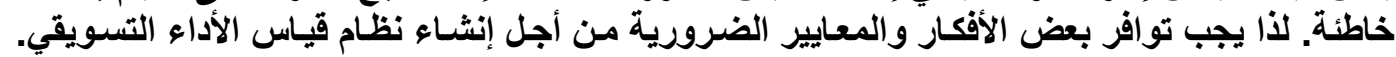

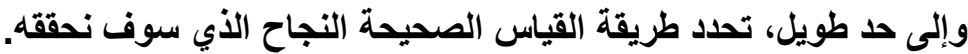

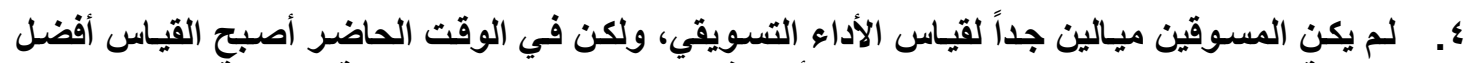

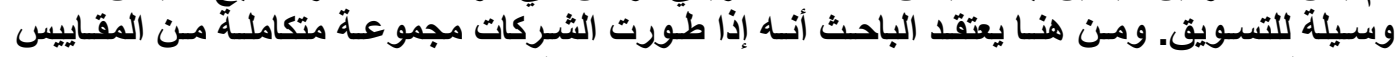

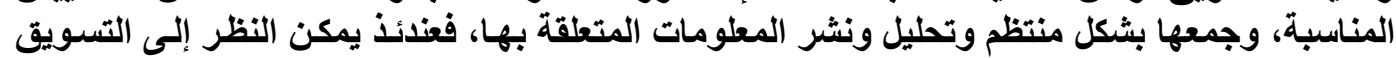

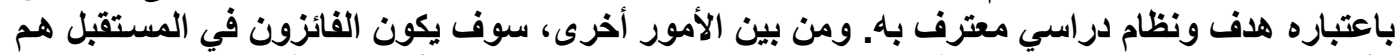

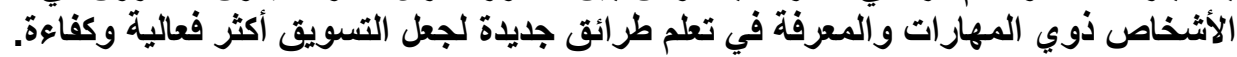

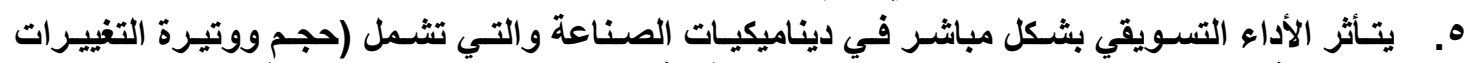

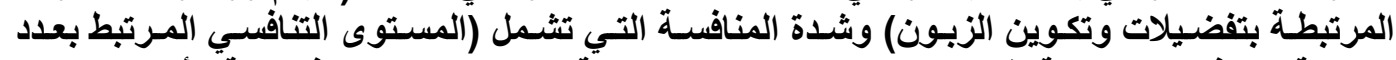

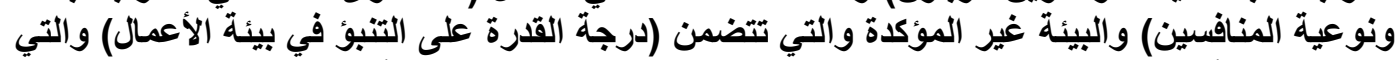

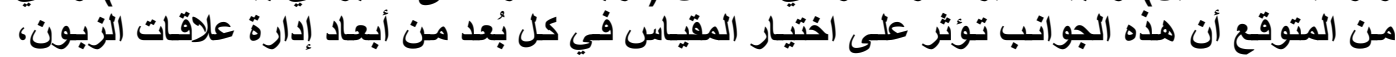
وتحديد أهداف الأداء التسويقي.

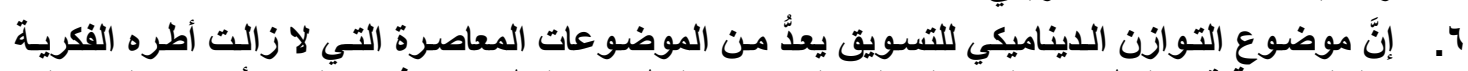

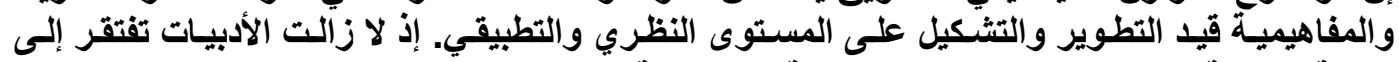

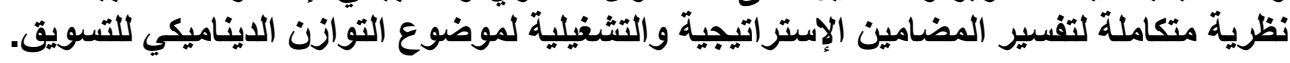

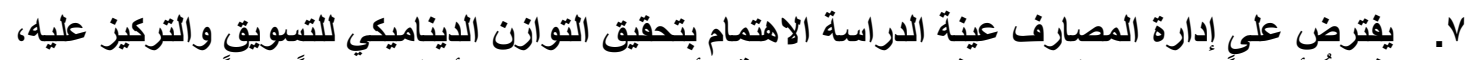

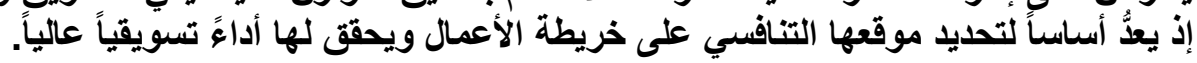

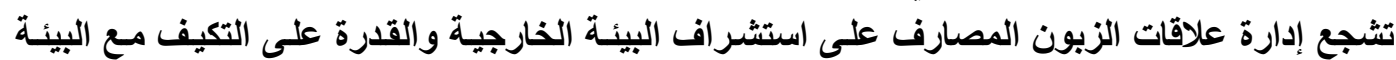

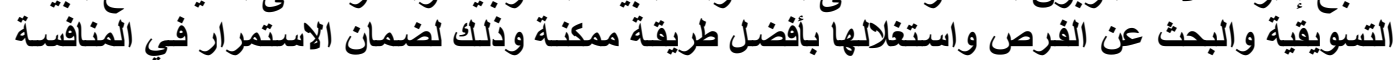

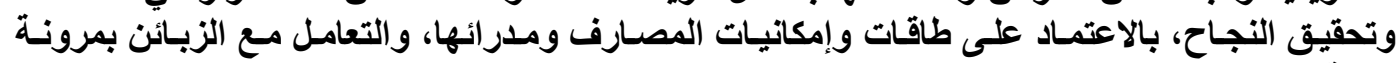
عالية.

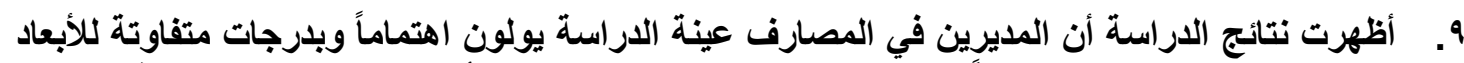

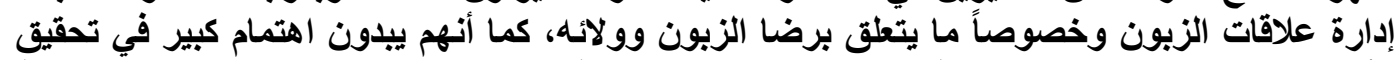

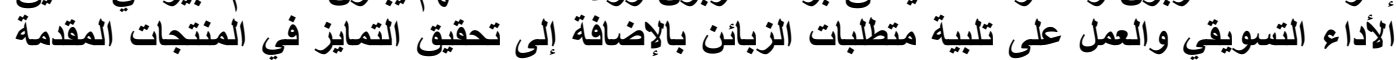
من قبل المصارف المبحوثة.

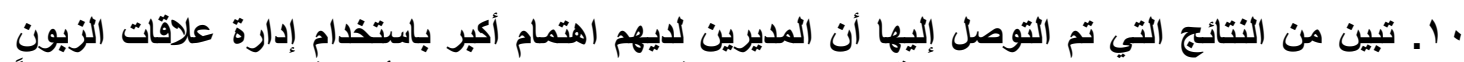

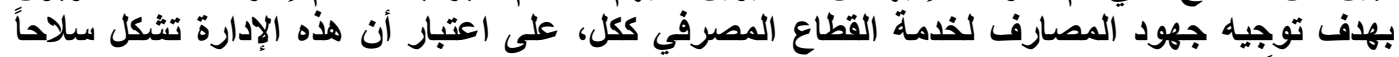

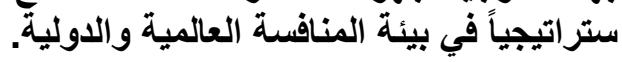

\footnotetext{
ثانيًاً : التوصويات في ضوء الاستنتاجات المشار إليها في فقرة الاستتتاجات توصي الاراسة بما يأتي :-
} 


\section{-1 ir \\ دور التوازن الديناميكي في الأداء التسويقي دراسة استطلا عية \\ على عدد من المصارف العراقية الفاصة}

ا. ضرورة الاستفادة بشكل أكبر من التوازن الديناميكي للتسويق وابعاده (التحالفات الستراتيجية، التنافس،

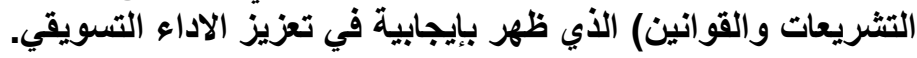

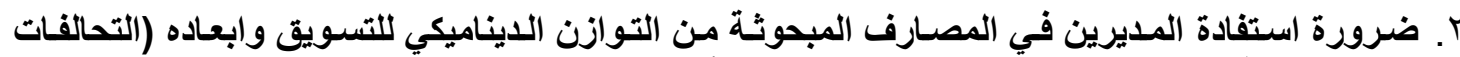

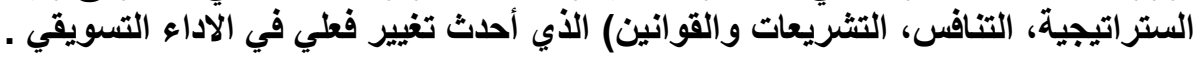

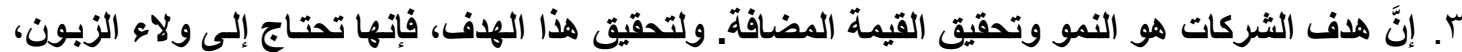

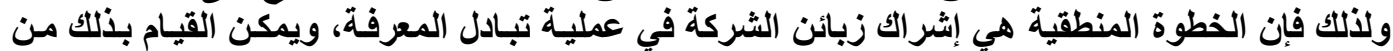

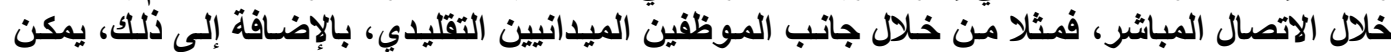

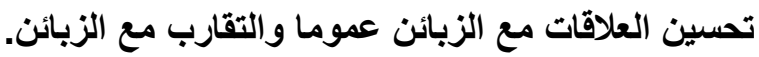

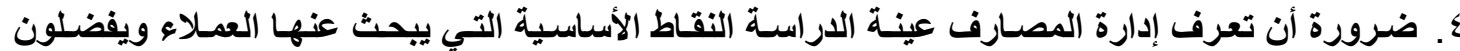

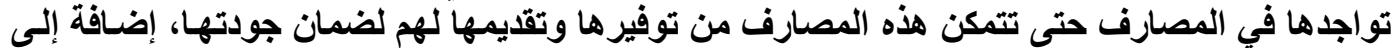

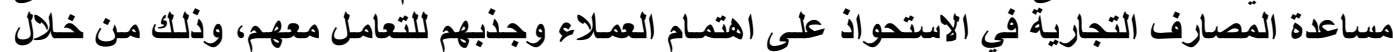

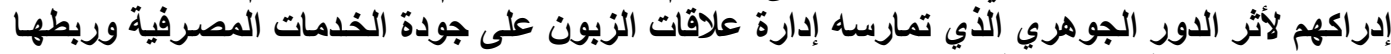

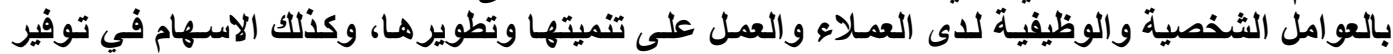

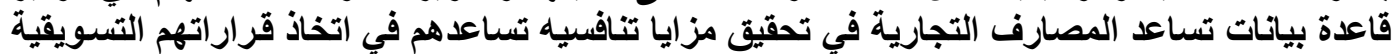

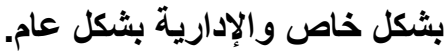

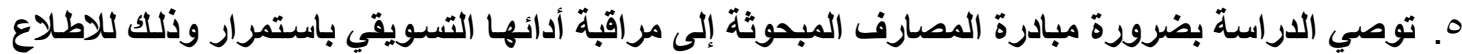

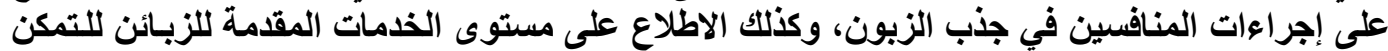

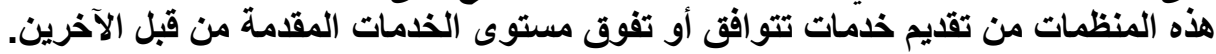

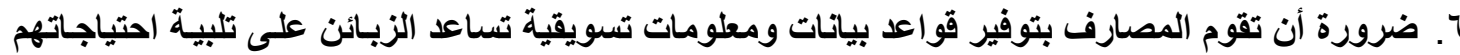

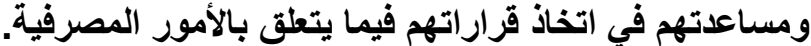

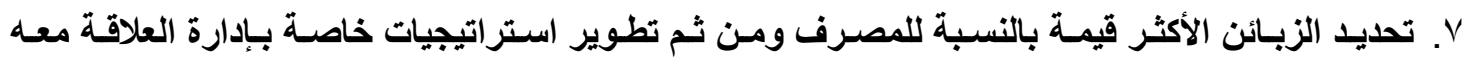

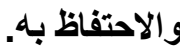
^. ضرورة إنَّ تعرف إدارة المصارف على التوازن الديناميكي للتسويق بعده من الأدوات والستراتيجيات التي

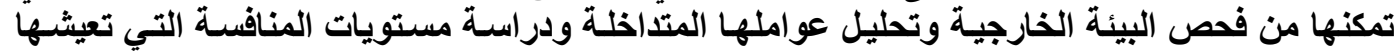

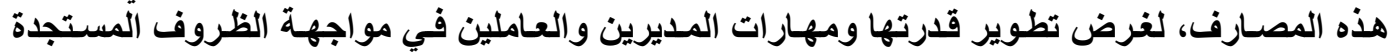
والقيام بالتغيرات اللازمة لمواجهة والتوير والتفوق على على المنافسين.

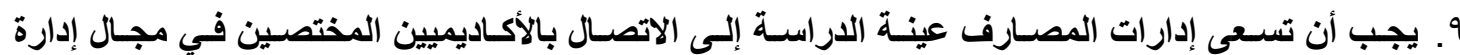

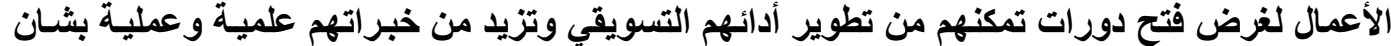
مراقبة أداء الآخرين مع إمكانية تمكينهم من تحقيق التورين أنوازن الآيناميكي للتسويق.

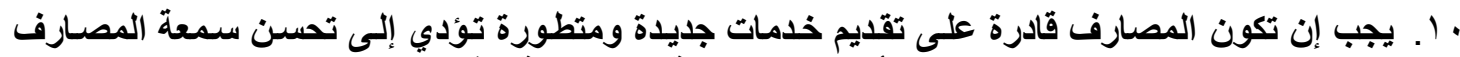

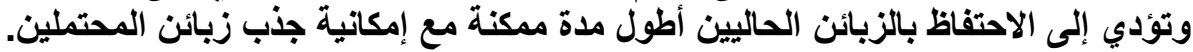

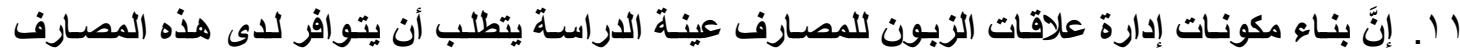

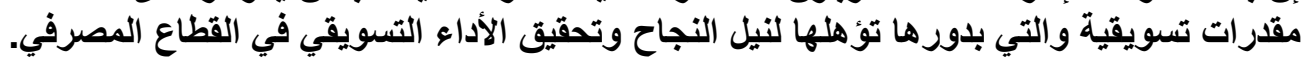

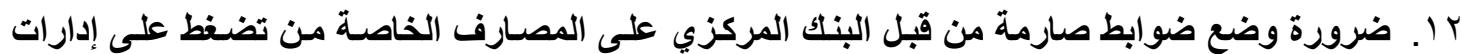

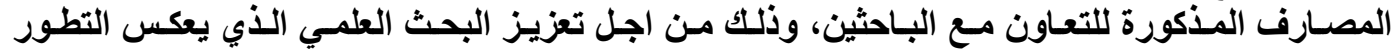

الاقتصادي للعراق المعارف

\section{المراجع المستخدهة}

تومسون،آرثر أيه، ستريكلاند، أيه جي، († . . ץ)،"الإدارة الإستراتيجية المفـاهيم والحالات العملية"، مكتبة لبنـان

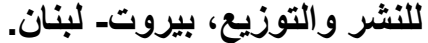

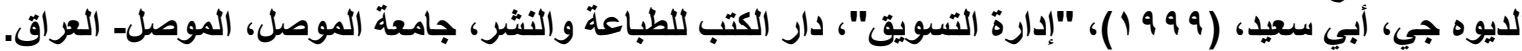

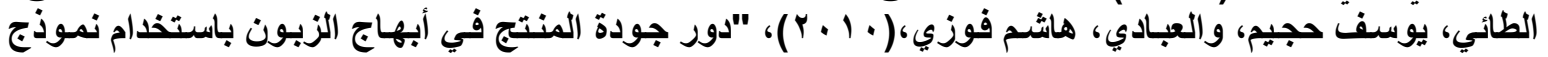




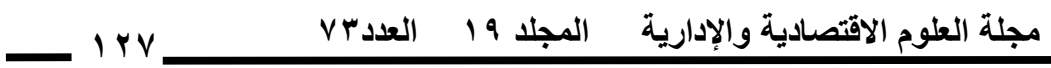 \\ دور التوازز الديناميكي في الأداء التسويقيي دراسة استطلا عية على عدد من المصارف العراقية الفاصة}

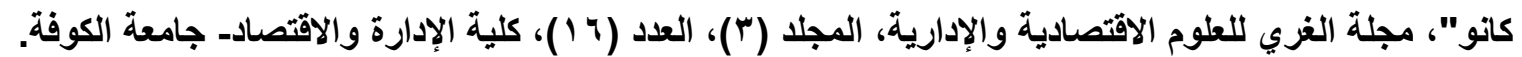

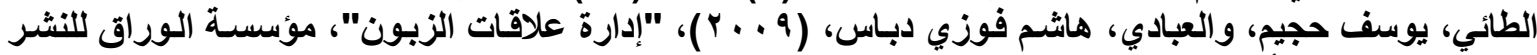
و التوزيع، عمان- الأردن.

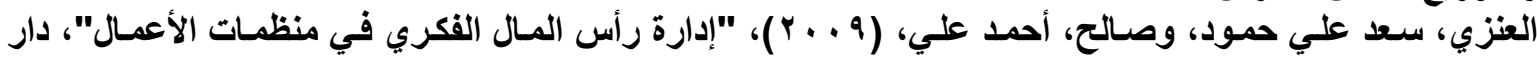

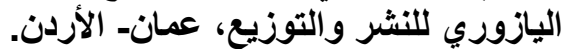

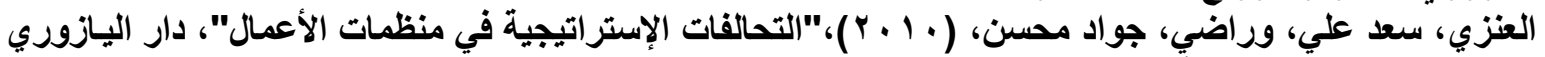
للنشر والتوزيع، عمان- الأردن.

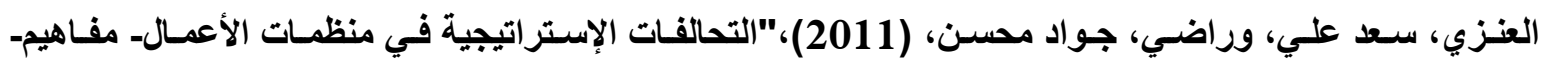
مداخل- تطبيقات"، دار اليازوري للنشر والتوزيع، واليع، عمان- الأردن.

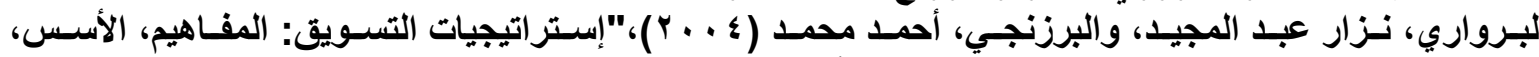
الوظائف"، طاري، دار وائل للنشر والتوزيع، واليرني، عمان- الأردن.

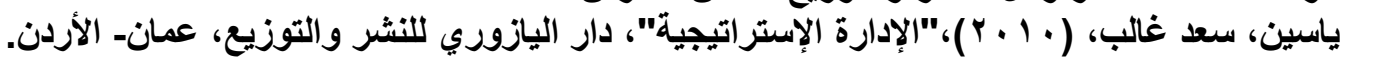

10 Adler, L,(2001), “Merger Mess”, Business Mexico, 11(7).

11 sor, Henry,(2012),"Alliances as collaborative regimes: An institutional based Ination of interfirm collaboration", Competitiveness Review: An International ness Journal incorporating Journal of Global Competitiveness, Vol. 21 Iss: 1.

12 Ambler, T. and Kokkinaki, F,(1997), "Measures of marketing success", Journal of Marketing Management, Vol. 5 No. 13.

13 Ambler, T. and Riley, D,(2000), "Marketing metrics: a review of performance measures in use in the UK and Spain", Report No. 00-500, Marketing Science Institute, Cambridge, MA.

14 Appiah-Adu, K,(1998), “Marketing activities and business performance: evidence from foreign and domestic manufacturing firms in liberalized developing economy", Marketing Intelligence \& Planning, Vol. 16 No. 7.

15 Appiah-Adu, K., Fyall, A. and Singh, S. (2001), "Marketing effectiveness and business performance in the financial services industrial", Journal of Services Marketing, Vol. 15 No. 1.

16 Arndt, J. (1983),"The Political Economy Paradigm: Foundation for Theory Building in Marketing",Journal of Marketing, 47(Fall).

17 Awara, Nsobiari Festus,(2008),"Strengthening Customer Retention Through The Management Of Customer Relationships In Services Marketing", electronic copy available at: http://ssrn.com. 

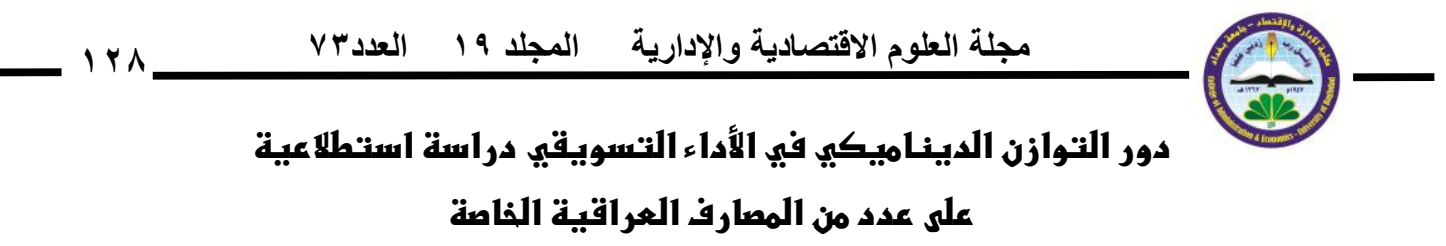

18 Baker, M,(2000), "The future of marketing", in Baker, M. (Ed.), Marketing Theory - A Student Text, South-Western, Boston, MA.

19 Buttle, F,(1989).“Relationship marketing”, in Relationship Marketing: Theory and Practice, F. Buttle, ed. London: Paul Chapman Publishing,V0L.79 N0.4 1.

20 Chen, I.J., and Popovich, K,(2003), “Understanding customer relationship management (CRM)", Business Process Management Journal, 9(5).

21 Chopra, Scott,(2009),"The One-Day Marketing Plan:Organization and Completing a Plan That Works" , $3^{\text {rd }}$ Edition , McGraw-Hall Companies , Inc. , New York.

22 Cornelius, I. and Davies, M,(1997),"Shareholder Value", FT Publishing, London.

23 da Gama, António Pimenta,(2011), "A renewed approach to services marketing effectiveness", Emerald Group Publishing Limited,VOL. 15 NO. 2,

24 da Gama, Anto'nio Pimenta,(2011),"An expanded model of marketing performance", Marketing Intelligence \& Planning Vol. 29 No. 7.

25 Doyle, P,(2000), “Valuing marketing's contribution", European Management Journal, Vol. 18, No. 3.

26 Eusebio, R., Andreu, J.L. and Belbeze, M.P.L,(2006), "Measure of marketing performance; a comparative study from Spain",International Journal of Contemporary Hospitality Management, Vol. 18, No. 2.

27 Eusebio, Rossano\&Andreu, Joan Llonch\&Belbeze, Pilar López,(2006), "Measures of marketing performance: a comparative study from Spain:, International Journal of Contemporary Hospitality.

28 Flynn, B.B., Schroeder, R.G., Sakakibara, S.,(1995), "The impact of quality management practices on performance and competitive advantage",Dec. Sci. Vol. (26), No. (5).

29 Fornell, C,(1992).“A national satisfaction barometer: the Swedish experience",Journal of Marketing, 56 (1).

30 Gomes-Gasseres, B,(1996),"The Alliance Revolution: The New Shape of Business Rivalry", Harvard University Press, Cambridge.

31 Gonzalez,M,(2001), "Strategic Alliances: The Right Way to Compete in the $21^{\text {st }}$ Century. Ivey Business Journal”, September/October.

32 Gratton,Heather,(2004),'Future Of Banking Study Regional and Other Midsize Banks Recent Trends and Short-term Prospects" by Federal Deposit Insurance Corporation, June 22.

http://www.fdic.gov/bank/analytical/future/fob_06.pdf

33 Gray, B., Matear, S., Boshoff, C. and Matheson, P,(1998), "Developing a better measure of market orientation", European Journal of Marketing, Vol. 32 No. 9/10.

34 Grove, S., Fisk, R. and Johns, J,(2003), "The future of services marketing: forecasts from ten service experts', Journal of Services Marketing, Vol. 17 No. 2. 


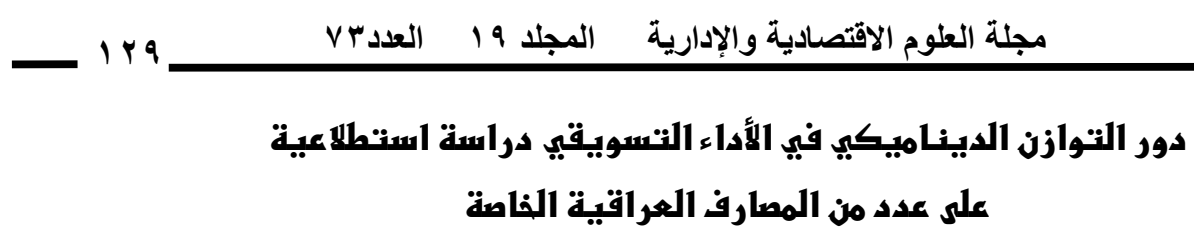

35 Gulati, R,(1998),"Alliances and Networks", Strategic Management Journal, Vol. (19), No. (5).

36 Gummesson, Evert,(2008), "Total Relationship Marketing", $3^{\text {rd }}$ ed., Elsevier Ltd. USA.

37 Hill, Jon \& Pullen, John,(2001),'Implementation A Strategic Performance Management system, Measuring Strategic Performance", Part three, Mercor Media, Inc.

38 Hill, Jon \& Pullen, John,(2001),'Implementation A Strategic Performance Management system, Measuring Strategic Performance", Part three, Mercor Media, Inc.

39 Hillier, T,(1999), “Market share matters”,Marketing Business. May.

40 Hitt, Michael A., Ireland, R.D. ,Hoskisson, Robert E,(2001), “Strategic Management: Competitiveness and Globalization", South-Western, $4^{\text {th }}$ ed., New York.

41 Hitt, Michael A., Hoskisson, E. Robert, Ireland, R.Duane,(2007), "Management of Strategy: Concepts and Cases", South-Western, $1^{\text {st }}$ ed., New York.

42 Hughes, Deborah \& Williams, Trefor \& Ren, Zhaomin, (2012), "Differing perspectives on collaboration in construction", Construction Innovation: Information, Process, Management, Vol. 12 Iss: 3.

43 Islam, Majidul\&Yang, Yi-Feng \& Mia \& Lokman,(2011),"The Impact of Company Learning and Growth Capabilities on the Customer Related Performance", Emerald Group Publishing Limited.

44 Islam,Rafiqul\&Sheel,Samir Kumar\&Biswas, Pallab Kumar,(2010), "Customer Satisfaction of ATM Service: A Case Study of HSBC ATM", http://ssrn.com.

45 Karl, Garbarro,(1985),"The dynamics of taking charge", Boston: Harvard Business School Press. New York.

46 Kolawole, OLADELE,(2010),"CUSTOMER ANALYSIS FOR CORPORATE SURVIVAL", Accounting and Finance Department, College of Administrative and Business Studies, Kaduna Polytechnic, Kaduna. http://ssrn.com

47 Kotabe, Masaaki\&Helsen,Kristiaan,(2007),“Global Marketing Management”, $4^{\text {th }}$ ed., John Wiley \& Sons, Inc., USA.

48 Kotler, P,(2000), ’Marketing Management Millennium Edition, New Delhi, India. Prentice Hall of India .

49 Kotler, Philip And Armstrong, Gary,(1999), "Principles of marketing", 8 ${ }^{\text {th }}$ Ed., New Jersey- Prentice Hall.

50 Kotler, Philip And Armstrong, Gary,(2008), “Principles of marketing”, $12^{\text {th }}$ Ed., New Jersey- Prentice Hall.

51 Kotler, Philip,(1997),"Marketing Management:Analysis Planning Implementation And Control", $9^{\text {th }}$ Ed., New Delhi, Prentice-Hill.

52 Kotler,Philip\&Keller, K. L.,(2009),"Marketing Management"Pearson Prentice Hall, $13^{\text {th }}$ ed., London. 


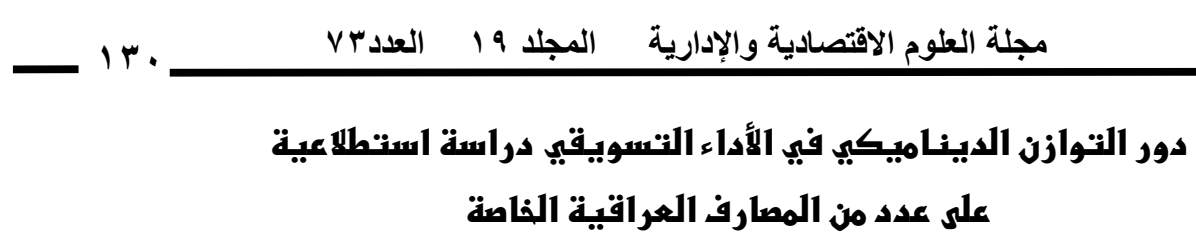

53 Levitt, T,(1983), After the sale is over'. Harvard Business Review, 61(5) .

54 Lindgreen, Adam\& Shergill, Gurvinder, (2003),"Customer Relationship Management Programmes and Their Impact on the Financial Performance of Businesses: A Proposed Model"

http://papers.ssrn.com/sol3/papers.cfm?abstract_id=519202

55 Mullins, John W, Walker, Orville C,and Boyd,Harper,(2008), "Marketing Management: A strategic Decision Making Approach”, ${ }^{\text {th }}$. Ed., Irwin McGraw - Hill.

56 Nwokah, N.G,(2006), "Market orientation and business performance. The study of food and beverages firms in Nigeria",PhD dissertation, Rivers State University of Science and Technology, Port Harcourt, Nigeria.

57 Nwokah, N.G,(2008), "Strategic market orientation and business performance: the study of foods and beverages firms in Nigeria",European Journal of Marketing, Vol. 42 No. 3.

58 Nwokah, N.G,(2009), “Customer focus, competitor focus and marketing performance", Measuring Business Excellence, Vol. 13 No. 3, pp. 20-8.

59 Nwokah, N.G. and Ahiauzu, A.I,(2008), "Managerial competency and marketing effectiveness in corporate organizations in Nigeria", Journal of Management Development, Vol. 27 No. 8.

60 Nwokah, N.G. and Maclayton, D.W,(2006), "Customer focus and business performance: the study of food and beverages organizations in Nigeria", Measuring Business Excellence, The Journal of Organizational Performance Management, Vol. 10 No. 4.

61 Nwokah,Gladson,(2009),"Customer-focus, competitor-focus and marketing performance", Emerald Group Publishing Limited,VOL. 13 NO. 3.

62 Nwokah,Gladson,(2009),"Customer-focus, competitor-focus and marketing performance", Emerald Group Publishing Limited VOL. 13 NO. 3.

63 O'Sullivan, D., Abela, A. and Hutchinson, M,(2009), "Marketing performance measurement and firm performance: evidence from the European hightechnology sector', European Journal of Marketing, Vol. 43 Nos 5/6.

64 Parkhe, Arvind,(1993),"Partner Nationality and the Structure-Performance Relationship in Strategic Alliances",Organization Science, Vol. 4, No. 2.

65 Parvatiyar, Atul \& Sheth, Jagdish,(2001),"Customer Relationship Management: Emerging Practice, Process, and Discipline",Journal of Economic and Social Research 3(2).

66 Payne, A. \& Frow , P,(2005),"A Strategic Framework for Customer Relationship Management"Journal of Marketing, 69.

67 Petersen, J., McAlister, L., Reibstein, D., Winer, R., Kumar, V. and Atkinson, G,(2009), "Choosing the right metrics to maximize profitability and shareholder value", Journal of Retailing, Vol. 85 No. 1.

68 Prid, William M,(2002),"Marketing:Concepts and Strategies,Houghton Mifflin" Co. , U.S.A 


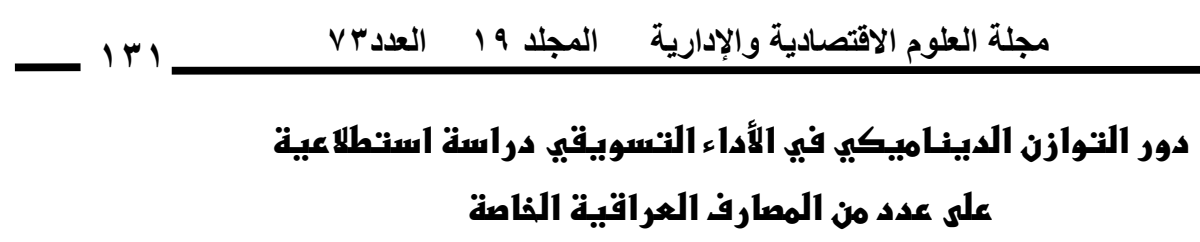

69 Quairel-Lanoizelée, Françoise,(2011),"Are competition and corporate social responsibility compatible?: The myth of sustainable competitive advantage", Society and Business Review, Vol. 6 Iss: 1.

70 Ranganathan, C.,\&Lertpittayapoom, Nongkran,(2002),"Towards a Conceptual Framework for Understanding Strategic Alliances in E-Commerce",Proceedings of the $35^{\text {th }}$ Hawaii International Conference on System Sciences.

71 Rappaport, A,(1986),"Creating Shareholder Value - The New Standard for Business Performance", The Free Press, New York, NY.

72 Singh, D.,\&Agrawal D.P”,(2003),“CRM practices in Indian industries", International Journal of Customer Relationship Management, 5(DecemberJanuary).

73 Stewart, G.B,(1999),"The Quest for Value: A Guide for Senior Managers", $2^{\text {nd }}$ ed., Harper Collins, New York, NY.

74 Sweeney, Jillian\&Soutar Geoffrey\&McColl-Kennedy,Janet,(2011),"The marketing practices-performance relationship in professional service firms", Journal of Service Management,Emerald Group Publishing Limited Vol. 22 No. 3.

75 Tangen, S,(2003), "An overview of frequently used performance measures", Work Study, Vol. 52 No. 7.

76 Terry, J. R. \& Keith, R,(2002)“Interactive Marketing: A Conceptualization and Application." Industrial Marketing, Management, 23.

77 Thompson, Arthur, A. \& Strickland, A. J,(2003), "Strategic Management: Concept and Cases", $13^{\text {th }}$ ed., McGraw Hill-Irwin.

78 Thompson, John, $\left(r_{\ldots} \cdot \cdot\right)$, "Strategic Management: Awareness and Change" $3^{\text {rd }}$ ed., International Thomson Publishing Co., U.K.

79 Thorelli, H. B,(1986),"Networks: Between Markets and Hierarchies'. Strategic Management Journal, 7.

80 Vankatrmn, A. \&Ramugam,D.,(1986), “How to measure marketing performance", Harvard Business Review, May/June.

81 Verrecchia, R.E,(1998), “Discussion of accrual accounting and equity valuation", Journal of Accounting Research, Vol. 36.

82 Webster, C,(1995), "Marketing culture and marketing effectiveness in service firms", Journal of Services Marketing, Vol. 9 No. 2.

83 Willcocks, L.\&Choi, C.J., ,(1999),"Cooperative Partnership and the Case of Total It Outsourcing: Form Contractual Obligation to Strategic Alliance", European Management Journal, Vol. (13) No 4.

84 Wilson, M. and McDonald, M,(1994),"Marketing at the crossroads - a comment", Marketing Intelligence \& Planning, Vol. 12.

85 Woodburn, D,(2004), 'Engaging marketing performance measurement", Measuring Business Excellence, the Journal of Organizational Performance Management, Vol. 8 No. 4.

86 Wright, S., Pickton, D.W. and Calliw, J,(2002), 'Competitive Intelligence in UK firms; a typology”, Marketing Intelligence \& Planning, Vol. 20 No. 6.

87 Ye, J., Singh, J. and Marinova, D,(2004), "A balancing act: bottom line issues for strategic orientation of service companies", AMA Proceedings, Vol. 15. 


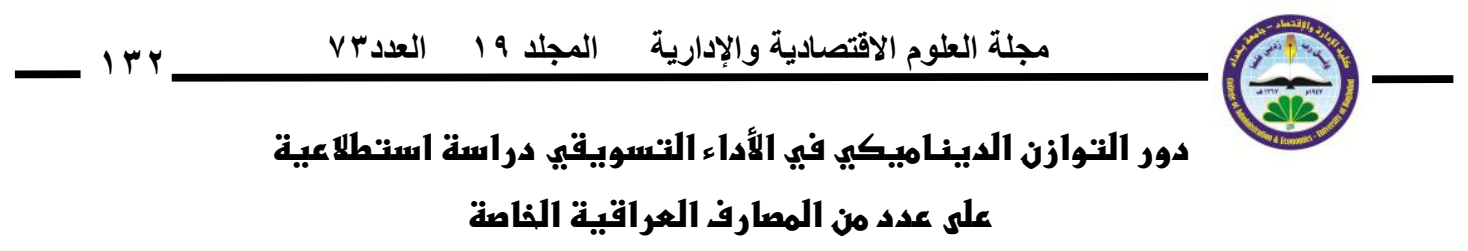

\title{
Dynamic Equilibrium of Marketing and Its Role in Achieving Excellence Performance Experimental research on a number of Iraqi private banks
}

\begin{abstract}
Purpose : This study seeks to provide the point of view stands on the marketing performance of the banks in the context of Dynamic Equilibrium of marketing. It aims to develop a prototype of measuring marketing performance under the umbrella of marketing dynamic prototype, embodied of the strategic alliance and competition, and the laws and legislation, and to explore any of the dimensions more effective in achieving performance. This study aims to discusses the importance of the Dynamic Equilibrium of marketing and it role in achieving the marketing performance under Dynamic Equilibrium of marketing and its impact on the Iraqi banking sector.

Design/Methodology/Approach: The experimental method has been used, the questionnaire used to collect the data in order to develop a trustworthy prototype measurement and correct for the changes of the Dynamic Equilibrium of marketing and customer relationship management With the dimensions of marketing performance, the hypotheses were tested through the use of some statistical treatments.

Findings: The study of the sample found that marketing performance is effected directly in the dynamics of the industry, and the intensity of competition, and the uncertain environment that includes (degree of predictability in the business environment), a model measuring variables Dynamic Equilibrium of Marketing has been developing (alliances strategy, competition, legislation/ laws) with marketing performance variables (focus on the customer, focus on the competitors), moreover, the results support the hypothesis influence and correlation between the surveyed variables.

Practical Implications: This study provides useful measurement of marketing balance, it helps the managers to use to assess the current situation in the capabilities of the banks performance. Managers may improve their marketing performance programs more effectively and efficiently through their strategic orientation towards competition and alliance.

Originality/ Value : This study undertakes help service providers in banking sector to deal with the challenge imbedded in increase the marketing performance and achieve the dynamic marketing balance, and how to influence the marketing balance dimensions in achieve the marketing performance.
\end{abstract}

Key Words : Dynamic Equilibrium Of Marketing- Marketing PerformanceCollaboration- Regulations/Institutions- Focus On The customer- Focus On The Competitors. 